\title{
DEVELOPMENT OF A PRECISION STATEMENT FOR ASTM A1061
}

\author{
By \\ Rémy D. Lequesne \\ William N. Collins \\ Enrico Lucon \\ Ashwin Poudel \\ David Darwin
}
Structural Engineering and Engineering Materials
SM Report No. 131
May 2019
(Second Printing)

THE UNIVERSITY OF KANSAS CENTER FOR RESEARCH, INC. 2385 Irving Hill Road, Lawrence, Kansas 66045-7563 



\title{
DEVELOPMENT OF A PRECISION STATEMENT FOR ASTM A1061
}

\author{
By: \\ Rémy D. Lequesne \\ William N. Collins \\ Enrico Lucon \\ Ashwin Poudel \\ David Darwin
}

A Report on Research Sponsored by:

Precast/Prestressed Concrete Institute

Structural Engineering and Engineering Materials

SM Report No. 131

THE UNIVERSITY OF KANSAS CENTER FOR RESEARCH, INC.

LAWRENCE, KANSAS

May 2019

(Second Printing) 


\section{SECOND PRINTING REVISIONS}

(April 2020)

Page 8: Added a new Section 3.2 Selection of Laboratories

Tables 4, 8, 9, and 11 and related text and figures: Revised reported values for yield strength of 0.5 in. diameter strand

Other minor editorial revisions to improve clarity 


\begin{abstract}
An interlaboratory study involving 19 laboratories was conducted to quantify the precision of ASTM A1061-16, Standard Test Methods for Testing Multi-wire Steel Prestressing Strand. This standard includes methods for measuring strand yield strength, elastic modulus, elongation, and breaking strength. Strand specimens were $0.375,0.500$, and 0.600-in. [9.5, 12.7, and $15.2 \mathrm{~mm}$ ] diameter Grade 270 [1860] low-relaxation seven-wire steel prestressing strand compliant with ASTM A416. The reported results were used to examine how the methods are implemented in practice and how precise the results are when the methods are implemented correctly, resulting in the development of a precision statement proposed for adoption into the standard.
\end{abstract}

Precision statistics were calculated for yield strength, elastic modulus, elongation, and breaking strength. Methods for obtaining the yield strength, elastic modulus, and breaking strength were found to be acceptably precise, with reproducibility limits less than 4,10 , and $3 \%$, respectively, of the mean reported values. Methods for obtaining elongation were highly imprecise, resulting in a reproducibility limit near 50 $\%$ of the mean reported value. Compliance with requirements of ASTM A1061 was also an issue. At least one result was classified as valid from $74,82,32$, and $100 \%$ of laboratories that submitted results for yield strength, elastic modulus, elongation, and breaking strength, respectively. It was found that the frequency with which strands fracture within a distance of $0.25 \mathrm{in}$. [6 mm] of the grips is very dependent on the type of grips used, with V-grips without cushioning material resulting in strand fracture near grips in $78 \%$ of tests. Other methods of gripping strand resulted in no more than $35 \%$ of specimens fracturing within a distance of $0.25 \mathrm{in}$. [ $6 \mathrm{~mm}$ ] of the grips. This may be cause to disallow use of serrated V-grips without cushioning material, as fracture near grips was shown to correlate with a statistically significant reduction in breaking strength and elongation for some strand diameters. Finally, use of the $0.2 \%$ offset method to determine yield strength, currently not an accepted method, resulted in added variability and small (1 to 5 $\%)$ but consistent increases in yield strength compared to other methods that were statistically significant. Several changes to ASTM A1061 are proposed aimed at improving the clarity of the standard.

Keywords: Multi-wire Steel Strand, Tension, Elastic Modulus, Yield Strength, Breaking Strength, Elongation, Precision 


\section{ACKNOWLEDGEMENTS}

Primary financial support was provided by the Precast/Prestressed Concrete Institute. The materials used in this study were donated by Insteel Wire Products, Sumiden Wire Products Corporation, and Wire Mesh Corporation.

Several laboratories provided testing services at no or reduced cost, including laboratories at Bekaert Corporation; CTL Group; Insteel Wire Products; Sumiden Wire Products Corporation; Wire Mesh Corporation; and Wiss, Janney, Elstner Associates, Inc; as well as laboratories at departments of transportation located in California, Georgia, Illinois, Missouri, Montana, Nevada, Pennsylvania, Tennessee, and Texas.

Some laboratories were very familiar with ASTM A1061-16 $6^{[6]}$ and others were less so. Throughout this report laboratory identities are divorced from discussions of results to avoid negatively affecting the reputation of laboratories that participated in the study on a voluntary basis. The research team did not operate as auditors sent to evaluate laboratory personnel or procedures. Rather, this effort was focused solely on obtaining a dataset comprised of results obtained strictly following the procedures described in ASTM A1061 ${ }^{[6]}$. If there was ambiguity in the results or responses received by the research team, results were excluded from the final dataset even though they may have been obtained in a valid manner. 


\section{TABLE OF CONTENTS}

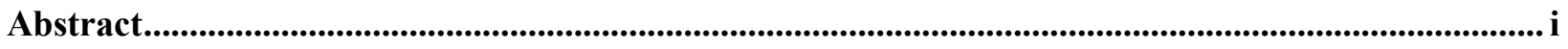

Acknowledgements ................................................................................................................................................... ii

Table of Contents .........................................................................................................................................................iii

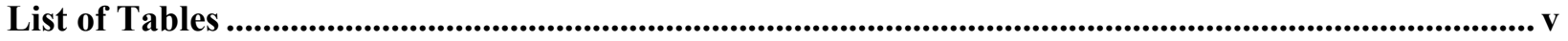

List of Figures............................................................................................................................................................ vi

1 Introduction .............................................................................................................................................. 1

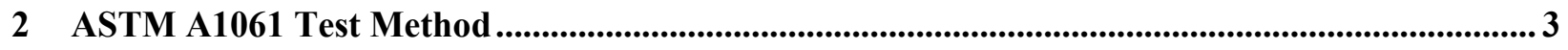

3 Inter-Laboratory Study Procedures ...................................................................................................... 8

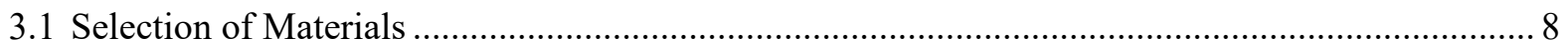

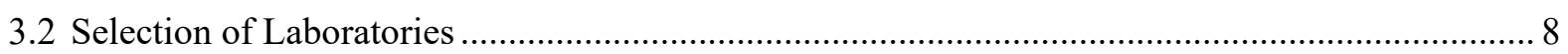

3.3 Procurement and Distribution of Test Specimens.................................................................... 9

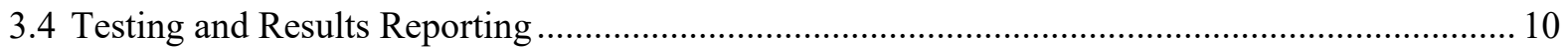

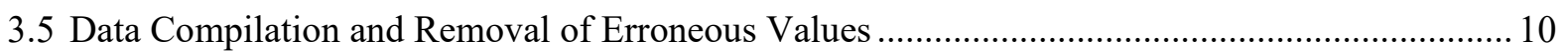

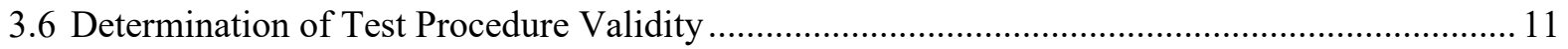

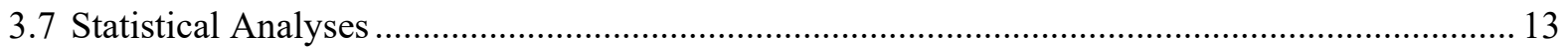

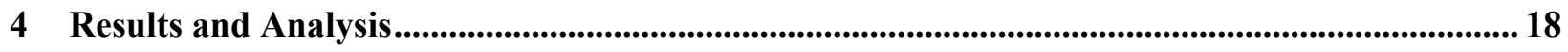

4.1 Equipment and Procedures used by Participating Laboratories................................................ 18

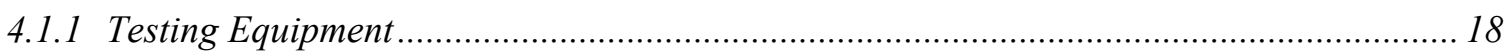

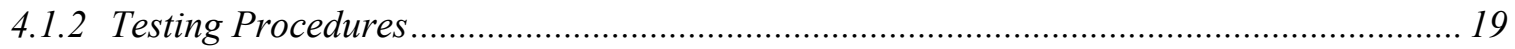

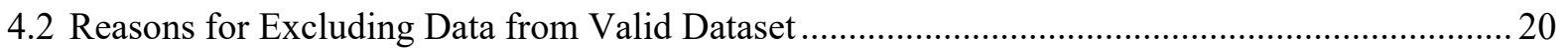

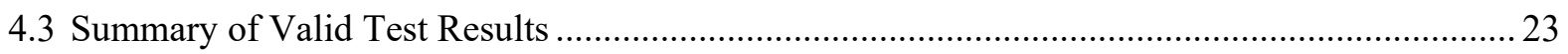

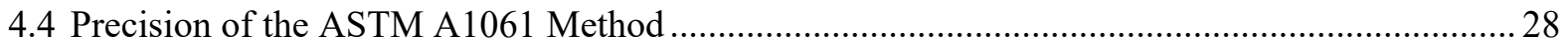

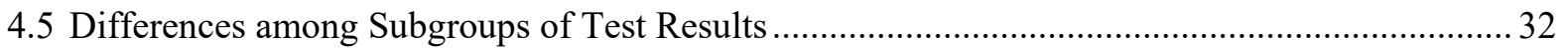

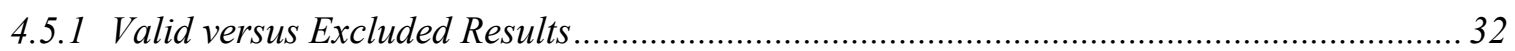

4.5.2 Preload Method versus Elastic Modulus Extrapolation Method for Determining Yield

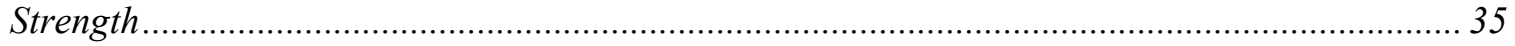

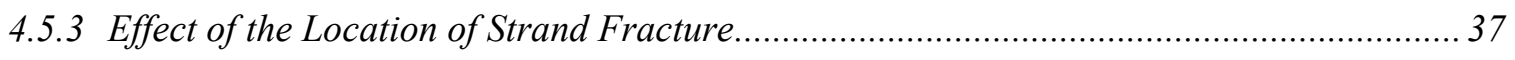

4.5.4 Cylindrical Grips with Gritty Surface Coating .............................................................. 41

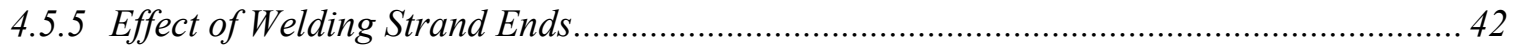

$4.60 .2 \%$ Offset Method for Determining Yield Strength............................................................. 45

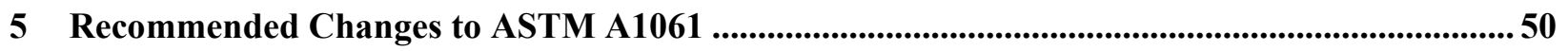

5.1 Terminology, Section 3 of ASTM A1061 ............................................................................ 50

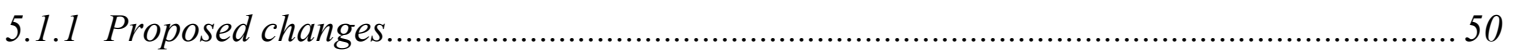

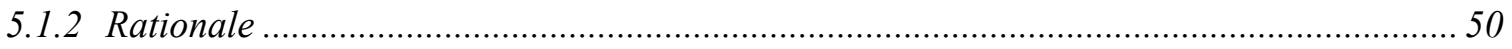

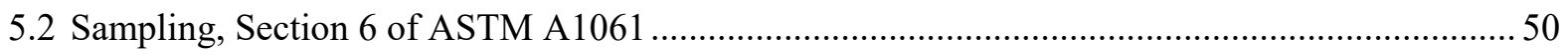




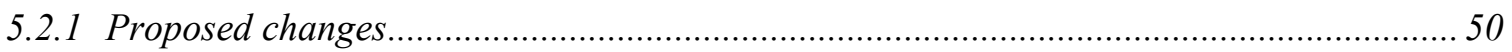

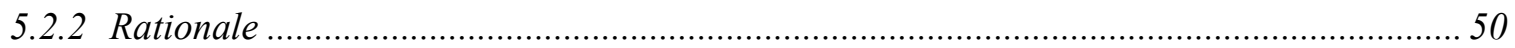

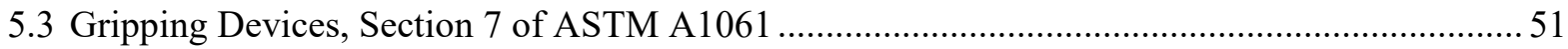

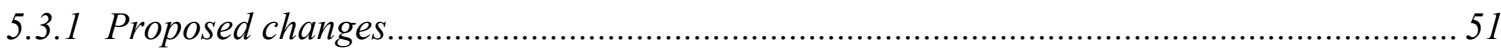

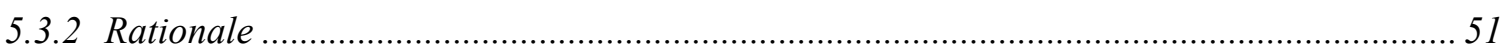

5.4 Preload Method for Yield Strength, Section 9.1.1 of ASTM A1061 ........................................... 52

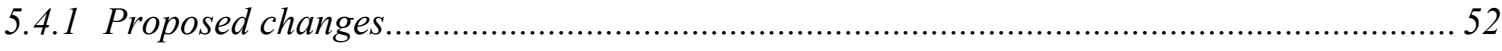



5.5 Elastic Modulus Extrapolation Method for Yield Strength, Section 9.1.2 of ASTM A1061 ........52

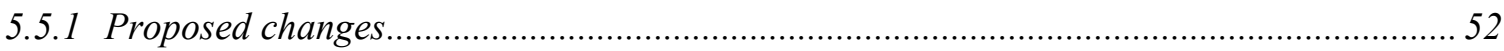

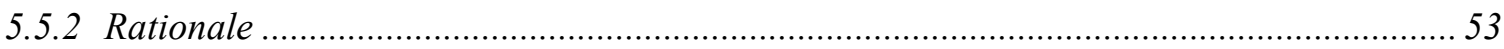

5.6 Methods for Determining Elongation, Section 9.2 of ASTM A1061 …..................................... 53

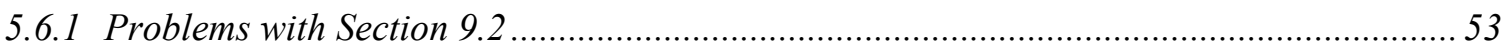

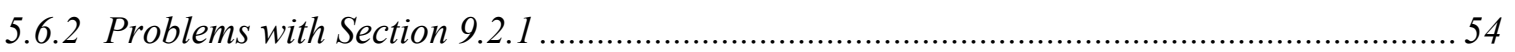



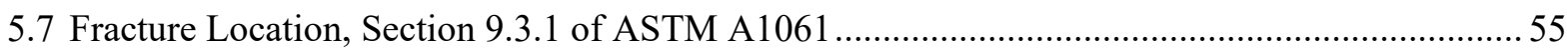

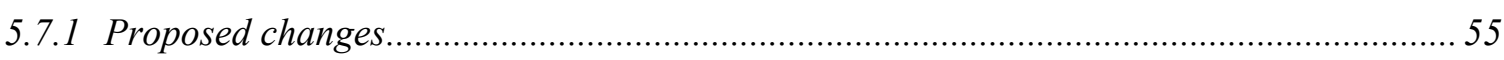

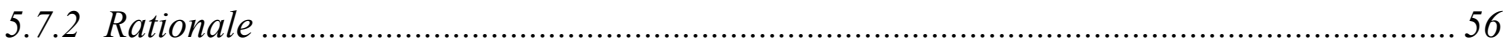

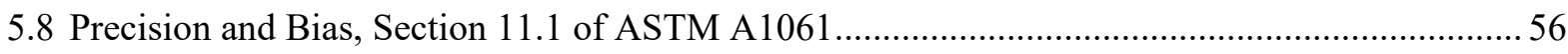

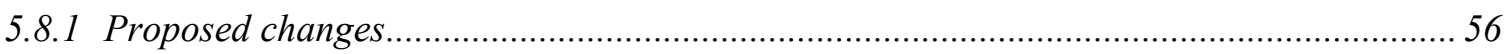

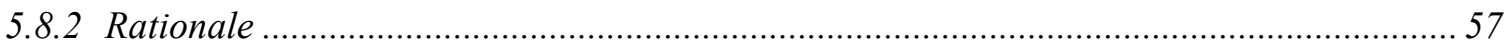

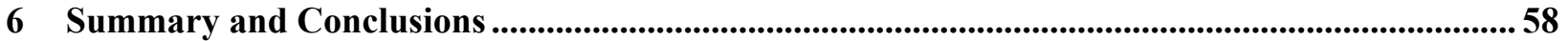

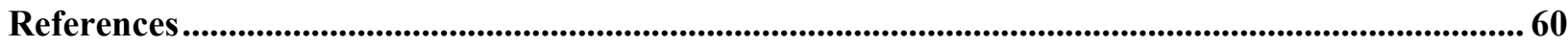

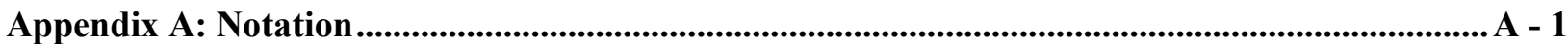

Appendix B: Results Reporting Forms and Questionnaire Sent to Laboratories............................. B - 1

Appendix C: Sample Response Reporting Form from Laboratory 11 for Sample 2........................ - 1

Appendix D: Excerpts of ASTM E691-18 Describing Statistical Methods of Analysis .................... - 1

Appendix E: Draft of ASTM Report Justifying the Proposed Precision Statement ......................... E - 1

Appendix F: Precision with Results from Welded Strand Excluded .............................................. F - 1 


\section{LIST OF TABLES}

Table 1 - Categories of validity/reasons for excluding data from the dataset ........................................ 12

Table 2 - Summary of valid/excluded classification by laboratory .........................................................22

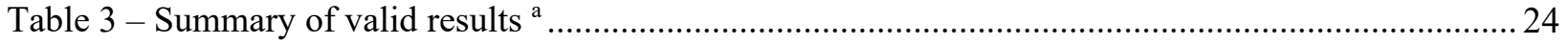

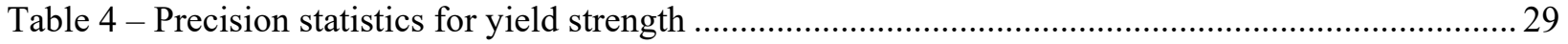

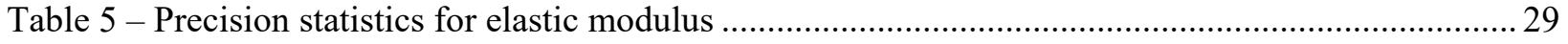

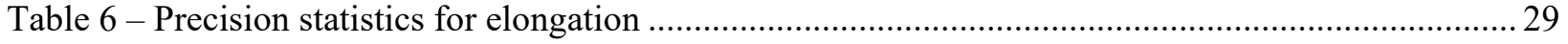

Table 7 - Precision statistics for breaking strength ......................................................................... 30

Table 8 - Precision statistics for data classified as valid versus data excluded from database...................33

Table 9 - Precision statistics for yield strength obtained using the preload and elastic modulus

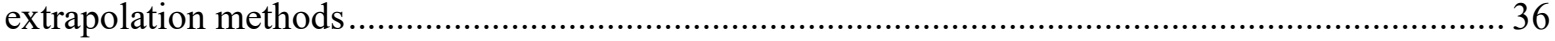

Table 10 - Precision statistics for elongation and breaking strength, separated into subgroups of specimens fracturing near the grips and specimens fracturing away from the grips ......................... 38

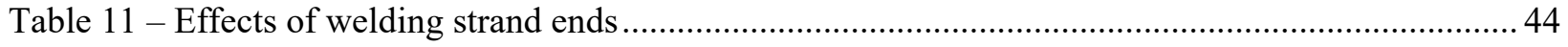

Table 12 - Calculated yield strength by method based on submitted point-by-point data ....................... 48

Table 13 - Statistical significance ( $p$-values) of differences in yield strengths obtained with preload, elastic modulus extrapolation, and $0.2 \%$ offset methods 


\section{LIST OF FIGURES}

Figure 1 - Example of test frame and data acquisition system used for tensile testing of strands .............. 4

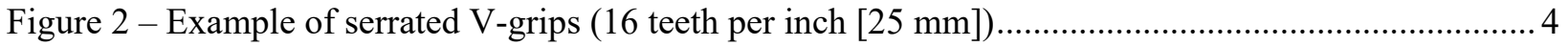

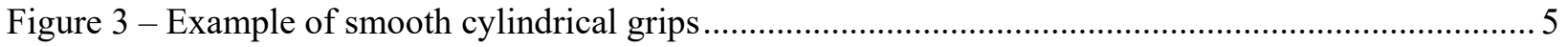

Figure 4 - Deviation in mean yield strength for each laboratory from mean of all valid results for 0.375 ,

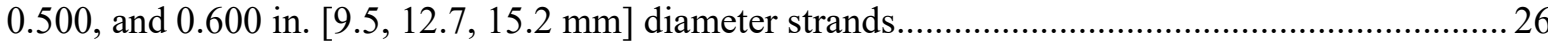

Figure 5 - Deviation in mean elastic modulus for each laboratory from mean of all valid results for 0.375 ,

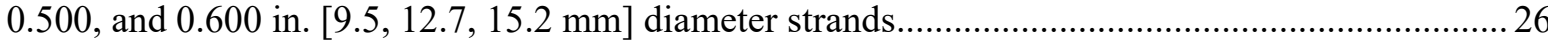

Figure 6 - Deviation in mean elongation for each laboratory from mean of all valid results for 0.375 , 0.500 , and 0.600 in. $[9.5,12.7,15.2 \mathrm{~mm}]$ diameter strands

Figure 7 - Deviation in mean breaking strength for each laboratory from mean of all valid results for $0.375,0.500$, and 0.600 in. $[9.5,12.7,15.2 \mathrm{~mm}]$ diameter strands.

Figure 8 - Repeatability limit divided by the mean of laboratory means for each strand diameter and test outcome $[1$ in. $=25.4 \mathrm{~mm}]$

Figure 9 - Reproducibility limit divided by the mean of laboratory means for each strand diameter and test outcome $[1$ in. $=25.4 \mathrm{~mm}]$

Figure 10 - Comparison of excluded and valid results in terms of mean of laboratory means (*subgroups of elastic modulus include fewer than six laboratories) $[1 \mathrm{in.}=25.4 \mathrm{~mm}]$.

Figure 11 - Comparison of excluded and valid results in terms of reproducibility limit (*subgroups of elastic modulus include fewer than six laboratories) $[1 \mathrm{in} .=25.4 \mathrm{~mm}]$.

Figure 12 - Comparison of yield strength results obtained using the preload and elastic modulus extrapolation methods in terms of mean and reproducibility limit (Note: the subgroup of data obtained with the elastic modulus extrapolation method includes fewer than six laboratories) [ 1 in. $=$ $25.4 \mathrm{~mm}]$

Figure 13 - Comparison of subgroups of data from tests with fracture occurring near the grips versus fracture occurring away from grips in terms of mean (*subgroups of elongation data include fewer than six laboratories) $[1 \mathrm{in.}=25.4 \mathrm{~mm}]$.

Figure 14 - Comparison of subgroups of data from tests with fracture occurring near the grips versus fracture occurring away from grips in terms of reproducibility limit (*subgroups of elongation data



Figure 15 - Photograph of cylindrical grips with gritty tungsten-carbide coating welded to surface ........ 42

Figure 16 - Photograph of welded strand end (portions of background blocked to hide brand identification)

Figure 17 - Photograph of strand that exhibited nominally simultaneous fracture of seven wires 44

Figure 18 - Yield strengths determined with different methods for specimen 3 of the $0.5 \mathrm{in}$. diameter strand tested by laboratory $11[1 \mathrm{in} .=25.4 \mathrm{~mm}, 1000 \mathrm{lbf}=4.448 \mathrm{kN}]$ 


\section{INTRODUCTION}

Seven-wire low-relaxation strand conforming to ASTM A416 $6^{[2]}$ is the most widely used type of strand in prestressed concrete applications in the United States. Qualification of this type of strand for use in production requires that samples are tested in tension according to ASTM A $1061^{[6]}$ to determine the yield strength, elongation, and breaking strength. Although not explicitly required by ASTM A1061 ${ }^{[6]}$, test results can also be used to determine elastic modulus. Measurements of strand relaxation properties, also described in ASTM A1061 ${ }^{[6]}$, are outside the scope of this study. Relaxation properties were omitted because they are assessed using a test that is distinct from the tension test examined in this study and would have required a distinct ILS protocol. Also, because relaxation properties are often not specified by purchasers, many laboratories that conduct the tension test examined in this study are not equipped to test strand relaxation.

ASTM A1061-16 $6^{[6]}$ does not have a precision and bias statement. Although it is not possible to establish the bias of the method as there is no accepted means of determining reference values, the precision of the test method can be determined through an interlaboratory study (ILS). Introduction of a precision statement into the standard has the potential to help resolve conflicts that arise in industry due to differing results being obtained from qualification and acceptance testing. Quantifiable measures of expected variability will allow laboratories to make more informed decisions about material acceptance/rejection.

In response to this need, a systematic ILS was conducted to quantify inter- and intra-laboratory variation in results from tests of strand conducted in accordance with ASTM A1061 ${ }^{[6]}$. The study evaluated variation in reported yield strength, elastic modulus, breaking strength, and elongation (relaxation properties were outside of the project scope). The ILS, conducted in accordance with ASTM E691 ${ }^{[9]}$, included 19 laboratories that tested Grade 270 [1860] low-relaxation seven-wire steel prestressing strand. Specimens included samples of $0.375,0.500$, and 0.600 in. [9.5, 12.7, and $15.2 \mathrm{~mm}]$ diameter. Samples of each strand diameter were sourced from the same coil of strand to minimize variations in material properties. Based on conversations with domestic strand producers and geographically disparate precast 
concrete manufacturers, it is believed these materials represent the vast majority of prestressing strand used in the United States.

Each participating laboratory reported the measured yield strength, elastic modulus (if recorded), breaking strength, and elongation for at least three samples of each strand diameter. Due to lack of appropriate gripping devices four laboratories did not test 0.375 in. [9.5 mm] diameter strand. Laboratories also responded to detailed questions posed by the research team that were aimed at documenting how the tests and calculations were conducted, as well as details about the test setup, instrumentation, and technicians responsible for conducting the tests. In addition, a member of the research team was present for approximately $40 \%$ of the tests in an effort to understand how different laboratories interpreted the test standard and questionnaire produced by the team.

The research team evaluated the results from each laboratory to establish whether they were obtained in a manner consistent with ASTM A1061 ${ }^{[6]}$ requirements using on-site observations and responses to the questionnaires. Where compliance with the standard could not be verified, the results were excluded from the final dataset used for analysis. The final dataset of valid results was analyzed in accordance with statistical methods described in ASTM E691 ${ }^{[9]}$ to quantify the precision of the method and propose a precision statement for ASTM A1061 ${ }^{[6]}$ in accordance with ASTM E177 ${ }^{[8]}$. 


\section{ASTM A1061 TEST METHOD}

ASTM A1061 ${ }^{[6]}$, Standard Test Methods for Testing Multi-Wire Steel Prestressing Strand, describes the method used to measure the yield strength, breaking strength, elongation at fracture, and relaxation properties of steel prestressing strand specimens. Although reporting of elastic modulus is not required, the standard also describes a method for determining the elastic modulus of the strand. Measurements of relaxation were outside the scope of this study.

ASTM A $1061^{[6]}$ is used for testing a variety of multi-wire strands, including compacted, indented, and low-relaxation strands comprised of 2,3 , or 7 wires. The most common application of the standard is testing of Grade 270 [1860] low-relaxation seven-wire steel strand compliant with ASTM A416 ${ }^{[2]}$. A brief description of the test method follows.

A tensile testing machine like that shown in Figure 1 is used for testing. ASTM A1061 ${ }^{[6]}$ permits the strand ends to be gripped using one of three methods:

- Standard V-grips with serrated teeth (Figure 2),

- Standard V-grips with serrated teeth and a cushioning material (e.g. lead foil, aluminum foil, etc.) placed between the grips and the test specimen, or

- Grips with smooth, semi-cylindrical grooves (Figure 3). When this method is used, an abrasive slurry may be applied to the grips and specimen prior to testing to reduce slippage.

It is permitted to use chucking devices of the type used for applying tension to strands in casting beds or post-tensioning anchorages as a secondary gripping system, in conjunction with one of the methods described above, to restrict strand slippage. 


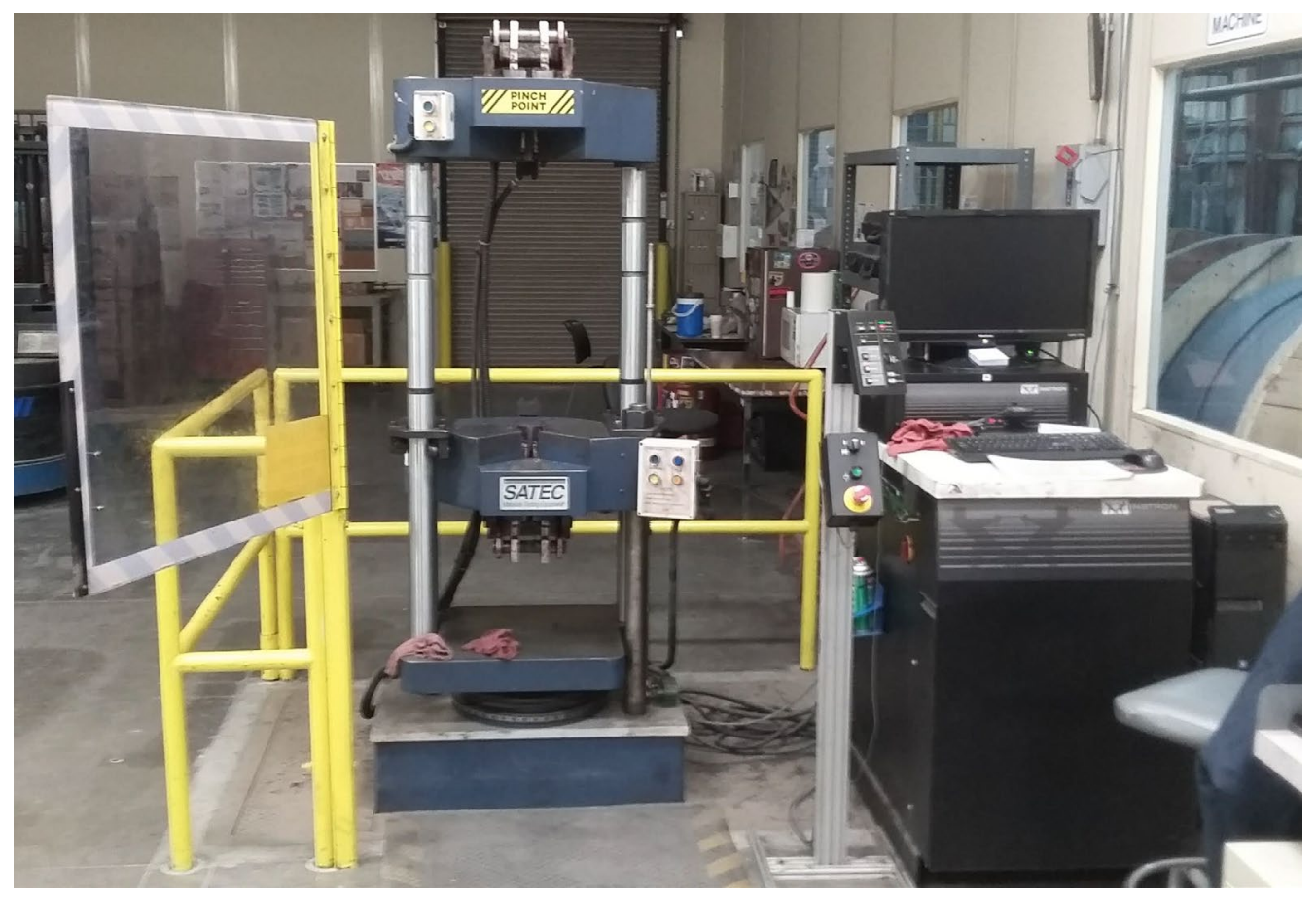

Figure 1 - Example of test frame and data acquisition system used for tensile testing of strands

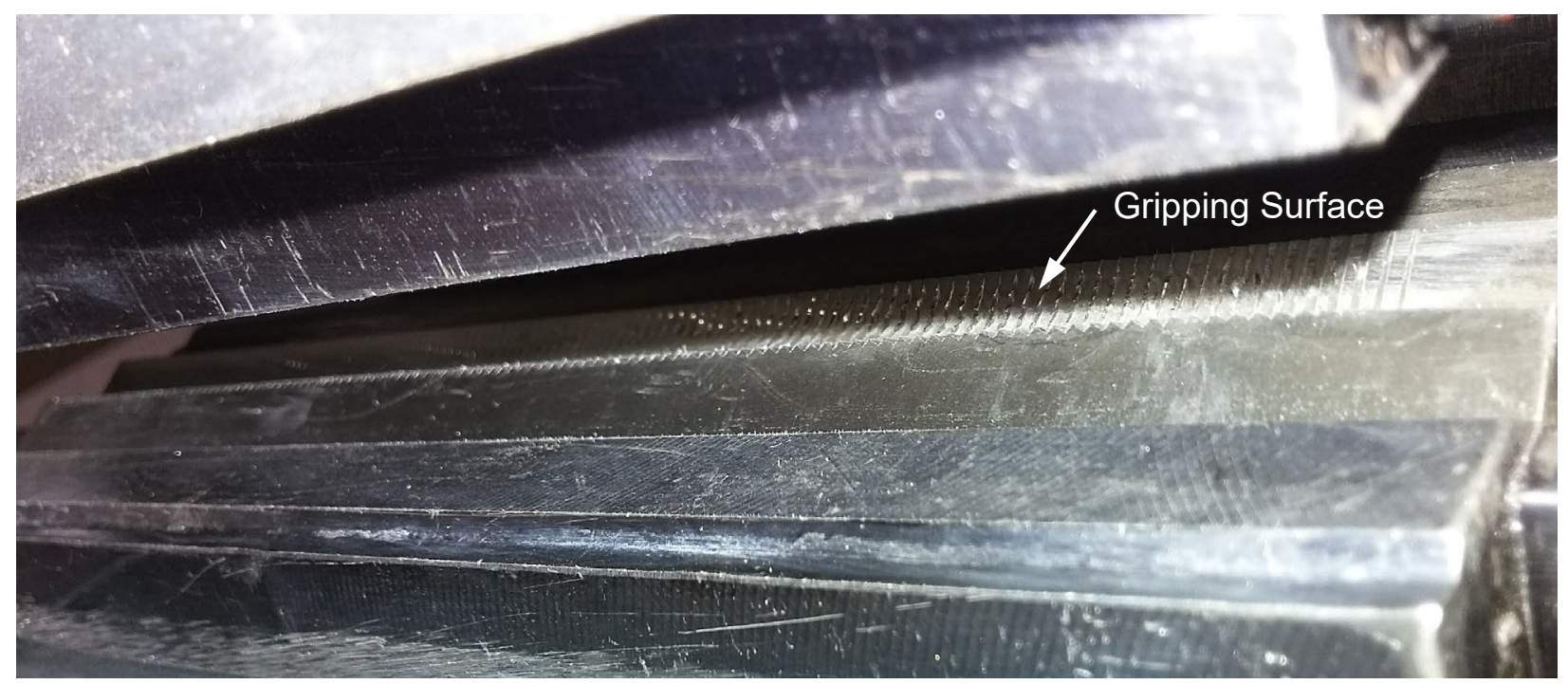

Figure 2 - Example of serrated V-grips (16 teeth per inch [25 mm]) 


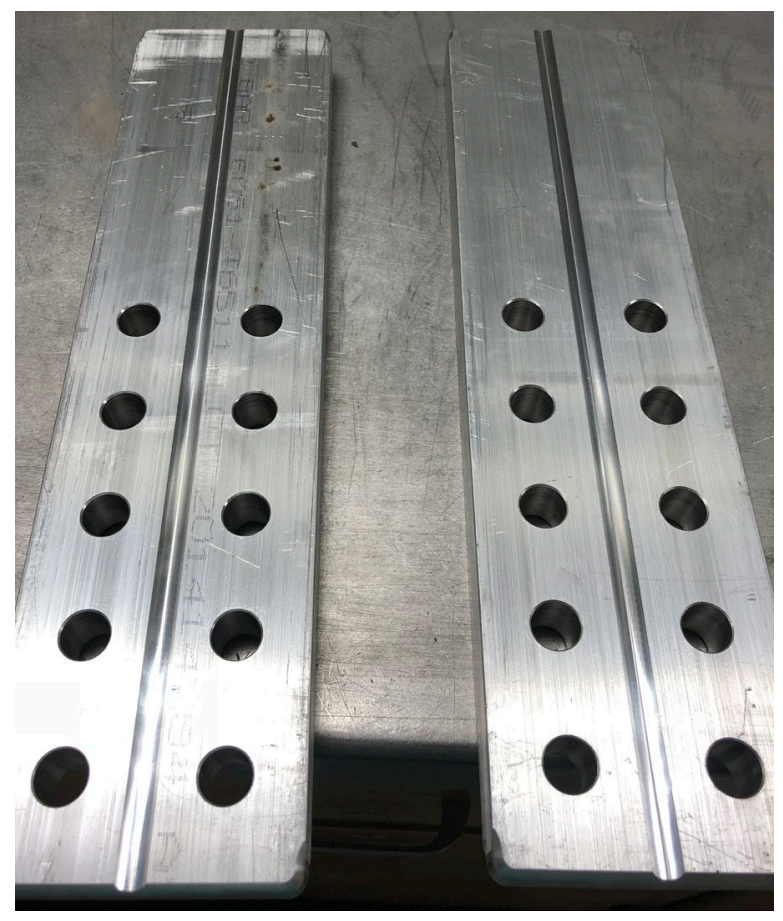

Figure 3 - Example of smooth cylindrical grips

Yield strength may be determined using one of two methods:

- Preload Method: The specimen is loaded to $10 \%$ of the required minimum breaking strength. The load is then held constant while an extensometer is attached to the specimen and adjusted to a reading of 0.1 $\%$ of the extensometer gauge length. The load is then increased. The yield strength is defined as the force corresponding to an elongation of $1.0 \%$ of the extensometer gauge length.

- Elastic Modulus Extrapolation Method: Using data collected with an extensometer mounted on the test specimen and the test frame load cell, the elastic modulus of a specimen is to be calculated using linear regression applied to at least $70 \%$ of the data collected between 20 and $65 \%$ of the required minimum breaking strength (inclusive). Participating laboratories who used this method reported elastic modulus as the slope of the linear regression fit line. The intersection of the linear regression and the horizontal axis is taken to be $0 \%$ elongation. Although not actually stated in Section 9.1.2 of ASTM A1061-16 ${ }^{[6]}$, the yield strength is defined as the force corresponding to an elongation of $1.0 \%$ of the extensometer gauge length, measured relative to the $0 \%$ elongation point. 
Elongation may be determined using one of two methods:

- Pre-Load Method: The specimen is loaded to $10 \%$ of the required minimum breaking strength. The load is then held constant while an extensometer is attached to the specimen and adjusted to a reading of $0 \%$ of the extensometer gauge length. The load is then increased until the measured elongation meets or exceeds the required minimum elongation, at which point the test is terminated. This method can be used to only determine whether a specimen possesses an elongation greater than the required minimum value or to determine the elongation at maximum force. The standard is not clear whether this method is intended to be used during a test when yield strength is also determined. The confusion arises because although this method is named similar to the preload method for yield strength, the instructions in Sections 9.1.1 and 9.2.1 of ASTM A1061-16 ${ }^{[6]}$ for mounting and adjusting the extensometer are incompatible.

- Elongation after Measuring Yield Strength Method: Regardless of which method was used to determine the yield strength, and therefore $1 \%$ elongation, the test is paused after $1.05 \%$ extension under load (EUL) to detach the extensometer from the specimen. The separation between the grips is then physically measured to document the gauge length prior to load reapplication. The change in separation between grips or crossheads (both are permitted) at strand fracture is then recorded, divided by the separation between grips measured when the extensometer was detached from the specimen, and added to the elongation value obtained by the extensometer during the yield strength portion of the test to obtain the elongation at fracture.

Breaking strength is taken as the maximum force applied to the specimen.

When a specimen fractures within a distance of $0.25 \mathrm{in} .[6 \mathrm{~mm}]$ from the grips, results from the test are valid only if they exceed the required minimum breaking strength, yield strength, and elongation. This language, which mirrors that used in ASTM A1061-16 ${ }^{[6]}$, is intended to include specimens that fracture anywhere within the grips or within a distance of $0.25 \mathrm{in}$. [6 mm] from the face of the grips. In the interest of brevity, the phrase "near the grips" will be used throughout this report to represent this requirement. 
According to ASTM A1061 ${ }^{[6]}$, tests of specimens that fracture near the grips are to be considered invalid if the measured values fall below the required minimums, and therefore should not be used to disqualify a strand. 


\section{INTER-LABORATORY STUDY PROCEDURES}

\subsection{Selection of Materials}

The ILS used Grade 270 [1860] low-relaxation seven-wire steel prestressing strand compliant with ASTM A $416^{[2]}$ requirements. Other types of strand, such as indented, compacted, stress-relieved, stainless,

and epoxy-coated strand produced in compliance with ASTM A779 ${ }^{[3]}$, A886 ${ }^{[4]}$, or A910 $0^{[5]}$, were not included in the project scope. The scope was defined after conversations with strand producers and precast concrete manufacturers throughout the United States (U.S.), who indicated most strand in the domestic marketplace is ASTM A416 ${ }^{[2]}$ Grade 270 [1860] strand.

The project included strands with $0.375,0.500$, and 0.600 in. $[9.5,12.7$, and $15.2 \mathrm{~mm}$ ] diameters. The two larger strands were selected because conversations with strand producers and precast concrete manufacturers indicated that 0.500 and $0.600 \mathrm{in}$. [12.7 and $15.2 \mathrm{~mm}$ ] diameter strands, which are typically used in structural applications, account for approximately $85 \%$ of the U.S. market for strand. Strand with a 0.375 in. [9.5 mm] diameter was also included for two reasons: 1) to determine whether the precision of the test method is sensitive to strand diameter and 2) it is commonly used in commercial precast applications and is the third most common size in the U.S.

\subsection{Selection of Laboratories}

A brief questionnaire was sent to dozens of laboratories within the United States to screen potential participants. Based on the responses, twenty-three laboratories were selected to participate in the ILS. The selected laboratories reported having the equipment and experience necessary to conduct the test in accordance with ASTM A1061 requirements and expressed a willingness to participate. Participants included strand producer laboratories, state department of transportation laboratories, and independent commercial laboratories. It is believed that participants were reasonably representative of the domestic strand-testing industry. 


\subsection{Procurement and Distribution of Test Specimens}

Samples of $0.375,0.500$, and 0.600 in. $[9.5,12.7$, and $15.2 \mathrm{~mm}]$ diameter strand were obtained from Sumiden Wire Products Corporation, Wire Mesh Corporation, and Insteel Wire Products, respectively. All samples of strand with a single diameter were obtained from a single coil from a single producer. Producers cut the samples to length and then shipped them to the University of Kansas (KU) Structural Engineering and Materials Laboratory for distribution.

Samples of each strand diameter were assigned unique identification numbers and sorted into groups of five using a random number generator. Each of the 23 participating laboratories was then sent a package containing five samples of 0.5 and $0.6 \mathrm{in}$. [12.7 and $15.2 \mathrm{~mm}$ ] diameter strands, a description of the test protocol, a detailed results reporting form for data collection, a questionnaire, ASTM A1061 ${ }^{[6]}$, and copies of relevant portions of ASTM E83 $3^{[7]}$ and ASTM A370 ${ }^{[1]}$. In addition, the 17 laboratories equipped to test 0.375 in. $[9.5 \mathrm{~mm}$ ] diameter strand were sent five samples of strand with that diameter. Surplus samples were stored at KU. Each participating laboratory was asked to perform a minimum of three successful tests for each strand size, although some chose to test all five. Two laboratories requested additional specimens, which were provided. The additional specimens were selected from the surplus at KU using a random number generator.

The results reporting forms and questionnaire (included in Appendix B) were developed by the research team with the aim of collecting the information necessary to allow the research team to make decisions regarding test validity. The reporting forms requested information on how the laboratory conducted each test, which measurements were made, and how calculations were executed to obtain the test results (yield strength, elastic modulus, breaking strength, and elongation). The questionnaire also requested more general information about the tests including the type of testing equipment used, equipment calibration dates, and loading rates. Care was taken in the development of the reporting forms to not guide the participating laboratories through the test procedure or influence their interpretation of ASTM A1061 ${ }^{[6]}$. To ensure that the reporting forms were sufficiently detailed but also relatively user friendly, the research 
team used them while conducting pilot tests at KU before the forms were sent to laboratories. Data obtained from tests conducted by the research team, including the pilot tests, were not included as part of the interlaboratory study.

\subsection{Testing and Results Reporting}

Nineteen laboratories reported results from tests of the distributed samples. A member of the research team was present to witness the testing at eight of the nineteen laboratories. To avoid biasing results, KU researchers did not intervene or comment when deviations from ASTM A1061 ${ }^{[6]}$ procedures were observed. Deviations from ASTM A1061 ${ }^{[6]}$ procedures were, however, recorded and used as a basis for excluding results from the results database.

Laboratories documented their results by completing the results reporting forms and questionnaire they were sent (an example of a completed results reporting form is provided in Appendix C) and, in many cases, submitted a pdf summary of the test results. These summaries typically included a plot of force versus elongation and a table listing the yield strength, elastic modulus, breaking strength, and elongation. Many laboratories also sent photographs of the test setup. Some laboratories provided point-by-point forceelongation data.

\subsection{Data Compilation and Removal of Erroneous Values}

Data sent to the KU research team were compiled in a spreadsheet wherein each row corresponded to a specimen and each column corresponded to a question on the questionnaire. Data entry was done by one member of the research team and then every value was independently checked by a different research team member to identify data entry errors. Data entry errors were identified, corrected, and then rechecked on a separate day to eliminate errors.

Values reported by technicians conducting the tests on the questionnaires were cross-checked against computer-generated test result summaries whenever they were provided. Where discrepancies were noted, the research team retained the value found on the computer-generated test result summary because 
these discrepancies were assumed to be attributable to transcription errors committed by the technicians. In each case, two members of the research team evaluated the discrepancy and agreed on the selected value. Approximately $2 \%$ of all reported values had this type of discrepancy.

A small number of clearly erroneous values were also identified (corresponding to less than $1 \%$ of all values). Examples of clearly erroneous values include: an elongation at yield of 39,060 psi [269.3 MPa], elastic moduli of 11,600 ksi [80,000 MPa] and $1698 \mathrm{psi}$ [11.7 MPa], and an elongation of $76.2 \%$. These values were considered to be obvious errors and were deleted from the database after independent evaluation by two members of the research team. Values that were not clearly erroneous, including outliers in the data, were retained.

\subsection{Determination of Test Procedure Validity}

A concerted effort was made to identify reported values obtained from tests that failed to adhere to ASTM A1061 ${ }^{[6]}$ procedures. A rubric was used to evaluate the reported results. When applicable, notes taken by the research team while observing tests were also used as a basis for excluding results based on test procedures used by the laboratory. Results were also separated into more specific categories based on the procedure selected (e.g. preload versus elongation method for yield strength determination) or the violation that was noted. Rubric categories are listed in Table 1.

Application of the rubric was, for the most part, systematic. For example, where an elastic modulus was calculated and used to identify the yield strength, the rubric requires the user to determine that the range of stresses used to obtain the elastic modulus complied with ASTM A1061 ${ }^{[6]}$ requirements. Where the reported range did not, both the reported modulus and yield strength were excluded from the dataset. All data were evaluated by two members of the research team to determine the validity of testing procedures. Whenever research team members differed in their judgement of whether a test result was valid, the evidence was discussed until consensus was reached. 
Table 1 - Categories of validity/reasons for excluding data from the dataset

\begin{tabular}{|c|c|c|}
\hline & Categories of Validity & Reasons for Excluding Data \\
\hline $\begin{array}{l}\text { Yield } \\
\text { Strength }\end{array}$ & $\begin{array}{l}\text {-Preload Method } \\
\text {-Extrapolation Method }\end{array}$ & $\begin{array}{l}\text {-Short Extensometer } \\
\text {-Extensometer Length Incorrect in } \\
\text { Calculations } \\
\text {-Extensometer Slipped } \\
\text {-Range of Elongations Incorrect - Preload } \\
\text { Method } \\
\text {-Range of Stresses Incorrect - Extrapolation } \\
\text { Method } \\
\text {-Other Issues } \\
\text {-Multiple Issues }\end{array}$ \\
\hline Elongation & $\begin{array}{l}\text {-Extrapolation Method } \\
\text {-Extrapolation Method - Strand Fracture } \\
\text { in/at Grip } \\
\text {-Mixed Methods } \\
\text {-Mixed Methods - Strand Fracture in/at } \\
\text { Grip }\end{array}$ & $\begin{array}{l}\text {-Short Extensometer } \\
\text {-Extensometer Length Incorrect in } \\
\text { Calculations } \\
\text {-Range of Stresses Incorrect - Extrapolation } \\
\text { Method } \\
\text {-Other Issues } \\
\text {-Multiple Issues }\end{array}$ \\
\hline $\begin{array}{l}\text { Elastic } \\
\text { Modulus }\end{array}$ & $a$ & $\begin{array}{l}\text {-Short Extensometer } \\
\text {-Extensometer Length Incorrect in } \\
\text { Calculations } \\
\text {-Range of Stresses Incorrect - Extrapolation } \\
\text { Method } \\
\text {-Other Issues } \\
\text {-Multiple Issues }\end{array}$ \\
\hline $\begin{array}{l}\text { Breaking } \\
\text { Strength }\end{array}$ & $\begin{array}{l}\text {-Strand Fracture in/at Grip } \\
\text {-Strand Fracture Away from Grips }\end{array}$ & $\mathrm{b}$ \\
\hline
\end{tabular}

Where insufficient information was available to determine the validity of procedures, the data were excluded from the dataset. This approach was applied to individual test procedures and general requirements alike (e.g. calibration dates, loading rates, etc.). It had the greatest impact when evaluating the procedures for strand elongation because many laboratories reported the output from their preprogrammed testing system without additional information. Although for these cases the research team contacted the laboratory seeking information, several laboratories were unable to explain how the test system determined elongation. This is because some laboratories use software pre-programmed by the test 
frame manufacturer and nobody at the facility fully understands how test results are determined. Procedures for obtaining yield and breaking strengths were easier to evaluate in terms of validity.

It is possible that some results excluded from the dataset are valid. There is evidence that some technicians misunderstood the questionnaire and provided responses consistent with improper procedures even when their procedures were, in fact, valid. For example, one laboratory that used the preload method for yield strength reported that the extensometer was mounted on the specimen at $0.1 \%$ elongation (a correct procedure) and that yield strength was taken as the force corresponding to $1.1 \%$ elongation (an incorrect procedure). However, because this laboratory also provided plots of the recorded data, the researchers were able to determine that the reported yield strength actually corresponded with $1 \%$ elongation and was, therefore, a valid result. Had plots of the data not been provided, the results would have been excluded from the dataset. It, therefore, follows that some excluded results from laboratories that did not provide plots may be valid.

\subsection{Statistical Analyses}

The valid data were analyzed in accordance with the procedures described in ASTM E691 ${ }^{[9]}$ to determine the precision of the ASTM A $1061^{[6]}$ method. These procedures are summarized below; excerpts from ASTM E691 ${ }^{[9]}$ including the relevant sections are located in Appendix D.

The following analyses were conducted for each test result from each material type (e.g. yield strength of 0.600 in. [15.2 mm] diameter strand). Because each laboratory reported results from between three and five tests on each material type, the first step of the analysis was to calculate the mean, $\bar{x}_{i}$, and standard deviation, $s_{i}$, of the test results (e.g. yield strengths for 0.600 in. [15.2 mm] strand) reported by each laboratory. This was done using Eq. 1 and Eq. 2.

$$
\bar{x}_{i}=\frac{\sum_{1}^{n_{i}} x}{n_{i}}
$$

Eq. 1 


$$
s_{i}=\sqrt{\frac{\sum_{i=1}^{n_{i}}\left(x-\bar{x}_{i}\right)^{2}}{\left(n_{i}-1\right)}}
$$

where: $\bar{x}_{i}$ is the mean of results reported by the $\mathrm{i}^{\text {th }}$ laboratory, $n_{i}$ is the number of results reported by $\mathrm{i}^{\text {th }}$ laboratory, $x$ is an individual test result, and $s_{i}$ is the standard deviation of results reported by $\mathrm{i}^{\text {th }}$ laboratory. See Appendix A for a more detailed description of notation.

Because many of the following calculations are more easily understood in terms of variance, it is noted here that variance equals standard deviation squared. Therefore, the variance observed for the results reported by the $i^{\text {th }}$ laboratory is $s_{i}{ }^{2}$.

The mean of the laboratory means, $\overline{\bar{x}}$, was calculated using Eq. 3.

$$
\overline{\bar{x}}=\frac{\sum_{i=1}^{P_{L}} \bar{x}_{i}}{P_{L}}
$$

where: $P_{L}$ is the number of laboratories.

The standard deviation of the laboratory means, $s_{\bar{x}}$, was calculated with Eq. 4.

$$
s_{\bar{x}}=\sqrt{\frac{\sum_{i=1}^{P_{L}}\left(\bar{x}_{i}-\overline{\bar{x}}\right)^{2}}{\left(P_{L}-1\right)}}
$$

To quantify the intra-laboratory variation of the test method, the Repeatability Standard Deviation, $s_{r}$, was calculated using Eq. 5. In terms of variance, $s_{r}{ }^{2}$ equals the mean of the variances $\left(s_{i}{ }^{2}\right)$ calculated for results from each laboratory.

$$
s_{r}=\sqrt{\frac{\sum_{i=1}^{P_{L}} s_{i}{ }^{2}}{P_{L}}}
$$


The Repeatability Limit, $r$, was then calculated using Eq. 6. The Repeatability Limit is a key finding of this study. It is defined in ASTM E691 ${ }^{[9]}$ as "the value below which the absolute difference between two individual test results obtained under repeatability conditions may be expected to occur with a probability of approximately $0.95(95 \%)$ ". Repeatability conditions refer to "conditions where independent [results from tests of nominally identical specimens] are obtained in the same laboratory by the same operator using the same equipment within short intervals of time". In other words, there is a $95 \%$ probability that two test results will differ by not more than $r$ if they are obtained from tests of nominally identical specimens conducted by a single technician on the same equipment.

$$
r=2.8 s_{r}
$$

To quantify inter-laboratory variation, the Between Laboratory Standard Deviation, $s_{L}$, was calculated with Eq. 7. Under repeatability conditions, a test method that is perfectly repeatable would have $s_{r}=0$ and therefore the Between Laboratory Standard Deviation would equal the standard deviation of the laboratory means, $s_{\bar{x}}$. When $s_{r} \neq 0$, which is typically the case, $s_{L}<s_{\bar{x}}$ because some of the differences between laboratory means are attributable to variations under repeatability conditions.

$$
s_{L}=\sqrt{s_{\bar{x}}^{2}-\frac{s_{r}^{2}}{n}}
$$

The Reproducibility Standard Deviation, $s_{R}$, was then calculated with Eq. 8. In terms of variance, the value of ${s_{R}}^{2}$, which might be called the reproducibility variance, is the sum of $s_{L}{ }^{2}$ and $s_{r}{ }^{2}$, which respectively might be called the between laboratory variance and the repeatability variance. The Reproducibility Standard Deviation therefore represents the variability observed between results from tests on a single material conducted by different technicians at different laboratories. It includes effects of both between laboratory variability and the variability observed under repeatability conditions. 


$$
s_{R}=\sqrt{s_{L}^{2}+s_{r}^{2}}
$$

The Reproducibility Limit, $R$, was then calculated using Eq. 9. The Reproducibility Limit is another key finding of this study. It is defined in ASTM E691 ${ }^{[9]}$ as "the value below which the absolute difference between two test results obtained under reproducibility conditions may be expected to occur with a probability of approximately 0.95 (95\%)". Reproducibility conditions refer to "conditions where test results are obtained with the same method on [nominally] identical test items in different laboratories with different operators using different equipment". In other words, there is a $95 \%$ probability that two test results will differ by not more than $R$ if they are obtained from tests of nominally identical specimens conducted by different technicians on different equipment.

$$
R=2.8 s_{R}
$$

To ensure that the Repeatability Limit, $r$, and Reproducibility Limit, $R$, are based on a sound dataset, ASTM E691 ${ }^{[9]}$ requires the use of statistical methods to identify data that warrant additional investigation and should potentially be excluded from the dataset. This was done by first calculating consistency statistics $h$ and $k$, respectively, using Eq. 10 and Eq. 11.

$$
\begin{gathered}
h=\frac{\bar{x}_{i}-\overline{\bar{x}}}{s_{\bar{x}}} \\
k=\frac{s_{i}}{s_{r}}
\end{gathered}
$$

The Between-Laboratory Consistency Statistic, $h$, is a unitless measure of how much the mean result from a given laboratory, $\bar{x}_{i}$, differs from the mean of all laboratory means, $\overline{\bar{x}}$, relative to the standard deviation of the laboratory means, $s_{\bar{x}}$. If $h$ exceeds the limit specified in ASTM E691 ${ }^{[9]}$ for a laboratory or if the pattern in calculated $h$ values is suspicious (e.g. $h$ is positive for all laboratories except for one), 
results from that laboratory should be investigated and potentially excluded from the dataset. The limits for $h$ in ASTM E691 ${ }^{[9]}$ are a function of the number of ILS laboratories.

The Within-Laboratory Consistency Statistic, $k$, is a unitless measure of how much the standard deviation among results from a given laboratory, $s_{i}$, varies from the Repeatability Standard Deviation, $s_{r}$. If the value of $k$ exceeds the limit provided in ASTM E691 ${ }^{[9]}$ or if there are suspicious trends (e.g. $k$ is small or large for all values reported by a single laboratory), results from that laboratory should be investigated and potentially excluded from the dataset. The limits for $k$ in ASTM E691 ${ }^{[9]}$ are a function of the number of ILS laboratories and the number of replicate tests conducted by each laboratory. 


\section{RESULTS AND ANALYSIS}

\subsection{Equipment and Procedures used by Participating Laboratories}

\subsubsection{Testing Equipment}

Force was applied using self-reacting frames. Research team members observed tests in screw-type and hydraulically actuated frames with rated capacities between approximately 120 and 600 kips. Several methods were employed for gripping the strand specimens:

- Five laboratories used serrated V-grips with approximately 16 teeth per inch [25 mm] with nothing placed between the teeth and the strand. For those laboratories, 40 of 51 specimens (78\%) fractured near the grips.

- One laboratory used serrated V-grips with an aluminum cushioning material. Only one of nine specimens $(11 \%)$ fractured near the grips at this laboratory.

- One laboratory used smooth cylindrical steel grips without pretreatment. Two of nine specimens (22 $\%)$ tested at this laboratory fractured near the grips.

- Eight laboratories used smooth cylindrical grips combined with various methods to increase friction, including aluminum oxide, silica sand slurries, or metal shavings. At these laboratories, 20 of 75 (27 $\%)$ fractured near the grips.

- Three laboratories used cylindrical grips with a gritty tungsten-carbide coating welded to the surface of the grips. Fracture occurred near the grips for 11 of 31 specimens (35\%). This type of grip is not explicitly addressed in ASTM A1061-16 $6^{[6]}$, but perhaps it should be given its prevalence.

- One laboratory reported using smooth cylindrical aluminum grips with no pre-treatment. None of the nine specimens $(0 \%)$ tested at this laboratory fractured near the grips.

Two laboratories reported using secondary chucking devices in a manner consistent with ASTM A1061 ${ }^{[6]}$ requirements. Though not observed in this study, it was reported anecdotally to research team members that some laboratories (not included in the study) use grips that are so worn that strand slip through 
the grips is inevitable. When these laboratories use secondary chucking devices, it is common to observe strand fracture in the secondary chucking device. If true, it would be evidence that the chucking devices are improperly acting as the primary gripping device.

With two exceptions, laboratories used a 24 in. [610 mm] extensometer that was typically clipped onto the strand specimen for elongation measurements up to the yield strength. Some of these laboratories used duct tape or hot glue between the blade of the extensometer fixture and the surface of the strand to reduce slippage. The two other laboratories reported using extensometers with gauge lengths of 8 and 20 in. $[200$ and $510 \mathrm{~mm}]$. Because ASTM A1061 ${ }^{[6]}$ requires that the extensometer gauge length exceed the lay length of the strand, results for yield strength, elastic modulus, and elongation reported by these two laboratories were excluded from the dataset except for results for the $0.375 \mathrm{in}$. [9.5 mm] diameter strand reported by the laboratory with a $20 \mathrm{in.}[510 \mathrm{~mm}]$ gauge length extensometer.

Beyond $1 \%$ elongation, most laboratories used computer-recorded crosshead displacement to monitor elongation, although several reported using rulers and tape measures to determine elongation. Section 9.2.2 of ASTM A1061 ${ }^{[6]}$ indicates the separation between grips, $L_{o}$, should be measured when loading is paused to remove the extensometer shortly after reaching the yield force. Either crosshead displacement or the change in separation between grips may then be used to quantify the change in length after yield. Total elongation is taken as this change in length after yield, divided by $L_{o}$, and added to $1 \%$. However, most laboratories chose to automate this process and either used crosshead separation at yield or the separation between grips at the start of the test instead of $L_{o}$. As will be discussed later, the results reported for elongation were highly scattered.

\subsubsection{Testing Procedures}

As described in Chapter 2, ASTM A1061 ${ }^{[6]}$ includes two methods for determining yield strength: the Preload Method and the Elastic Modulus Extrapolation Method. Of the 19 participating laboratories, 11 used the preload method for yield strength. Among the yield strength results obtained using the preload 
and elastic modulus extrapolation methods, 91 and $50 \%$ were classified as valid, respectively. As a result, 10 of the $14^{\mathrm{a}}$ laboratories that reported yield strengths classified as valid used the preload method.

ASTM A $1061^{[6]}$ also includes two approved methods for determining elongation. Because every laboratory measured yield strength, every laboratory in this study used the elongation after measuring yield strength method to determine elongation. Per ASTM A1061 ${ }^{[6]}$, elongation results are to be considered valid if either: 1) the strand fractures within the free length of the specimen, or 2) the measured elongation exceeds the required minimum elongation listed in ASTM A416 $6^{[2]}(3.5 \%)$ regardless of where the strand fracture occurs. Because all recorded elongations exceeded 3.5\%, the dataset of valid elongations includes results from specimens that fractured both within the free length and near the grips. These subgroups of results are treated jointly and separately in the subsequent sections, as appropriate.

ASTM A1061 ${ }^{[6]}$ includes one method for determining breaking strength. As with elongation, the dataset of valid breaking strengths includes results from specimens that fractured within the free length and near the grips. These subgroups of results are also treated jointly and separately in the subsequent sections, as appropriate.

\subsection{Reasons for Excluding Data from Valid Dataset}

The methods described in Section 3.5 were used to evaluate whether the procedures used by each participating laboratory complied with ASTM A1061 ${ }^{[6]}$. Results obtained in a manner compliant with ASTM A $1061^{[6]}$ are referred to herein as valid. Of the nineteen laboratories that submitted test results, 14 , 6 , and 19 laboratories $(74,32$, and $100 \%)$ reported at least one result that was classified as valid for yield strength, elongation, and breaking strength, respectively. Of the 11 laboratories that reported elastic modulus, $9(82 \%)$ had at least one result classified as valid. Again, for the reasons noted in Section 3.5,

\footnotetext{
${ }^{a}$ Several laboratories reported results that were valid for some specimens and not for others. Consequently, the number of laboratories that reported one valid result may not equal the number of laboratories that reported a valid result for each strand diameter (see Table 3 ).
} 
some results excluded from the database of valid results might have been valid. The research team used a strict interpretation of the requirements in ASTM A1061 ${ }^{[6]}$ to obtain a dataset of valid results, and any ambiguity in the submitted results or responses was cause for excluding the associated data.

The reasons results were excluded from the database of valid results are listed in Table 2, with the identity of each laboratory replaced with a randomly assigned integer. As expressed in the acknowledgements, laboratory identities are divorced from discussions of results.

Yield strengths and elastic moduli were excluded from the valid dataset for the following reasons:

- Two laboratories used an incorrect range of elongations to determine yield strength when the preload method was used (ASTM A1061 ${ }^{[6]}$ Section 9.1.1). For example, a laboratory set elongation equal to 0 $\%$ when force was $10 \%$ of the required minimum breaking strength and reported the force at $1 \%$ elongation as the yield strength (the reported value therefore incorrectly corresponds to the force at 1.1 $\%$ elongation).

- Two laboratories used an incorrect range of forces to determine the elastic modulus when using the elastic modulus extrapolation method for yield strength (ASTM A $1061^{[6]}$ Section 9.1.2). For example, forces less than $20 \%$ or greater than $65 \%$ of the required minimum breaking strength were included in the range, with forces up $92 \%$ of the required minimum breaking strength used in one case.

- One laboratory set the elastic modulus to a fixed value for all specimens instead of calculating modulus when using the elastic modulus extrapolation method for yield strength. Plotted results submitted to the research team clearly showed the assumed value was incorrect for some specimens.

- One laboratory used an incorrect gauge length in the calculation of elongation (and did not report the correct gauge length, so elongation values could not be recalculated).

- One laboratory allowed the extensometer to slip relative to the specimen and made no apparent attempt to correct the reported results or repeat the tests.

- One laboratory reported using an extensometer with a gauge length that was shorter than the lay-length of the 0.5 and 0.6 in. [12.7 and $15.2 \mathrm{~mm}$ ] diameter strand samples. 
- One laboratory reported using an extensometer that did not meet the requirements of ASTM E83 ${ }^{[7]}$ for B-1 classification.

Table 2 - Summary of valid/excluded classification by laboratory

\begin{tabular}{|c|c|c|c|c|}
\hline Lab ID & Yield Strength & Elongation & Elastic Modulus & Breaking Strength \\
\hline $1^{a}$ & Valid - Preload & $\begin{array}{c}\text { Excluded - Calculation } \\
\text { Incorrect }\end{array}$ & Not reported & Valid \\
\hline 2 & Valid - Preload & $\begin{array}{l}\text { Excluded - Short } \\
\text { Extensometer }\end{array}$ & Valid & Valid \\
\hline $3^{a}$ & $\begin{array}{l}\text { Excluded - Modulus } \\
\text { Stress Range Incorrect }\end{array}$ & $\begin{array}{l}\text { Excluded - Modulus } \\
\text { Stress Range Incorrect }\end{array}$ & $\begin{array}{c}\text { Excluded - Modulus } \\
\text { Stress Range } \\
\text { Incorrect }\end{array}$ & Valid \\
\hline 4 & Valid - Preload & Valid - Mixed & Not reported & Valid \\
\hline 5 & $\begin{array}{l}\text { Excluded - Preload } \\
\text { Elongation Range } \\
\text { Incorrect }\end{array}$ & Valid - Mixed & Valid & Valid \\
\hline $6^{a}$ & Valid - Preload & Valid - Mixed & Not reported & Valid \\
\hline $7^{a}$ & Valid - Preload & Valid - Mixed & Not reported & Valid \\
\hline 8 & Valid - Preload & Valid - Mixed & Not reported & Valid \\
\hline $9^{a}$ & $\begin{array}{l}\text { Excluded - Modulus } \\
\text { Stress Range Incorrect }\end{array}$ & $\begin{array}{l}\text { Excluded - Modulus } \\
\text { Stress Range Incorrect }\end{array}$ & $\begin{array}{c}\text { Excluded - Modulus } \\
\text { Stress Range } \\
\text { Incorrect }\end{array}$ & Valid \\
\hline 10 & $\begin{array}{c}\text { Excluded - } \\
\text { Extensometer Slipped }\end{array}$ & $\begin{array}{c}\text { Excluded - } \\
\text { Extensometer Slipped }\end{array}$ & Not reported & Valid \\
\hline $11^{a}$ & Valid - Extrapolation & Valid - Mixed & Valid & Valid \\
\hline 12 & Valid - Preload & Valid - Mixed & Not reported & Valid \\
\hline 13 & Valid - Extrapolation & Valid - Mixed & Valid & Valid \\
\hline 14 & $\begin{array}{l}\text { Excluded for } 0.5^{\prime \prime}+0.6 " \\
\text { - Short Extensometer }\end{array}$ & $\begin{array}{c}\text { Excluded for } 0.5^{\prime \prime}+ \\
0.6^{\prime \prime} \text { - Short } \\
\text { Extensometer }\end{array}$ & $\begin{array}{c}\text { Excluded for } 0.5^{\prime \prime}+ \\
0.6^{\prime \prime} \text { - Short } \\
\text { Extensometer }\end{array}$ & Valid \\
\hline 15 & Valid - Preload & Valid - Mixed & Valid & Valid \\
\hline $16^{\mathrm{a}}$ & Valid - Extrapolation & Valid - Extrapolation & Valid & Valid \\
\hline 17 & $\begin{array}{c}\text { Excluded - Preload } \\
\text { Elongation Range } \\
\text { Incorrect, Extensometer } \\
\text { not B-1 }\end{array}$ & $\begin{array}{l}\text { Excluded - Preload } \\
\text { Elongation Range } \\
\text { Incorrect, } \\
\text { Extensometer not B-1, } \\
\text { Calculations seem } \\
\text { Incorrect }\end{array}$ & Not reported & Valid \\
\hline 18 & $\begin{array}{c}\text { Excluded - Modulus is } \\
\text { Assumed, Not } \\
\text { Calculated }\end{array}$ & $\begin{array}{c}\text { Excluded - Modulus is } \\
\text { Assumed, Not } \\
\text { Calculated }\end{array}$ & $\begin{array}{c}\text { Excluded - Modulus is } \\
\text { Assumed, Not } \\
\text { Calculated }\end{array}$ & Valid \\
\hline $19^{a}$ & $\begin{array}{l}\text { Excluded - Incorrect } \\
\text { Gauge Length in } \\
\text { Calculation }\end{array}$ & $\begin{array}{l}\text { Excluded - Incorrect } \\
\text { Gauge Length in } \\
\text { Calculation }\end{array}$ & $\begin{array}{l}\text { Excluded - Incorrect } \\
\text { Gauge Length in } \\
\text { Calculation }\end{array}$ & Valid \\
\hline
\end{tabular}

${ }^{a}$ Tests witnessed by member of research team 
For results obtained according to Section 9.2.2 to be valid, a valid identification of $1 \%$ elongation is required, effectively requiring a valid determination of yield strength. Elongation results were, therefore, excluded from the valid dataset when yield strength results were excluded. Elongation results were also excluded for the following reasons:

- Two laboratories used an incorrect gauge length to calculate elongation from measured crosshead displacement values. This occurred when, for instance, technicians divided crosshead displacement by 24 in. [610 mm], the gauge length of the extensometer, and not the distance between grips.

- One laboratory reported elongation values recorded by the software immediately after breakage, when crosshead displacement measurements were erratic and large due to the energy released by strand fracture. The research team was able to determine that the reported values were unrelated to specimen elongation because this laboratory submitted point-by-point data.

- Two laboratories used extensometers with gauge lengths less than 24 in. [600 mm].

In no case was the reported value of breaking strength excluded from the valid dataset.

\subsection{Summary of Valid Test Results}

Valid results for each test outcome (yield strength, elastic modulus, elongation, breaking strength) were received for each strand diameter from a minimum of six laboratories, which satisfies the minimum requirement of ASTM E691 ${ }^{[9]}$ for establishing a precision statement.

Valid test results are summarized in Table 3. The mean, coefficient of variation, and range are shown for the valid reported values of yield strength, elastic modulus, elongation, and breaking strength. The results are presented separately for $0.375,0.500$, and 0.600 in. $[9.5,12.7$, and $15.2 \mathrm{~mm}$ ] diameter strands. In addition, the number of results, the number of valid results, and the number of laboratories that reported valid results are reported for each strand diameter and parameter. For instance, there were 52 reported values of yield strength for $0.375 \mathrm{in}$. [9.5 mm] diameter strand. Of those values, 35 values obtained from 11 laboratories were considered valid. The number of valid results is not three times the number of 
laboratories even though each laboratory was asked to conduct three tests. This is because some laboratories reported results from more than three valid tests and others had one or two of their three results excluded from the dataset.

Table 3 - Summary of valid results ${ }^{\text {a }}$

\begin{tabular}{|c|c|c|c|c|}
\hline & & \multicolumn{3}{|c|}{ Strand Diameter, in. [mm] } \\
\hline & & $0.375[9.5]$ & $0.5[12.7]$ & $0.6[15.2]$ \\
\hline \multirow{7}{*}{ Yield Strength } & Mean, Ibf [kN] & $23083[102.7]$ & $38816[172.7]$ & 55818 [248.3] \\
\hline & $\operatorname{COV}^{b}, \%$ & 1.32 & 0.983 & 1.16 \\
\hline & Minimum, Ibf [kN] & $22550[100.3]$ & 38118 [169.6] & 54828 [243.9] \\
\hline & Maximum, lbf [kN] & $23850[106.1]$ & $40128[178.5]$ & 57967 [257.9] \\
\hline & $\begin{array}{l}\text { Number of Reported } \\
\text { Results }\end{array}$ & 52 & 66 & 66 \\
\hline & Number of Valid Results & 35 & 39 & 40 \\
\hline & $\begin{array}{l}\text { Number of Laboratories } \\
\text { with Valid Results }\end{array}$ & 11 & 12 & 12 \\
\hline \multirow{7}{*}{ Elastic Modulus } & Mean, ksi [GPa] & $29233[201.6]$ & 29594 [204.0] & 29102 [200.7] \\
\hline & $\operatorname{COV}^{b}, \%$ & 1.41 & 2.99 & 2.80 \\
\hline & Minimum, ksi [GPa] & $28500[196.5]$ & 28700 [197.9] & 27400 [188.9] \\
\hline & Maximum, ksi [GPa] & $30000[206.8]$ & 32300 [222.7] & $30970[213.5]$ \\
\hline & $\begin{array}{l}\text { Number of Reported } \\
\text { Results }\end{array}$ & 30 & 40 & 40 \\
\hline & Number of Valid Results & 19 & 23 & 26 \\
\hline & $\begin{array}{l}\text { Number of Laboratories } \\
\text { with Valid Results }\end{array}$ & 6 & 7 & 8 \\
\hline \multirow{7}{*}{ Elongation } & Mean, \% & 6.30 & 6.55 & 6.18 \\
\hline & $\operatorname{cOV}^{b}, \%$ & 17.6 & 16.9 & 17.7 \\
\hline & Minimum, $\%$ & 4.90 & 4.95 & 4.40 \\
\hline & Maximum, \% & 8.80 & 8.80 & 7.80 \\
\hline & $\begin{array}{l}\text { Number of Reported } \\
\text { Results }\end{array}$ & 52 & 66 & 66 \\
\hline & Number of Valid Results & 20 & 20 & 20 \\
\hline & $\begin{array}{l}\text { Number of Laboratories } \\
\text { with Valid Results }\end{array}$ & 6 & 6 & 6 \\
\hline \multirow{7}{*}{$\begin{array}{l}\text { Breaking } \\
\text { Strength }\end{array}$} & Mean, Ibf [kN] & $25759[114.6]$ & $43803[194.8]$ & $61949[275.6]$ \\
\hline & $\operatorname{COV}^{\mathrm{b}}, \%$ & 0.934 & 0.802 & 0.740 \\
\hline & Minimum, lbf [kN] & $25000[111.2]$ & 43132 [191.9] & 60680 [269.9] \\
\hline & Maximum, lbf [kN] & $26300[117.0]$ & $44700[198.8]$ & $62900[279.8]$ \\
\hline & $\begin{array}{l}\text { Number of Reported } \\
\text { Results }\end{array}$ & 52 & 66 & 66 \\
\hline & Number of Valid Results & 52 & 66 & 66 \\
\hline & $\begin{array}{l}\text { Number of Laboratories } \\
\text { with Valid Results }\end{array}$ & 15 & 19 & 19 \\
\hline
\end{tabular}

${ }^{a}$ Mean, $\mathrm{COV}^{\mathrm{b}}$, Minimum, and Maximum for valid results only

${ }^{b}$ Coefficient of variation 
Table 3 shows that yield strength and breaking strength were very consistent within the population of valid results, with coefficients of variation less than 1.5 and $1.0 \%$, respectively. Valid results for elastic modulus were somewhat more scattered, with coefficients of variation between 1.4 and $3.0 \%$ for the different strand diameters. Among laboratories, reported values of elongation were highly scattered. Valid elongation values ranged from less than $5 \%$ to greater than $7.5 \%$ for all three strand diameters, resulting in coefficients of variation near $17 \%$.

Variability was not correlated with strand size. Coefficients of variation for yield strength, elastic modulus, elongation, and breaking strength were largest for the $0.375,0.500,0.600$, and $0.375 \mathrm{in}$. [9.5, 12.7, 15.2, and $9.5 \mathrm{~mm}$ ] diameter strand samples, respectively. Figure 4 shows the deviation in mean yield strength for each laboratory from mean of all valid results for all strand diameters. Analogous plots are provided for elastic modulus, elongation, and breaking strength in Figure 5, Figure 6, and Figure 7. Note that Figure 6 has a different range on the vertical axis than the other figures due to the large variability. Consistent with the coefficients of variation listed in Table 3, it is clear in these figures that results for yield strength and breaking strength had low variability, results for elastic modulus were somewhat more scattered, and results for elongation were extremely scattered. Figure 6 shows that results from some laboratories (laboratory number 4 ) had mean elongations that were $25 \%$ greater than the mean of all valid results, while others (laboratories 8 and 11) had some that were nearly $25 \%$ less than the mean of all valid results. 


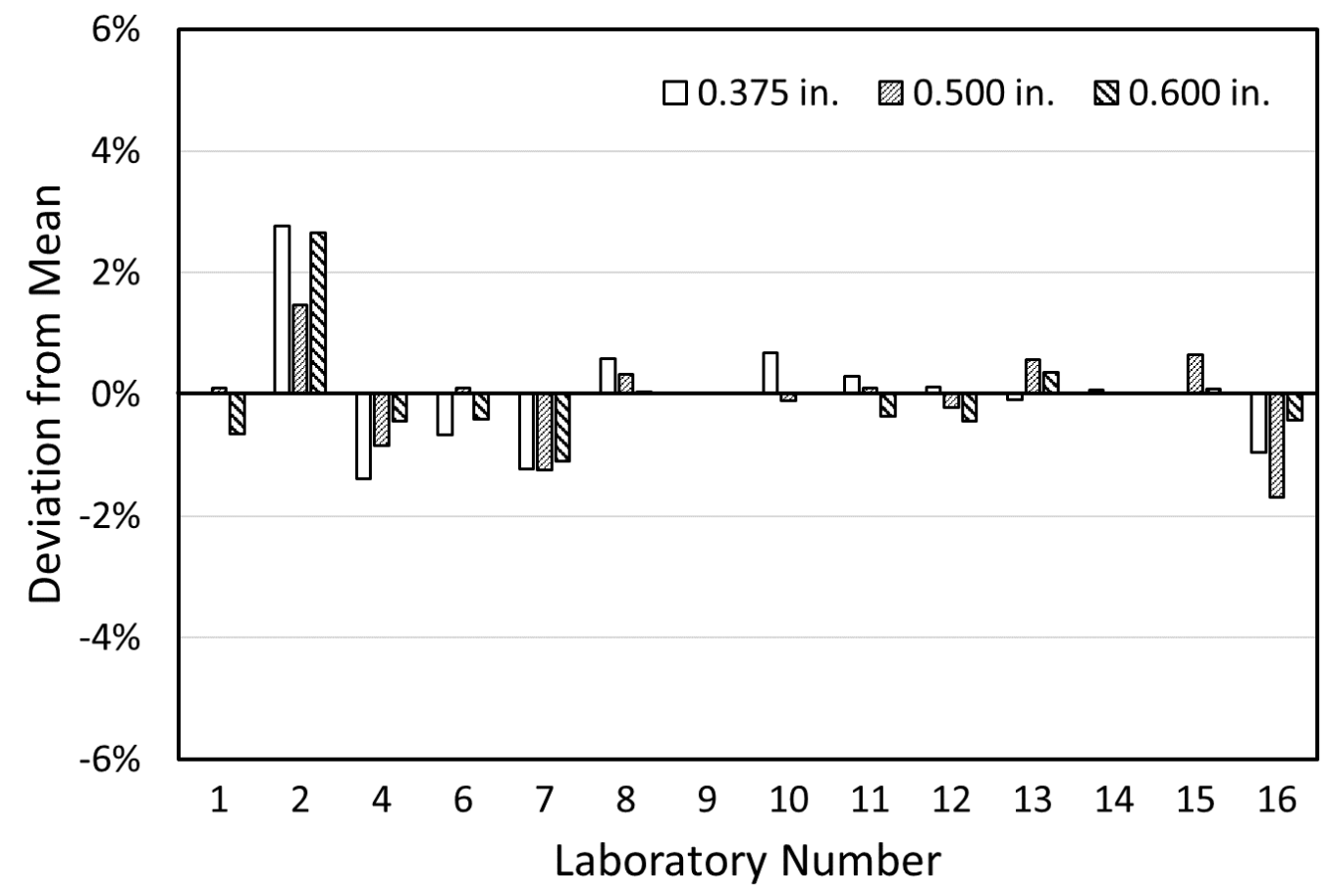

Figure 4 - Deviation in mean yield strength for each laboratory from mean of all valid results for 0.375 , 0.500 , and 0.600 in. $[9.5,12.7,15.2 \mathrm{~mm}]$ diameter strands

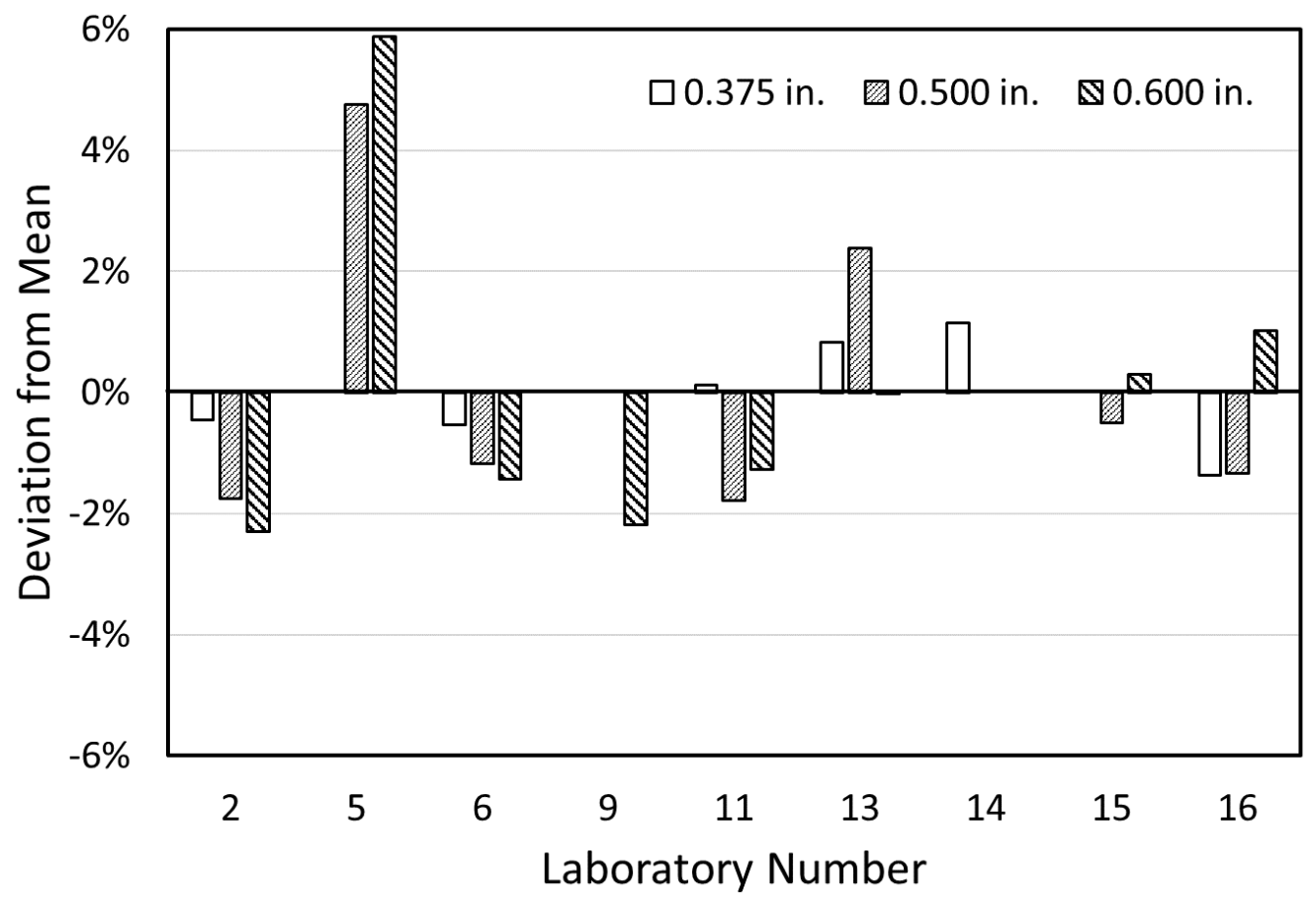

Figure 5 - Deviation in mean elastic modulus for each laboratory from mean of all valid results for 0.375 , 0.500 , and 0.600 in. $[9.5,12.7,15.2 \mathrm{~mm}]$ diameter strands 




Figure 6 - Deviation in mean elongation for each laboratory from mean of all valid results for 0.375 , 0.500 , and 0.600 in. $[9.5,12.7,15.2 \mathrm{~mm}]$ diameter strands

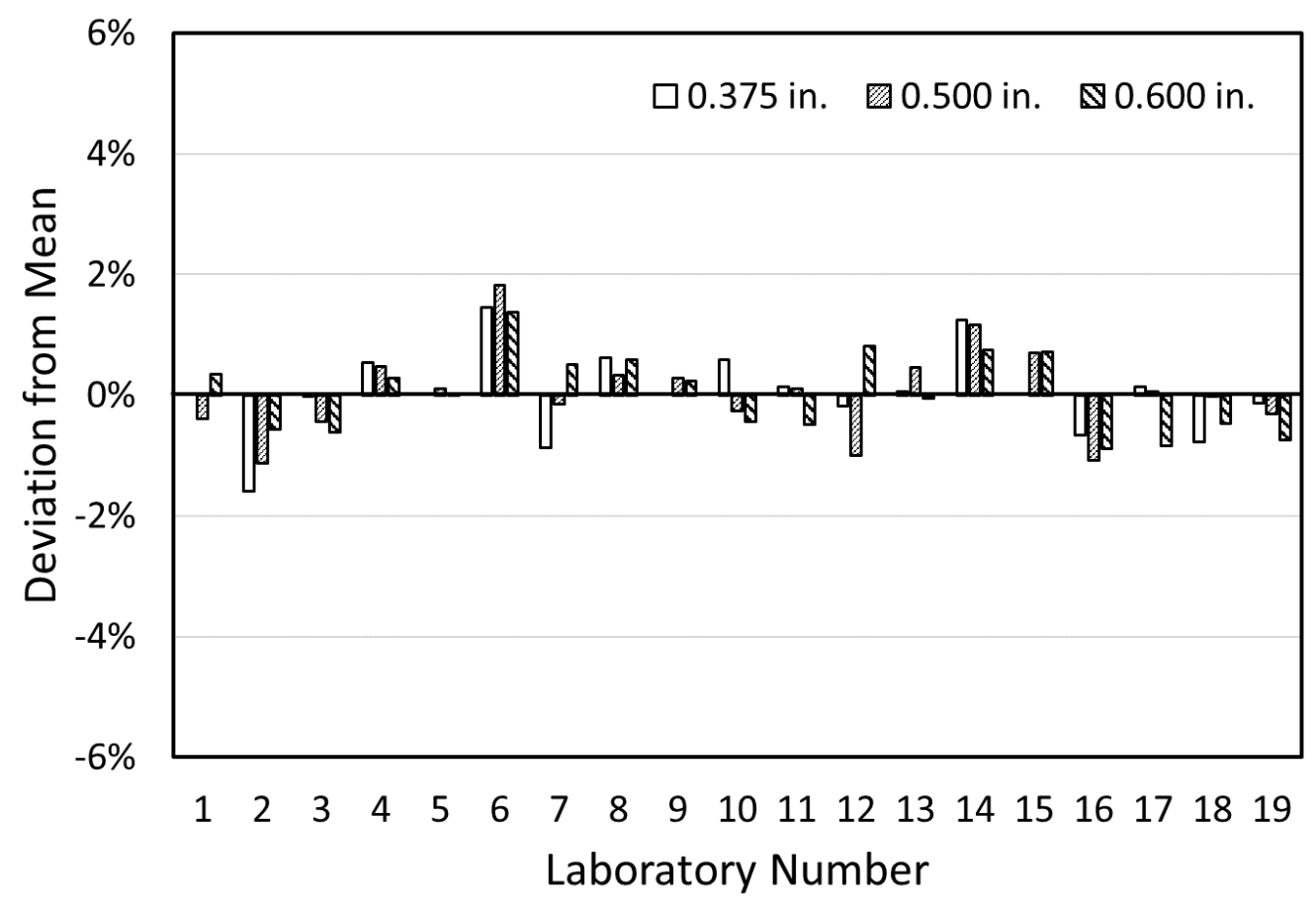

Figure 7 - Deviation in mean breaking strength for each laboratory from mean of all valid results for $0.375,0.500$, and 0.600 in. [9.5, 12.7, $15.2 \mathrm{~mm}]$ diameter strands 
Figure 4 to Figure 7 also show that results for different stand diameters from a single laboratory tended to all be either greater than the mean, near the mean, or less than the mean. In other words, a single laboratory seldom reported results that were greater than the mean for one strand diameter and less than the mean for another strand diameter. This could be an indication that differences between laboratories in terms of how test procedures are interpreted and implemented may account for some of the observed variability.

\subsection{Precision of the ASTM A1061 Method}

The calculations prescribed in ASTM E69 ${ }^{[9]}$ and described in Section 3.6 were used to quantify the precision of the ASTM A1061[6] test methods. Statistical calculations are described in greater detail in Appendix E, a detailed report that will be submitted to ASTM to support the proposed precision statement described in Section 5. Calculations done to quantify the precision of the ASTM A1061 ${ }^{[6]}$ methods used only test results classified as valid. Furthermore, the laboratory that reported only one yield strength result classified as valid was not considered when quantifying the precision of yield strength measurements. The dataset used to quantify precision therefore included at least two valid results for each test outcome from each laboratory considered.

Results of the calculations are listed in Table 4 through Table 7 for yield strength, elastic modulus, elongation, and breaking strength, respectively. Five statistical parameters are listed in each table for each strand diameter. The first statistical parameter is $\overline{\bar{x}}$, the mean of laboratory means. Values for $\overline{\bar{x}}$ do not equal the mean values listed in Table 3 because the values in Table 3 are the means of all reported valid results whereas $\overline{\bar{x}}$ is calculated with Eq. 3. If all laboratories reported the same number of valid results, $\overline{\bar{x}}$ would equal the mean of all results; however, some laboratories reported more than three valid results while others had fewer than three reported results classified as valid. The other parameters in Table 4 through Table 7 are the repeatability standard deviation, $s_{r}$, the reproducibility standard deviation, $s_{R}$, the repeatability limit, $r$, and the reproducibility limit, $R$. 
Table 4 - Precision statistics for yield strength

\begin{tabular}{|c|c|c|c|c|c|}
\hline $\begin{array}{l}\text { Strand Size } \\
\text { in. }[\mathrm{mm}]\end{array}$ & $\begin{array}{c}\text { Mean of } \\
\text { Laboratory } \\
\text { Means, } \\
\overline{\overline{\boldsymbol{x}}} \\
\text { lbf }[\mathrm{kN}] \\
\end{array}$ & $\begin{array}{c}\text { Repeatability } \\
\text { Standard } \\
\text { Deviation, } \\
\boldsymbol{s}_{\boldsymbol{r}} \\
\text { lbf [kN] }\end{array}$ & $\begin{array}{c}\text { Reproducibility } \\
\text { Standard } \\
\text { Deviation, } \\
\boldsymbol{S}_{\boldsymbol{R}} \\
\text { Ibf }[\mathrm{kN}] \\
\end{array}$ & $\begin{array}{c}\text { Repeatability } \\
\text { Limit, } \\
r \\
\text { Ibf }[\mathrm{kN}]\end{array}$ & $\begin{array}{c}\text { Reproducibility } \\
\text { Limit, } \\
R \\
\text { Ibf }[\mathrm{kN}]\end{array}$ \\
\hline $\begin{array}{l}0.375 \\
{[9.5]}\end{array}$ & $\begin{array}{c}23087 \\
{[102.69]}\end{array}$ & $\begin{array}{c}208.77 \\
{[0.92861]}\end{array}$ & $\begin{array}{c}304.94 \\
{[1.3564]}\end{array}$ & $\begin{array}{c}585 \\
{[2.60]}\end{array}$ & $\begin{array}{c}854 \\
{[3.80]}\end{array}$ \\
\hline $\begin{array}{c}0.5 \\
{[12.7]} \\
\end{array}$ & $\begin{array}{c}38792 \\
{[172.56]}\end{array}$ & $\begin{array}{c}222.74 \\
{[0.99080]}\end{array}$ & $\begin{array}{c}350.21 \\
{[1.5578]}\end{array}$ & $\begin{array}{c}624 \\
{[2.78]}\end{array}$ & $\begin{array}{c}981 \\
{[4.36]}\end{array}$ \\
\hline $\begin{array}{c}0.6 \\
{[15.2]}\end{array}$ & $\begin{array}{c}55785 \\
{[248.13]}\end{array}$ & $\begin{array}{c}397.33 \\
{[1.7673]}\end{array}$ & $\begin{array}{c}615.66 \\
{[2.7385]}\end{array}$ & $\begin{array}{c}1110 \\
{[4.95]}\end{array}$ & $\begin{array}{c}1720 \\
{[7.67]}\end{array}$ \\
\hline
\end{tabular}

Table 5 - Precision statistics for elastic modulus

\begin{tabular}{|c|c|c|c|c|c|}
\hline $\begin{array}{l}\text { Strand Size } \\
\text { in. }[\mathrm{mm}]\end{array}$ & $\begin{array}{c}\text { Mean of } \\
\text { Laboratory } \\
\text { Means, } \\
\overline{\overline{\boldsymbol{x}}} \\
10^{3} \mathrm{ksi}[\mathrm{GPa}] \\
\end{array}$ & $\begin{array}{c}\text { Repeatability } \\
\text { Standard } \\
\text { Deviation, } \\
\boldsymbol{s}_{\boldsymbol{r}} \\
10^{3} \mathrm{ksi}[\mathrm{GPa}]\end{array}$ & $\begin{array}{c}\text { Reproducibility } \\
\text { Standard } \\
\text { Deviation, } \\
\boldsymbol{S}_{\boldsymbol{R}} \\
10^{3} \mathrm{ksi}[\mathrm{GPa}] \\
\end{array}$ & $\begin{array}{c}\text { Repeatability } \\
\text { Limit, } \\
r \\
10^{3} \mathrm{ksi}[\mathrm{GPa}]\end{array}$ & $\begin{array}{c}\text { Reproducibility } \\
\text { Limit, } \\
R \\
10^{3} \mathrm{ksi}[\mathrm{GPa}]\end{array}$ \\
\hline $\begin{array}{l}0.375 \\
{[9.5]}\end{array}$ & $\begin{array}{c}29.22 \\
{[201.5]}\end{array}$ & $\begin{array}{l}0.396 \\
{[2.73]}\end{array}$ & $\begin{array}{l}0.423 \\
{[2.92]}\end{array}$ & $\begin{array}{c}1.11 \\
{[7.65]}\end{array}$ & $\begin{array}{c}1.18 \\
{[8.14]}\end{array}$ \\
\hline $\begin{array}{c}0.5 \\
{[12.7]} \\
\end{array}$ & $\begin{array}{c}29.62 \\
{[204.2]}\end{array}$ & $\begin{array}{l}0.820 \\
{[5.65]}\end{array}$ & $\begin{array}{l}0.943 \\
{[6.50]} \\
\end{array}$ & $\begin{array}{c}2.30 \\
{[15.9]} \\
\end{array}$ & $\begin{array}{c}2.64 \\
{[18.2]} \\
\end{array}$ \\
\hline $\begin{array}{c}0.6 \\
{[15.2]}\end{array}$ & $\begin{array}{c}29.10 \\
{[200.6]}\end{array}$ & $\begin{array}{l}0.497 \\
{[3.43]}\end{array}$ & $\begin{array}{l}0.874 \\
{[6.03]}\end{array}$ & $\begin{array}{c}1.39 \\
{[9.58]}\end{array}$ & $\begin{array}{c}2.45 \\
{[16.9]}\end{array}$ \\
\hline
\end{tabular}

Table 6 - Precision statistics for elongation

\begin{tabular}{c|c|c|c|c|c}
$\begin{array}{c}\text { Strand Size } \\
\text { in. [mm] }\end{array}$ & $\begin{array}{c}\text { Mean of } \\
\text { Laboratory } \\
\text { Means, } \\
\overline{\overline{\boldsymbol{x}}}\end{array}$ & $\begin{array}{c}\text { Repeatability } \\
\text { Standard } \\
\text { Deviation, } \\
\boldsymbol{s}_{\boldsymbol{r}}\end{array}$ & $\begin{array}{c}\text { Reproducibility } \\
\text { Standard } \\
\text { Deviation, } \\
\boldsymbol{s}_{\boldsymbol{R}}\end{array}$ & $\begin{array}{c}\text { Repeatability } \\
\text { Limit, } \\
\boldsymbol{r}\end{array}$ & $\begin{array}{c}\text { Reproducibility } \\
\text { Limit, } \\
R\end{array}$ \\
\hline $\begin{array}{c}0.375 \\
{[9.5]}\end{array}$ & $6.32 \%$ & $0.44 \%$ & $1.22 \%$ & $1.2 \%$ & $3.4 \%$ \\
\hline $\begin{array}{c}0.5 \\
{[12.7]}\end{array}$ & $6.59 \%$ & $0.33 \%$ & $1.21 \%$ & $0.9 \%$ & $3.4 \%$ \\
\hline $\begin{array}{c}0.6 \\
{[15.2]}\end{array}$ & $6.16 \%$ & $0.53 \%$ & $1.17 \%$ & $1.5 \%$ & $3.3 \%$
\end{tabular}


Table 7 - Precision statistics for breaking strength

\begin{tabular}{|c|c|c|c|c|c|}
\hline $\begin{array}{c}\text { Strand Size } \\
\text { in. }[\mathrm{mm}]\end{array}$ & $\begin{array}{l}\text { Mean of } \\
\text { Laboratory } \\
\text { Means, } \\
\overline{\overline{\boldsymbol{x}}} \\
\text { Ibf }[\mathrm{kN}]\end{array}$ & $\begin{array}{c}\text { Repeatability } \\
\text { Standard } \\
\text { Deviation, } \\
\boldsymbol{s}_{\boldsymbol{r}} \\
\text { lbf }[\mathrm{kN}]\end{array}$ & $\begin{array}{c}\text { Reproducibility } \\
\text { Standard } \\
\text { Deviation, } \\
\boldsymbol{s}_{\boldsymbol{R}} \\
\text { Ibf }[\mathrm{kN}]\end{array}$ & $\begin{array}{c}\text { Repeatability } \\
\text { Limit, } \\
r \\
\text { lbf }[\mathrm{kN}]\end{array}$ & $\begin{array}{c}\text { Reproducibility } \\
\text { Limit, } \\
R \\
\text { lbf }[\mathrm{kN}]\end{array}$ \\
\hline $\begin{array}{c}0.375 \\
{[9.5]}\end{array}$ & $\begin{array}{c}25768 \\
{[114.62]}\end{array}$ & $\begin{array}{c}151.70 \\
{[0.67476]}\end{array}$ & $\begin{array}{c}241.63 \\
{[1.0748]}\end{array}$ & $\begin{array}{c}425 \\
{[1.89]}\end{array}$ & $\begin{array}{c}677 \\
{[3.01]}\end{array}$ \\
\hline $\begin{array}{c}0.5 \\
{[12.7]}\end{array}$ & $\begin{array}{c}43819 \\
{[194.91]}\end{array}$ & $\begin{array}{c}189.12 \\
{[0.84121]}\end{array}$ & $\begin{array}{c}357.35 \\
{[1.5895]}\end{array}$ & $\begin{array}{c}530 \\
{[2.36]}\end{array}$ & $\begin{array}{c}1000 \\
{[4.45]}\end{array}$ \\
\hline $\begin{array}{c}0.6 \\
{[15.2]}\end{array}$ & $\begin{array}{c}61967 \\
{[275.63]}\end{array}$ & $\begin{array}{c}235.67 \\
{[1.0483]}\end{array}$ & $\begin{array}{c}452.60 \\
{[2.0132]}\end{array}$ & $\begin{array}{c}660 \\
{[2.94]}\end{array}$ & $\begin{array}{c}1270 \\
{[5.64]}\end{array}$ \\
\hline
\end{tabular}

As stated in Section 3.6, there is a $95 \%$ probability that two test results will differ by not more than the repeatability limit, $r$, if they are obtained from tests of nominally identical specimens conducted by a single technician on the same equipment. Likewise, there is a $95 \%$ probability that two test results will differ by not more than the reproducibility limit, $R$, if they are obtained from tests of nominally identical specimens conducted by different technicians on different equipment.

Figure 8 shows the repeatability limit divided by $\overline{\bar{x}}$ for each strand diameter and test outcome. Data are represented with markers that are linked with lines to illustrate trends. For yield strength and breaking strength, $r / \overline{\bar{x}}$ is less than 3 and $2 \%$, respectively, for all strand diameters. This means there is a $95 \%$ probability that at an operator will find the measured yield strength of one sample is within $\pm 3 \%$ of the measured yield strength and the breaking strength of one sample is within $\pm 2 \%$ of a different sample of the same material. As expected, $r / \overline{\bar{x}}$ is somewhat larger for elastic modulus (3 to $8 \%$ ) and very large for elongation (14 to $25 \%$ ). 


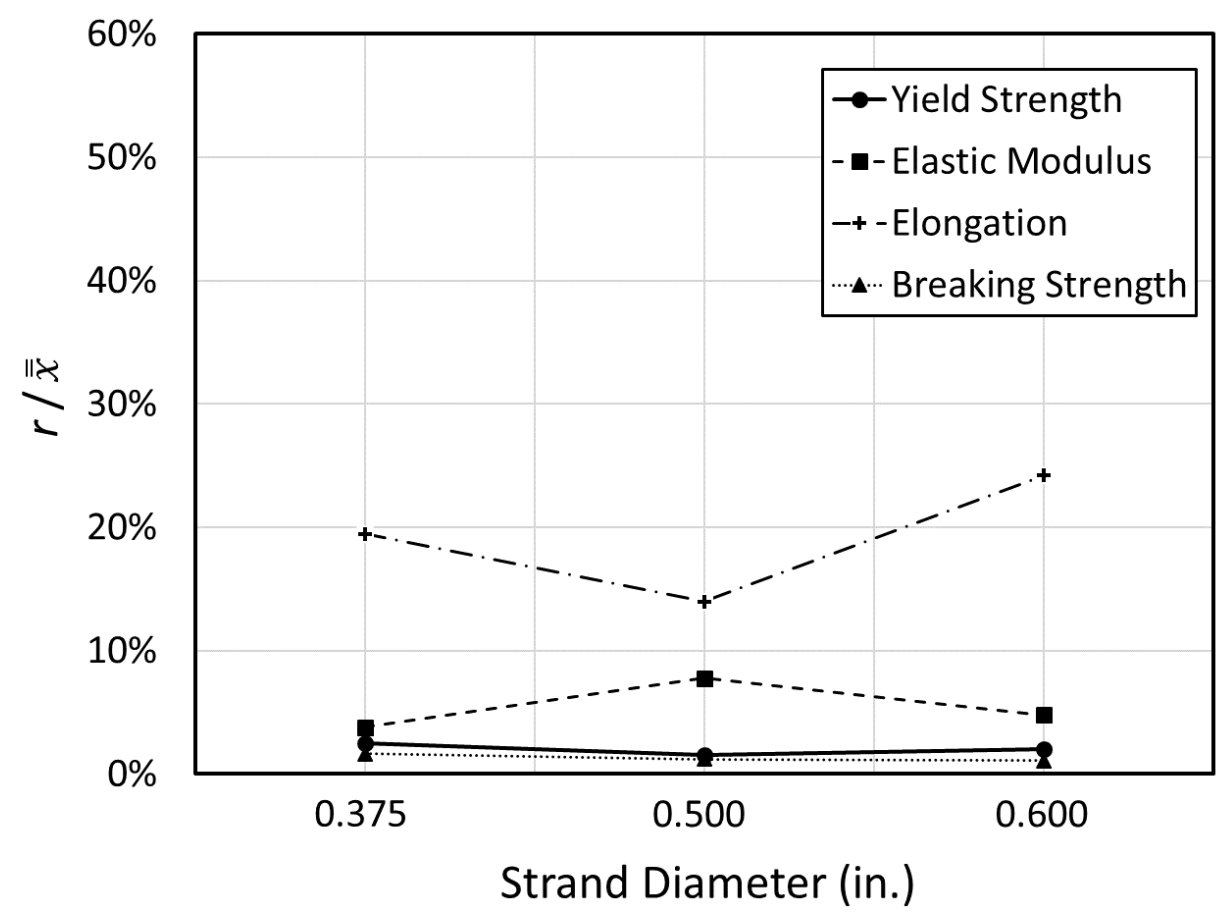

Figure 8 - Repeatability limit divided by the mean of laboratory means for each strand diameter and test outcome $[1 \mathrm{in.}=25.4 \mathrm{~mm}]$

Figure 9 is analogous to Figure 8; it is a plot of the reproducibility limit divided by $\overline{\bar{x}}$ for each strand diameter and test outcome. For yield strength and breaking strength, $R / \overline{\bar{x}}$ is less than 4 and $3 \%$, respectively, only slightly larger than $r / \overline{\bar{x}}$. For elastic modulus, $R / \overline{\bar{x}}$ is almost the same as $r / \overline{\bar{x}}$, with a range of 4 to $9 \%$. These results indicate that most of the inter-laboratory variability for these test outcomes is attributable to variations observed between consecutive tests of nominally identical specimens and not differences between laboratories. This was not the case for elongation, for which $R / \overline{\bar{x}}$ varied between 51 and $54 \%$, more than double the range observed for $r / \overline{\bar{x}}(14$ to $25 \%$ ). This is because of large differences in the elongation results obtained at different laboratories (Figure 6), which may result from differences in methods used to determine elongation. Because the ASTM A $1061^{[6]}$ method is relatively permissive in prescribing the different methods for determining elongation, it seems likely that the reproducibility limit would be reduced if ASTM A1061 ${ }^{[6]}$ were changed to be more prescriptive. Such changes are recommended because having $R / \overline{\bar{x}}$ values exceeding $50 \%$ compromises the utility of elongation measurements. One 
result of the high $R / \overline{\bar{x}}$ values is that a strand producer would need to produce strand that consistently has measured elongations greater than $7 \%$ to ensure a $95 \%$ probability that another laboratory will not measure an elongation less than $3.5 \%$, the required minimum elongation, and reject the strand.

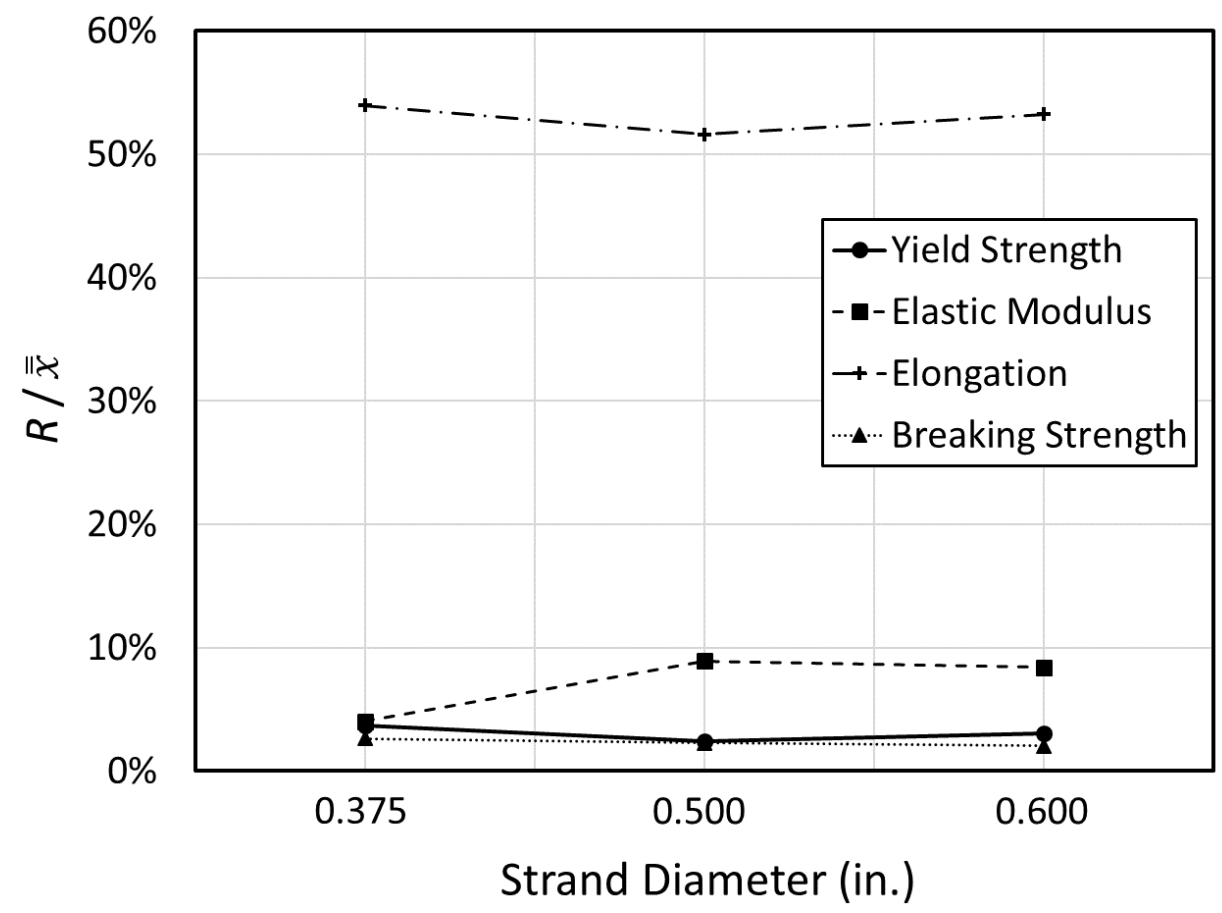

Figure 9 - Reproducibility limit divided by the mean of laboratory means for each strand diameter and test outcome $[1 \mathrm{in.}=25.4 \mathrm{~mm}]$

\subsection{Differences among Subgroups of Test Results}

\subsubsection{Valid versus Excluded Results}

Table 8 has several precision statistics $\left(\overline{\bar{x}}, s_{r}, s_{R}, r\right.$, and $R$ ) calculated for subgroups of reported yield strength, elastic modulus, and elongation results. The subgroups are results that were classified as valid and results that were excluded from the database. Because all breaking strength results were classified as valid, no values are shown for breaking strength. In some cases a subgroup includes results from fewer than six laboratories; such small samples of laboratories may not be representative of larger populations. 
Table 8 - Precision statistics for data classified as valid versus data excluded from database

\begin{tabular}{|c|c|c|c|c|c|c|c|}
\hline \multirow{2}{*}{$\begin{array}{c}\text { Strand } \\
\text { Diameter } \\
\text { in. }[\mathrm{mm}]\end{array}$} & \multirow{2}{*}{ Statistical Parameter } & \multicolumn{2}{|c|}{$\begin{array}{l}\text { Yield Strength } \\
\text { lbf }[k N]\end{array}$} & \multicolumn{2}{|c|}{$\begin{array}{c}\text { Elastic Modulus } \\
\mathrm{x} 10^{3} \mathrm{ksi}[\mathrm{GPa}]\end{array}$} & \multicolumn{2}{|c|}{$\begin{array}{c}\text { Elongation } \\
\% \\
\end{array}$} \\
\hline & & Valid & Excluded & Valid & Excluded & Valid & Excluded \\
\hline \multirow{6}{*}{$\begin{array}{l}0.375 \\
{[9.5]}\end{array}$} & Number of Laboratories, $P_{L}{ }^{a}$ & 11 & $5^{b}$ & 6 & $2^{b}$ & 6 & 9 \\
\hline & $\begin{array}{l}\text { Mean of Laboratory Means, } \\
\overline{\bar{x}}\end{array}$ & $\begin{array}{l}23090 \\
{[102.7]}\end{array}$ & $\begin{array}{c}23390 \\
{[104.0]}\end{array}$ & $\begin{array}{c}29.22 \\
{[201.5]}\end{array}$ & $\begin{array}{c}28.73 \\
{[198.1]}\end{array}$ & 6.322 & 6.612 \\
\hline & $\begin{array}{l}\text { Repeatability Standard } \\
\text { Deviation, } s_{r}\end{array}$ & $\begin{array}{c}209 \\
{[0.930]}\end{array}$ & $\begin{array}{c}265 \\
{[1.18]}\end{array}$ & $\begin{array}{l}0.396 \\
{[2.73]}\end{array}$ & $\begin{array}{l}0.513 \\
{[3.54]}\end{array}$ & 0.441 & 0.561 \\
\hline & $\begin{array}{l}\text { Reproducibility Standard } \\
\text { Deviation, } s_{R}\end{array}$ & $\begin{array}{c}305 \\
{[1.36]}\end{array}$ & $\begin{array}{c}352 \\
{[1.57]}\end{array}$ & $\begin{array}{l}0.423 \\
{[2.92]}\end{array}$ & $\begin{array}{l}0.513 \\
{[3.54]}\end{array}$ & 1.22 & 1.61 \\
\hline & Repeatability Limit, $r$ & $\begin{array}{c}585 \\
{[2.60]}\end{array}$ & $\begin{array}{c}741 \\
{[3.30]}\end{array}$ & $\begin{array}{c}1.11 \\
{[7.65]}\end{array}$ & $\begin{array}{c}1.44 \\
{[9.93]}\end{array}$ & 1.23 & 1.57 \\
\hline & Reproducibility Limit, $R$ & $\begin{array}{c}854 \\
{[3.80]}\end{array}$ & $\begin{array}{c}986 \\
{[4.39]}\end{array}$ & $\begin{array}{c}1.18 \\
{[8.14]}\end{array}$ & $\begin{array}{c}1.44 \\
{[9.93]}\end{array}$ & 3.42 & 4.52 \\
\hline \multirow{6}{*}{$\begin{array}{l}0.500 \\
{[12.7]}\end{array}$} & Number of Laboratories, $P_{L}{ }^{a}$ & 11 & 8 & 7 & $4^{b}$ & 6 & 13 \\
\hline & $\begin{array}{l}\text { Mean of Laboratory Means, } \\
\overline{\bar{x}}\end{array}$ & $\begin{array}{c}38792 \\
{[172.5]} \\
\end{array}$ & $\begin{array}{c}38870 \\
{[172.9]} \\
\end{array}$ & $\begin{array}{c}29.62 \\
{[204.2]}\end{array}$ & $\begin{array}{c}28.66 \\
{[197.6]} \\
\end{array}$ & 6.588 & 6.775 \\
\hline & $\begin{array}{l}\text { Repeatability Standard } \\
\text { Deviation, } s_{r}\end{array}$ & $\begin{array}{c}223 \\
{[0.991]} \\
\end{array}$ & $\begin{array}{c}266 \\
{[1.18]}\end{array}$ & $\begin{array}{l}0.820 \\
{[5.65]}\end{array}$ & $\begin{array}{l}0.198 \\
{[1.37]}\end{array}$ & 0.330 & 0.416 \\
\hline & $\begin{array}{l}\text { Reproducibility Standard } \\
\text { Deviation, } s_{R}\end{array}$ & $\begin{array}{c}350 \\
{[1.56]} \\
\end{array}$ & $\begin{array}{c}443 \\
{[1.97]}\end{array}$ & $\begin{array}{l}0.943 \\
{[6.50]}\end{array}$ & $\begin{array}{l}0.858 \\
{[5.92]}\end{array}$ & 1.21 & 1.25 \\
\hline & Repeatability Limit, $r$ & $\begin{array}{c}624 \\
{[2.77]}\end{array}$ & $\begin{array}{c}744 \\
{[3.31]}\end{array}$ & $\begin{array}{c}2.30 \\
{[15.9]}\end{array}$ & $\begin{array}{l}0.554 \\
{[3.82]}\end{array}$ & 0.924 & 1.16 \\
\hline & Reproducibility Limit, $R$ & $\begin{array}{c}981 \\
{[4.36]}\end{array}$ & $\begin{array}{c}1240 \\
{[5.52]} \\
\end{array}$ & $\begin{array}{c}2.64 \\
{[18.2]} \\
\end{array}$ & $\begin{array}{c}2.40 \\
{[16.6]} \\
\end{array}$ & 3.40 & 3.50 \\
\hline \multirow{6}{*}{$\begin{array}{l}0.600 \\
{[15.2]}\end{array}$} & Number of Laboratories, $P_{L}{ }^{a}$ & 12 & 8 & 8 & $3^{b}$ & 6 & 13 \\
\hline & $\begin{array}{l}\text { Mean of Laboratory Means, } \\
\overline{\bar{x}}\end{array}$ & $\begin{array}{l}55790 \\
{[248.2]}\end{array}$ & $\begin{array}{c}55690 \\
{[247.7]}\end{array}$ & $\begin{array}{c}29.10 \\
{[200.6]}\end{array}$ & $\begin{array}{c}28.39 \\
{[195.7]}\end{array}$ & 6.160 & 6.834 \\
\hline & $\begin{array}{l}\text { Repeatability Standard } \\
\text { Deviation, } s_{r}\end{array}$ & $\begin{array}{c}397 \\
{[1.77]}\end{array}$ & $\begin{array}{c}354 \\
{[1.58]}\end{array}$ & $\begin{array}{l}0.497 \\
{[3.43]}\end{array}$ & $\begin{array}{l}0.340 \\
{[2.34]}\end{array}$ & 0.533 & 0.637 \\
\hline & $\begin{array}{l}\text { Reproducibility Standard } \\
\text { Deviation, } s_{R}\end{array}$ & $\begin{array}{c}616 \\
{[2.74]} \\
\end{array}$ & $\begin{array}{c}703 \\
{[3.13]}\end{array}$ & $\begin{array}{l}0.874 \\
{[6.03]}\end{array}$ & $\begin{array}{l}0.959 \\
{[6.61]}\end{array}$ & 1.17 & 1.37 \\
\hline & Repeatability Limit, $r$ & $\begin{array}{l}1110 \\
{[4.94]}\end{array}$ & $\begin{array}{c}991 \\
{[4.41]}\end{array}$ & $\begin{array}{c}1.39 \\
{[9.58]}\end{array}$ & $\begin{array}{l}0.952 \\
{[6.56]}\end{array}$ & 1.49 & 1.78 \\
\hline & Reproducibility Limit, $R$ & $\begin{array}{l}1720 \\
{[7.65]}\end{array}$ & $\begin{array}{c}1970 \\
{[8.76]}\end{array}$ & $\begin{array}{c}2.45 \\
{[16.9]}\end{array}$ & $\begin{array}{c}2.69 \\
{[18.6]}\end{array}$ & 3.29 & 3.84 \\
\hline
\end{tabular}

\footnotetext{
a The sum of the number of laboratories with valid data and excluded data may not equal the number of laboratories; some laboratories had both valid and excluded results

${ }^{b}$ Interpret results based on fewer than six laboratories with caution, as they may not be representative of larger populations of laboratories
}

Results classified as valid and results excluded from the database are compared in terms of $\overline{\bar{x}}$ and $R$ in Figure 10 and Figure 11, respectively. Data are represented with markers that are linked with lines to illustrate trends. Valid and excluded yield strength results had the same mean values, but excluded data 
were consistently more scattered than valid data. For elastic modulus, excluded data had lower mean values than the valid data. This was expected; data were often excluded because the range of forces used to determine elastic modulus was larger than prescribed, potentially resulting in elastic moduli calculated based on nonlinear portions of the force-elongation curves. As with yield strength, elastic modulus results tended to be more scattered among the excluded data. Excluded elongation data had larger mean values and higher variability than results classified as valid. In general, the observation that excluded data were more scattered than valid data matched expectations. Results obtained following a prescribed method should be more consistent than results obtained otherwise.

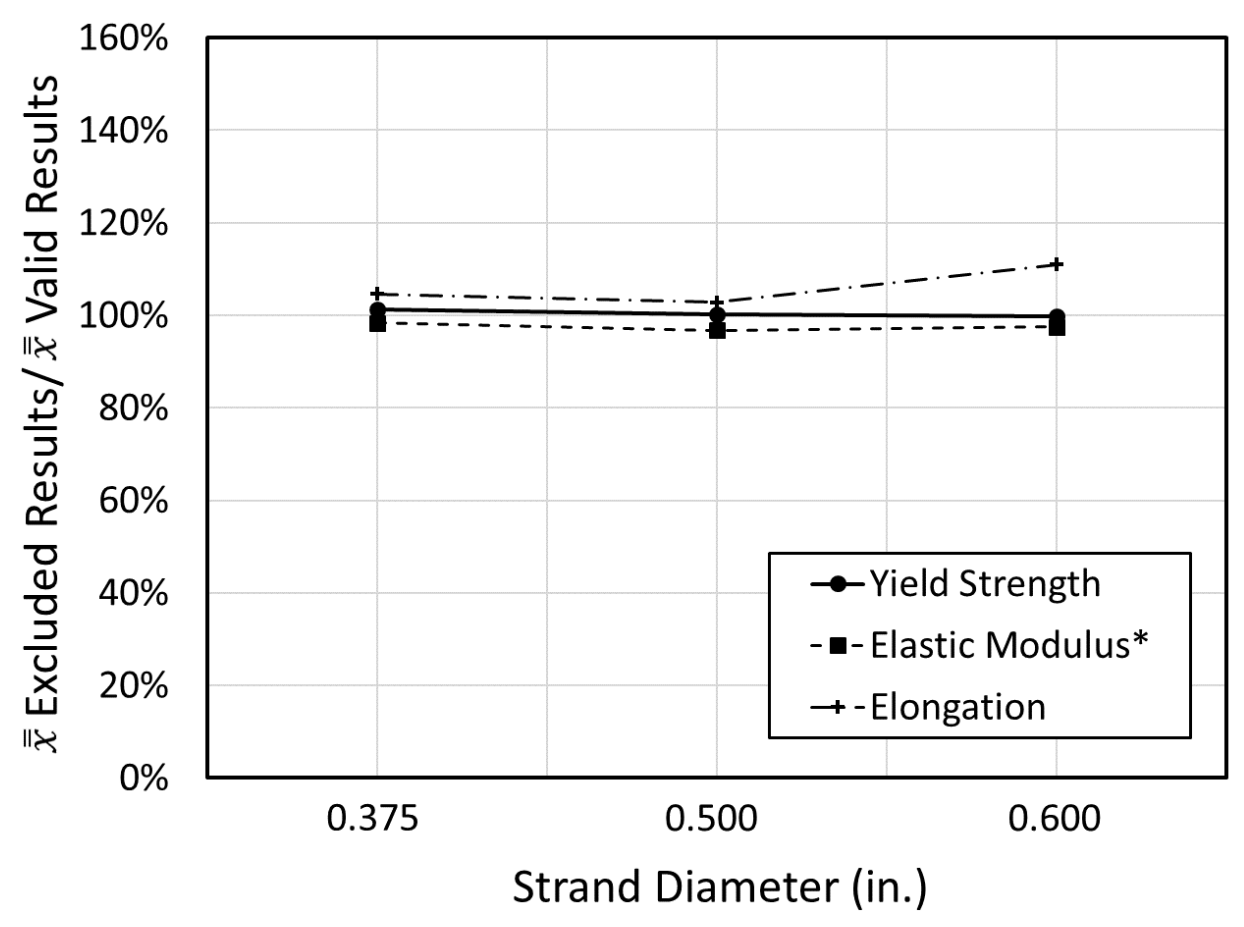

Figure 10 - Comparison of excluded and valid results in terms of mean of laboratory means (*subgroups of elastic modulus include fewer than six laboratories) $[1 \mathrm{in.}=25.4 \mathrm{~mm}]$ 


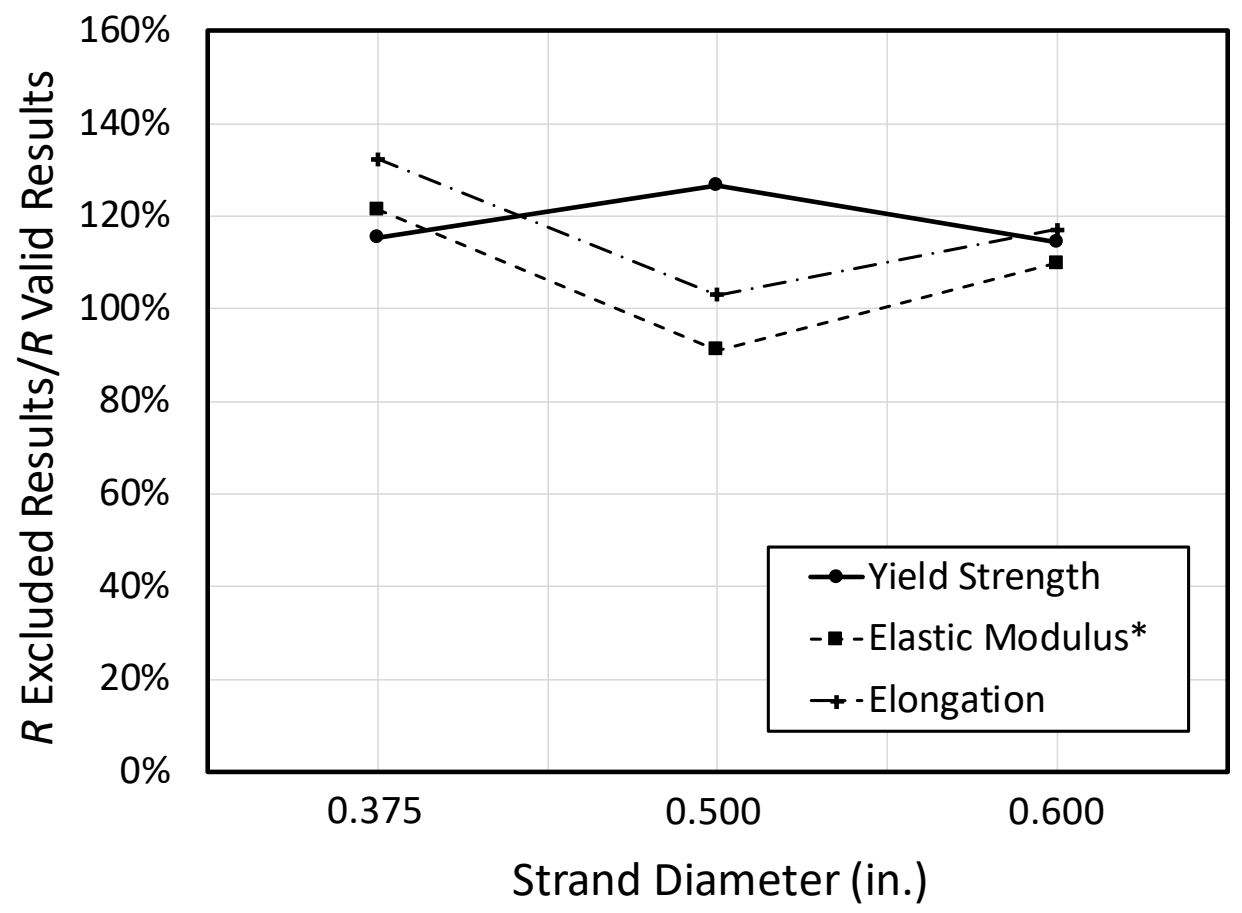

Figure 11 - Comparison of excluded and valid results in terms of reproducibility limit (*subgroups of elastic modulus include fewer than six laboratories) $[1 \mathrm{in.}=25.4 \mathrm{~mm}]$

\subsubsection{Preload Method versus Elastic Modulus Extrapolation Method for Determining Yield Strength}

Table 9 shows precision statistics calculated for subgroups of yield strength data obtained using either the preload method or the elastic modulus extrapolation method, including: $\overline{\bar{x}}, s_{r}, s_{R}, r$, and $R$ as well as mean and coefficient of variation $(\mathrm{COV})$ for all valid results. The mean of laboratory means and reproducibility limit calculated for these subgroups are plotted in Figure 12 for each strand diameter. The ratio of mean results is nearly 1.0 for all three strand diameters, with yield strengths obtained using the preload method being between 0.1 and $0.33 \%$ larger than those obtained with the elastic modulus extrapolation method. The statistical significance of differences in values for the two methods was determined using a two-tailed Student's t-test, based on the $p$-value, which is the probability of obtaining a difference at least as large as observed for two groups of data, assuming that there is, in fact, no difference $^{[10]}$. A $p$-value less than or equal to 0.05 indicates that a difference is statistically significant. On this basis, the differences were not statistically significant, with $p$-values of $0.44,0.50$, and 0.76 for 0.375 , 0.500 , and 0.600 in. $[9.5,12.7$, and $15.2 \mathrm{~mm}]$ diameter strand, respectively Table 9. 
Table 9 - Precision statistics for yield strength obtained using the preload and elastic modulus extrapolation methods

\begin{tabular}{|c|c|c|c|c|c|c|}
\hline \multirow[b]{2}{*}{ Statistical Parameter } & \multicolumn{2}{|c|}{$\begin{array}{l}0.375 \mathrm{in} . \\
{[9.5 \mathrm{~mm}]}\end{array}$} & \multicolumn{2}{|c|}{$\begin{array}{c}0.500 \mathrm{in} . \\
{[12.7 \mathrm{~mm}]}\end{array}$} & \multicolumn{2}{|c|}{$\begin{array}{c}0.600 \mathrm{in} . \\
{[15.2]}\end{array}$} \\
\hline & $\mathrm{PM}^{\mathrm{a}}$ & $\mathrm{EM}^{\mathrm{b}}$ & $\mathrm{PM}^{\mathrm{a}}$ & $\mathrm{EM}^{\mathrm{b}}$ & $\mathrm{PM}^{\mathrm{a}}$ & $\mathrm{EM}^{\mathrm{b}}$ \\
\hline Number of Laboratories, $P_{L}$ & 8 & $3^{c}$ & 8 & $3^{c}$ & 8 & $4^{c}$ \\
\hline Mean of Laboratory Means, $\overline{\bar{x}}$, Ibf $[\mathrm{kN}]$ & $\begin{array}{l}23110 \\
{[102.8]}\end{array}$ & $\begin{array}{l}23030 \\
{[102.4]}\end{array}$ & $\begin{array}{c}38830 \\
{[172.7]}\end{array}$ & $\begin{array}{c}38680 \\
{[172.0]}\end{array}$ & $\begin{array}{c}55800 \\
{[248.2]}\end{array}$ & $\begin{array}{l}55760 \\
{[248.0]}\end{array}$ \\
\hline Repeatability Standard Deviation, $s_{r}$, Ibf [kN] & $\begin{array}{c}210 \\
{[0.934]}\end{array}$ & $\begin{array}{c}206 \\
{[0.916]}\end{array}$ & $\begin{array}{c}251 \\
{[1.12]}\end{array}$ & $\begin{array}{c}118 \\
{[0.525]}\end{array}$ & $\begin{array}{c}411 \\
{[1.83]}\end{array}$ & $\begin{array}{c}368 \\
{[1.64]}\end{array}$ \\
\hline Reproducibility Standard Deviation, $s_{R}, \mathrm{lbf}[\mathrm{kN}]$ & $\begin{array}{c}340 \\
{[1.51]}\end{array}$ & $\begin{array}{c}223 \\
{[0.992]}\end{array}$ & $\begin{array}{c}387 \\
{[1.72]}\end{array}$ & $\begin{array}{c}471 \\
{[2.10]}\end{array}$ & $\begin{array}{c}724 \\
{[3.22]}\end{array}$ & $\begin{array}{c}368 \\
{[1.64]}\end{array}$ \\
\hline Repeatability Limit, $r$, Ibf [kN] & $\begin{array}{c}589 \\
{[2.62]}\end{array}$ & $\begin{array}{c}576 \\
{[2.56]}\end{array}$ & $\begin{array}{c}703 \\
{[3.13]}\end{array}$ & $\begin{array}{c}331 \\
{[1.47]}\end{array}$ & $\begin{array}{c}1150 \\
{[5.12]}\end{array}$ & $\begin{array}{c}1030 \\
{[4.58]}\end{array}$ \\
\hline Reproducibility Limit, $R, \mathrm{lbf}[\mathrm{kN}]$ & $\begin{array}{c}951 \\
{[4.23]}\end{array}$ & $\begin{array}{c}625 \\
{[2.78]}\end{array}$ & $\begin{array}{c}1080 \\
{[4.80]}\end{array}$ & $\begin{array}{c}1320 \\
{[5.87]}\end{array}$ & $\begin{array}{l}2030 \\
{[9.03]}\end{array}$ & $\begin{array}{c}1030 \\
{[4.58]}\end{array}$ \\
\hline Mean of Valid Results ${ }^{d}$, lbf $[\mathrm{kN}]$ & $\begin{array}{l}23100 \\
{[102.8]}\end{array}$ & $\begin{array}{c}23030 \\
{[102.4]}\end{array}$ & $\begin{array}{l}38850 \\
{[172.8]}\end{array}$ & $\begin{array}{c}38750 \\
{[172.3]}\end{array}$ & $\begin{array}{l}55840 \\
{[248.4]}\end{array}$ & $\begin{array}{l}55780 \\
{[248.1]}\end{array}$ \\
\hline $\operatorname{COV}^{\mathrm{e}}, \%$ & 1.44 & 0.99 & 0.99 & 1.04 & 1.35 & 0.64 \\
\hline$p$-value ${ }^{f}$ & \multicolumn{2}{|c|}{0.44} & \multicolumn{2}{|c|}{0.50} & \multicolumn{2}{|c|}{0.76} \\
\hline \multicolumn{7}{|c|}{ a Yield strength results obtained using the Preload Method (PM) } \\
\hline \multicolumn{7}{|c|}{ b Yield strength results obtained using the Elastic Modulus Extrapolation Method (EM) } \\
\hline \multirow{2}{*}{\multicolumn{7}{|c|}{$\begin{array}{l}\text { c Interpret results based on fewer than six laboratories with caution, as they may not be representative } \\
\text { of larger populations of laboratories } \\
\text { d Not necessarily equal to } \overline{\bar{x}} \text { because the number of valid results from each laboratory was not constant } \\
\text { e Coefficient of variation }\end{array}$}} \\
\hline & & & & & & \\
\hline \multicolumn{7}{|c|}{$\begin{array}{l}{ }^{\mathrm{f}} \text { Result from a two-tailed Student's t-test; values } \leq 0.05 \text { indicate that differences are statistically } \\
\text { significant }\end{array}$} \\
\hline
\end{tabular}

There were large differences in the variability observed in results obtained using the two methods, with the preload method having a much smaller $R$ for 0.375 and 0.600 in. [9.5 and $15.2 \mathrm{~mm}$ ] diameter strands and a much larger $R$ for 0.500 in. [12.7 mm] diameter strand. There did not appear to be a consistent trend in terms of which method provided less scattered results. 


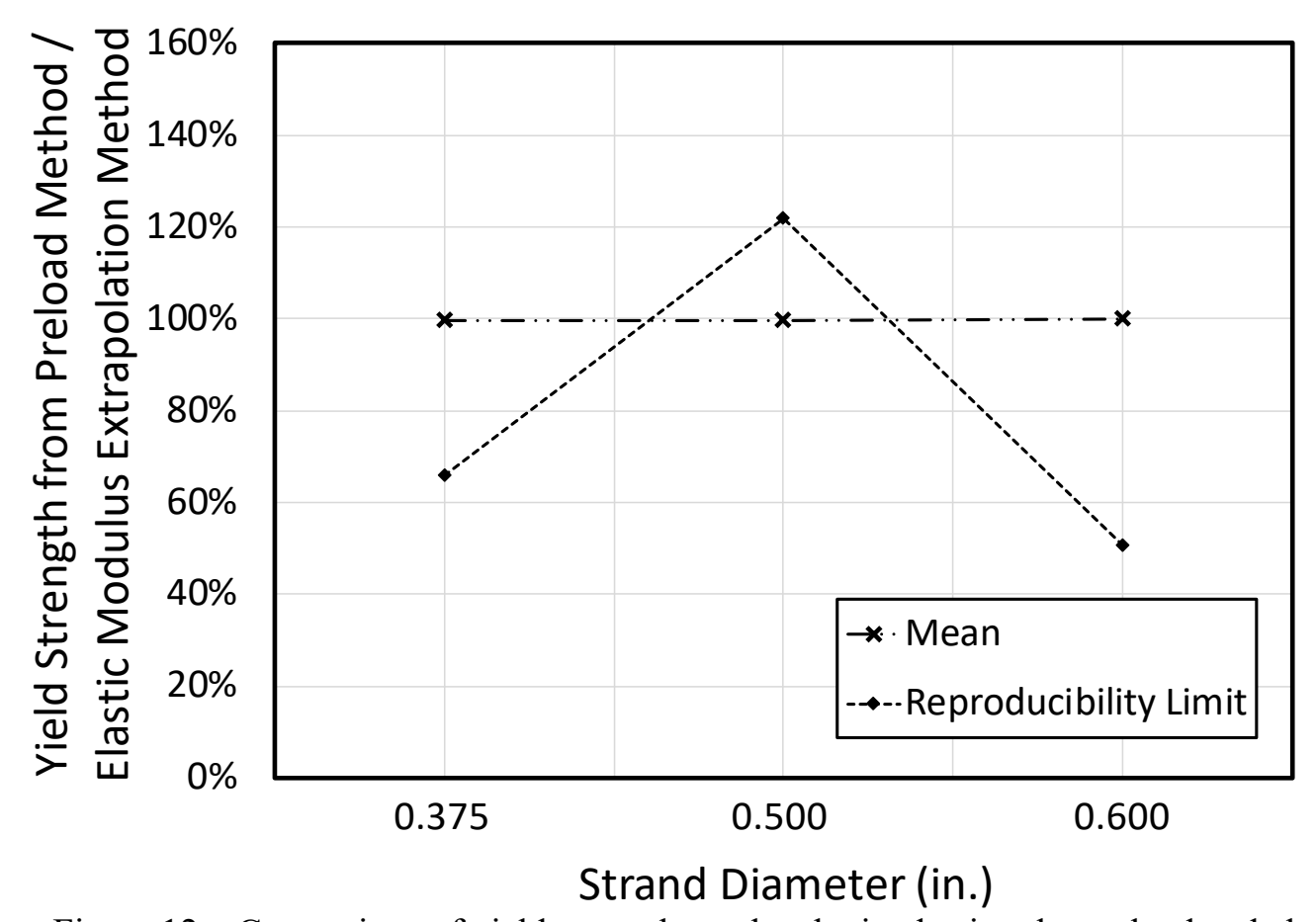

Figure 12 - Comparison of yield strength results obtained using the preload and elastic modulus extrapolation methods in terms of mean and reproducibility limit (Note: the subgroup of data obtained with the elastic modulus extrapolation method includes fewer than six laboratories) [ 1 in. $=25.4 \mathrm{~mm}]$

A consistent difference between the two methods for determining yield strength was the percentage of results classified as valid. As described in Section 4.1.2, 91 and $50 \%$ of results were classified as valid when obtained with the preload and elastic modulus extrapolation methods, respectively. Changes to ASTM A $1061^{[6]}$ that clarify the requirements for the elastic modulus extrapolation method may improve this.

\subsubsection{Effect of the Location of Strand Fracture}

As described in Section 4.1.2, reported results for elongation and breaking strength may be considered valid if the measured values exceed the required minimum values, regardless of where strand fracture occurs. Because all reported results exceeded required minimum values, the dataset of valid results includes specimens that fractured near the grips.

Table 10 shows precision statistics calculated for elongation and breaking strength for subgroups of data obtained from tests where the strand specimens either fractured near the grips or away from the grips. The precision statistics shown are: $\overline{\bar{x}}, s_{r}, s_{R}, r$, and $R$ as well as mean and coefficient of variation 
(COV) for all valid results. Results for elongation and breaking strength are compared for these subgroups

in Figure 13 and Figure 14 in terms of $\overline{\bar{x}}$ and $R$, respectively. Comparisons are not made for yield strength and elastic modulus results because strand fracture location has no effect on these measures.

Table 10 - Precision statistics for elongation and breaking strength, separated into subgroups of specimens fracturing near the grips and specimens fracturing away from the grips

\begin{tabular}{|c|c|c|c|c|c|}
\hline \multirow{2}{*}{$\begin{array}{l}\text { Strand } \\
\text { Diameter } \\
\text { in. }[\mathrm{mm}]\end{array}$} & \multirow[t]{2}{*}{ Statistical Parameter } & \multicolumn{2}{|c|}{$\begin{array}{c}\text { Elongation } \\
\%\end{array}$} & \multicolumn{2}{|c|}{ Breaking Strength lbf [kN] } \\
\hline & & Away ${ }^{a}$ & Near ${ }^{b}$ & Away ${ }^{a}$ & Near ${ }^{b}$ \\
\hline \multirow{9}{*}{$\begin{array}{l}0.375 \\
{[9.5]}\end{array}$} & Number of Laboratories, $P_{L}{ }^{c}$ & $4^{d}$ & $2^{d}$ & 11 & 6 \\
\hline & Mean of Laboratory Means, $\overline{\bar{x}}$ & 6.664 & 5.637 & $25770[114.6]$ & $25800[114.8]$ \\
\hline & Repeatability Standard Deviation, $s_{r}$ & 0.420 & 0.480 & $152[0.676]$ & $123[0.547]$ \\
\hline & Reproducibility Standard Deviation, $s_{R}$ & 1.32 & 0.813 & $245[1.09]$ & $186[0.827]$ \\
\hline & Repeatability Limit, $r$ & 1.18 & 1.35 & $425[1.89]$ & $343[1.53]$ \\
\hline & Reproducibility Limit, $R$ & 3.70 & 2.28 & $686[3.05]$ & $521[2.32]$ \\
\hline & Mean of Valid Results ${ }^{\mathrm{e}}$, Ibf [kN] & 6.664 & 5.763 & $25750[114.5]$ & $25770[114.6]$ \\
\hline & $\operatorname{COV}^{f}, \%$ & 18.1 & 12.3 & 1.07 & 0.69 \\
\hline & $p$-value ${ }^{g}$ & \multicolumn{2}{|c|}{0.050} & \multicolumn{2}{|c|}{0.67} \\
\hline \multirow{9}{*}{$\begin{array}{l}0.500 \\
{[12.7]}\end{array}$} & Number of Laboratories, $P_{L}{ }^{c}$ & $4^{d}$ & $2^{d}$ & 12 & 9 \\
\hline & Mean of Laboratory Means, $\overline{\bar{x}}$ & 6.967 & 5.830 & $43920[195.4]$ & $43660[194.2]$ \\
\hline & Repeatability Standard Deviation, $s_{r}$ & 0.306 & 0.373 & $180[0.801]$ & $161[0.716]$ \\
\hline & Reproducibility Standard Deviation, $s_{R}$ & 1.32 & 0.557 & $375[1.67]$ & 244 [1.09] \\
\hline & Repeatability Limit, $r$ & 0.857 & 1.04 & $505[2.25]$ & $451[2.01]$ \\
\hline & Reproducibility Limit, $R$ & 3.71 & 1.56 & $1050[4.67]$ & $684[3.04]$ \\
\hline & Mean of Valid Results ${ }^{\mathrm{e}}$, Ibf [kN] & 6.967 & 5.913 & $43930[195.4]$ & $43630[194.1]$ \\
\hline & $\operatorname{COV}^{f}, \%$ & 17.3 & 8.83 & 0.78 & 0.65 \\
\hline & $p$-value ${ }^{g}$ & \multicolumn{2}{|c|}{0.016} & \multicolumn{2}{|c|}{0.00025} \\
\hline \multirow{9}{*}{$\begin{array}{l}0.600 \\
{[15.2]}\end{array}$} & Number of Laboratories, $P_{L}{ }^{c}$ & $4^{d}$ & $4^{d}$ & 14 & 10 \\
\hline & Mean of Laboratory Means, $\overline{\bar{x}}$ & 6.493 & 6.197 & $62070[276.1]$ & $61930[275.5]$ \\
\hline & Repeatability Standard Deviation, $s_{r}$ & 0.492 & 0.430 & $180[0.801]$ & $267[1.19]$ \\
\hline & Reproducibility Standard Deviation, $s_{R}$ & 1.06 & 1.13 & $374[1.66]$ & $513[2.28]$ \\
\hline & Repeatability Limit, $r$ & 1.38 & 1.20 & $505[2.25]$ & 749 [3.33] \\
\hline & Reproducibility Limit, $R$ & 2.96 & 3.15 & $1050[4.67]$ & $1440[6.41]$ \\
\hline & Mean of Valid Results ${ }^{\mathrm{e}}$, Ibf [kN] & 6.408 & 5.959 & 62040 [275.9] & $61810[274.9]$ \\
\hline & $\operatorname{COV}^{f}, \%$ & 16.7 & 18.9 & 0.60 & 0.89 \\
\hline & $p$-value ${ }^{g}$ & \multicolumn{2}{|c|}{0.37} & \multicolumn{2}{|c|}{0.074} \\
\hline
\end{tabular}

\footnotetext{
${ }^{a}$ Results from specimens fracturing away from the grips

${ }^{b}$ Results from specimens fracturing near the grips

"The sum in columns "Away" and "Near" may not equal the number of laboratories; some laboratories had some specimens fracture near the grips and others fracture away from the grips

d Interpret results based on fewer than six laboratories with caution, as they may not be representative of larger populations of laboratories

e Not necessarily equal to $\overline{\bar{x}}$ because the number of valid results from each laboratory was not constant

${ }^{f}$ Coefficient of variation

${ }^{\mathrm{g}}$ Result from a two-tailed Student's t-test; values $\leq 0.05$ indicate that differences are statistically significant
} 


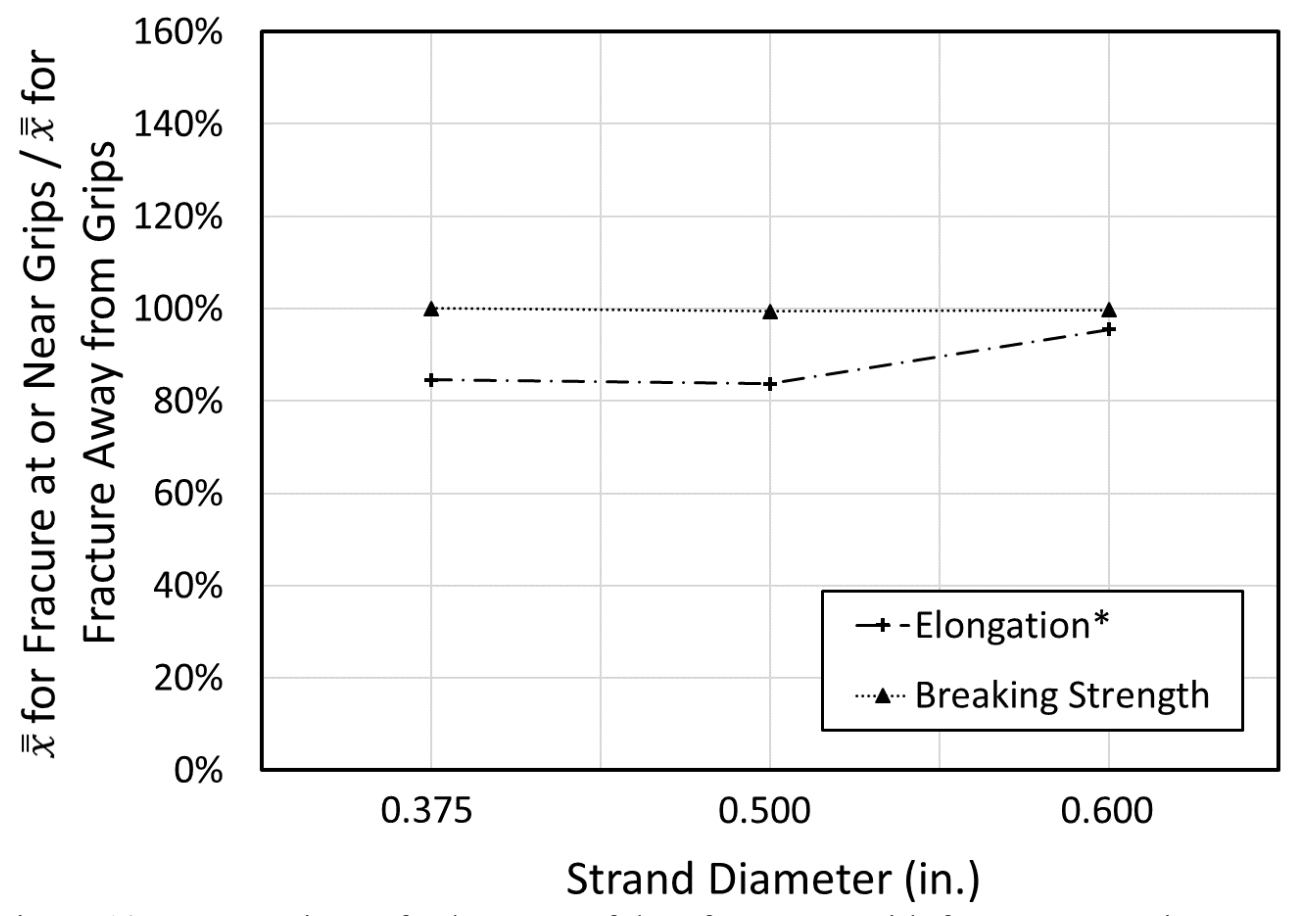

Figure 13 - Comparison of subgroups of data from tests with fracture occurring near the grips versus fracture occurring away from grips in terms of mean (*subgroups of elongation data include fewer than six laboratories) $[1$ in. $=25.4 \mathrm{~mm}]$

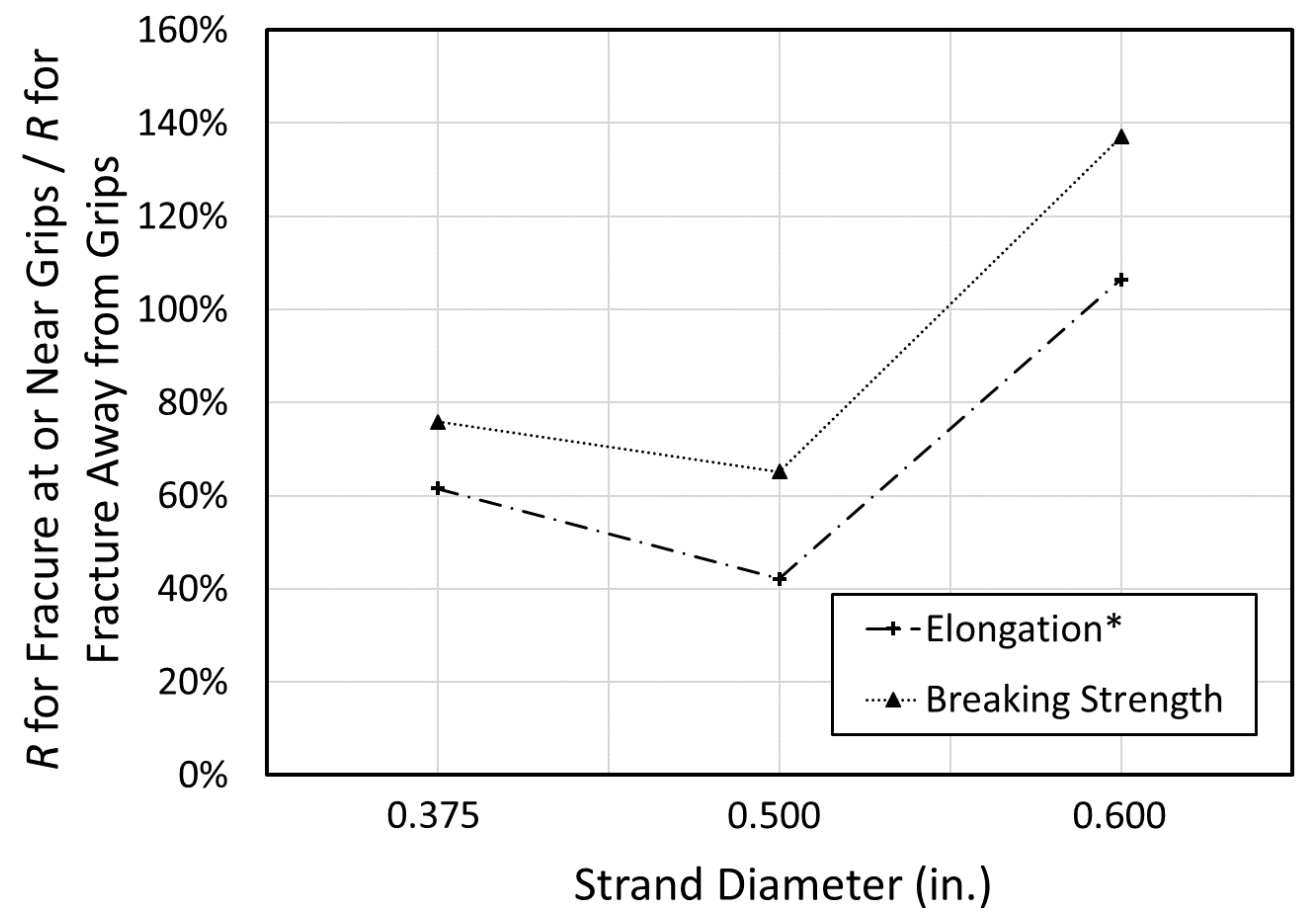

Figure 14 - Comparison of subgroups of data from tests with fracture occurring near the grips versus fracture occurring away from grips in terms of reproducibility limit (*subgroups of elongation data include fewer than six laboratories) $[1 \mathrm{in} .=25.4 \mathrm{~mm}]$ 
Figure 13 shows that strand fracture location had little effect on mean reported breaking strength but a large effect on elongation. The mean and COV of populations used to calculate $p$-values are shown in Table 10. Comparisons among all valid results show that breaking strength was $0.7 \%$ less for 0.500 in. $[12.7 \mathrm{~mm}]$ diameter strands fracturing near the grips, a result that was statistically significant $(p=0.00025)$. However, strand fracture location did not have a statistically significant effect on breaking strength for 0.375 and 0.600 in. [9.5 and $15.2 \mathrm{~mm}$ ] diameter strand ( $p=0.68$ and 0.074 , respectively). Overall, the effect of strand fracture location on breaking strength is therefore considered negligible. Reported elongations for the 0.375 and 0.500 in. [9.5 and $12.7 \mathrm{~mm}$ ] diameter specimens that fractured near the grips were approximately $15 \%$ less than for specimens that fractured away from the grips. These differences were statistically significant, with $p=0.050$ and 0.016 for 0.375 and 0.500 in. [9.5 and $12.7 \mathrm{~mm}$ ] diameter strands. Reported elongations were $7 \%$ less for 0.600 in. $[15.2 \mathrm{~mm}]$ diameter strands fracturing near the grips, but this difference was not statistically significant $(p=0.074)$. These results demonstrate that tests with specimens fracturing near the grips, which commonly occurs when serrated grips are used to grip the strand (see Section 4.1.1), should not be used to disqualify strand on the basis of measured elongation, because the grips result in large and statistically significant reductions in measured elongation. The effects of strand fracture location on breaking strength are much smaller.

Figure 14 shows that the reproducibility limit was smaller for 0.375 and 0.500 in. [9.5 and 12.7 $\mathrm{mm}$ ] strand and larger for $0.600 \mathrm{in} .[15.2 \mathrm{~mm}]$ strand for subgroups of specimens that fractured near the grips relative to specimens that fractured away from the grips. This was true for both elongation and breaking strength. There was, therefore, no consistent correlation between strand fracture location and the variability of elongation and breaking strength results.

Although tests with strand fracture occurring near the grips are valid tests per ASTM A1061 ${ }^{[6]}$, if the results exceed required minimum values, it is worth considering whether removing specimens that fractured near the grips would improve the high $R$ limits calculated for elongation in Table 6 . Table 10 lists the $r$ and $R$ limits calculated for elongation of specimens fracturing away from the grips. When compared 
with the same limits calculated using all valid elongation results (Table 6), it is seen that the repeatability limit, $r$, would decrease by 4 to $8 \%$ if only specimens fracturing away from the grips were considered. The results are not so clear for the reproducibility limit, $R$, which would increase by approximately $10 \%$ for 0.375 and 0.500 in. [9.5 and $12.7 \mathrm{~mm}$ ] diameter strand and decrease by approximately $10 \%$ for $0.600 \mathrm{in}$. [15.2 mm] diameter strand. These comparisons are not entirely appropriate, however, because $r$ and $R$ values are sensitive to the number of laboratories in the sample and only four laboratories had valid elongation results with strands fracturing away from the grips. Additional valid test results are required to establish $r$ and $R$ limits for specimens fracturing away from the grips.

\subsubsection{Cylindrical Grips with Gritty Surface Coating}

Three laboratories used cylindrical grips coated with a gritty textured coating (Figure 15), a type of grip that is not explicitly permitted in ASTM A1061 ${ }^{[6]}$. As reported in Section 4.1.1, $35 \%$ of specimens tested at these laboratories fractured near the grips $(67,55$, and $7 \%$ of specimens at laboratories 1,2 , and 13, respectively). This frequency of fracture near grips was much lower than for specimens gripped with serrated V-grips (78\% of specimens) and close to that observed for specimens tested with smooth cylindrical grips pretreated with gritty slurries (27\% of specimens).

The frequency of fracture near the grips is a major way that grip type influences reported results. Aside from the frequency of fracture near the grips, it is not possible to quantify whether use of such grips biased the collected data because 1) no valid elongation values were reported by these three laboratories and 2) breaking strength is not sensitive to strand fracture location (Section 4.5.3). Regardless, use of gritty textured coatings may be preferable to serrated V-grips based on the fracture frequencies cited above. 


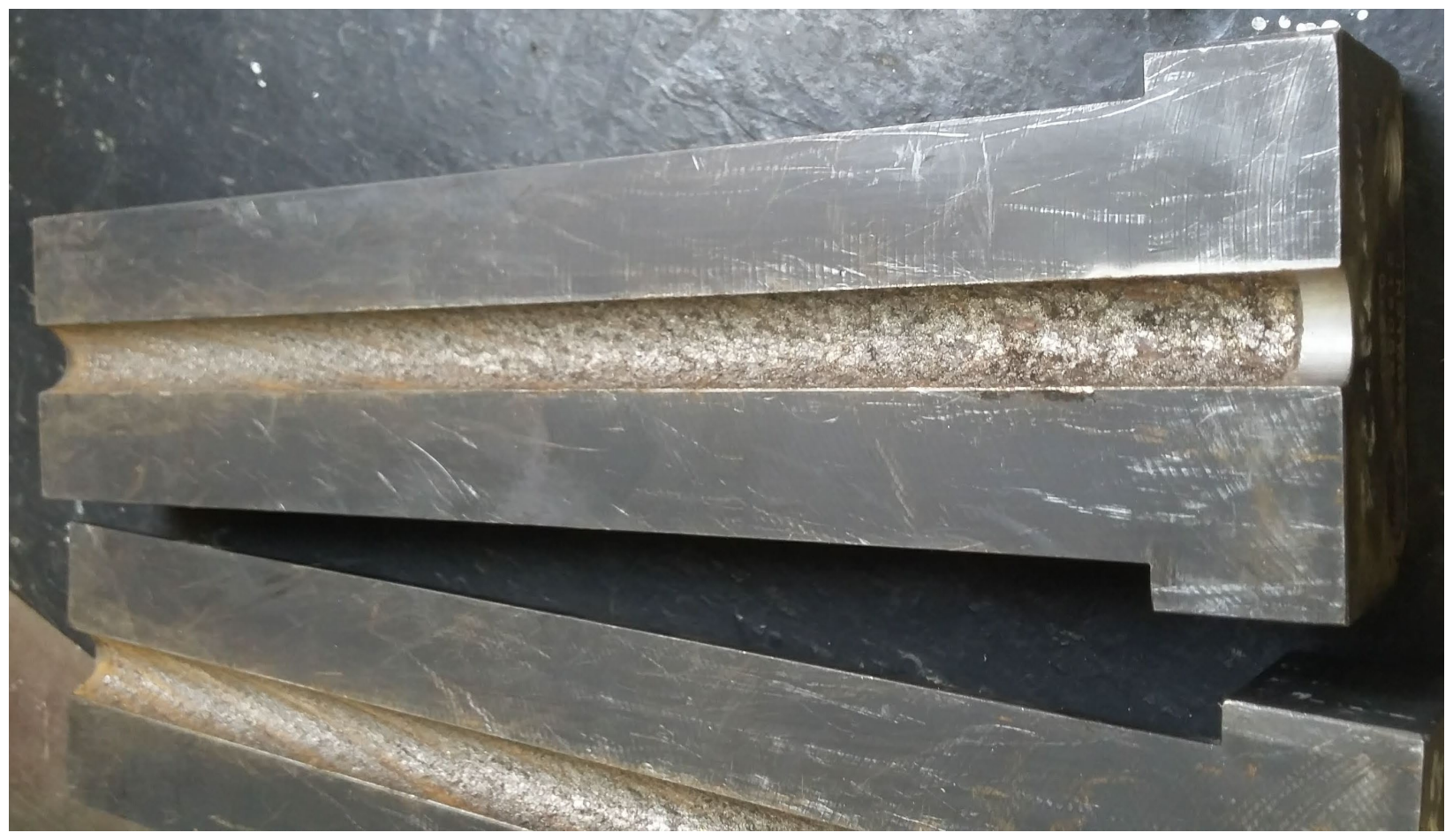

Figure 15 - Photograph of cylindrical grips with gritty tungsten-carbide coating welded to surface

\subsubsection{Effect of Welding Strand Ends}

Laboratory 6 welded the ends of all strand samples prior to testing (Figure 16). This is a standard practice at this laboratory, aimed at increasing the likelihood that strand fracture consists of simultaneously fracturing all seven wires (Figure 17). At other laboratories, it was typical for strand fracture to correspond to fracture of a single wire. ASTM A1061 ${ }^{[6]}$ does not prohibit welding the ends of strands, so results from Laboratory 6 were not excluded from the dataset of valid results.

To determine whether this had an effect on the results, the results from Laboratory 6 were compared with the results from the other laboratories that used similar procedures but did not weld the strand ends (Table 11). Laboratory 6 used the preload method for determining yield strength. When compared with other results obtained using the preload method, there was no statistically significant effect of welded strand ends on yield strength $(p=0.42,0.95,0.27$ for $0.375,0.500$, and 0.600 in. $[9.5,12.7$, and $15.2 \mathrm{~mm}]$ diameter strands, respectively). Similarly, welding strand ends had no effect on reported elongation values when only 
results from specimens fracturing away from the grips are considered $(p=0.13,0.94,0.51$ for $0.375,0.500$, and 0.600 in. $[9.5,12.7$, and $15.2 \mathrm{~mm}]$ diameter strands, respectively). Only strands fracturing away from the grips were considered, because eight of nine tests reported by Laboratory 6 had strand fracture occur away from grips. The only effect that welded strand ends had on reported values was on breaking strength. Breaking strengths of strands with welded ends were 5.7, 1.7, and $1.3 \%$ greater than those of strands without welded ends for all strand diameters for $0.375,0.500$, and 0.600 in. [9.5, 12.7, and $15.2 \mathrm{~mm}$ ] diameter strands, respectively. Considering only results where strands fractured away from grips, these differences were statistically significant $(p=0.024,0.000074$, and 0.019 for $0.375,0.500$, and 0.600 in. $[9.5,12.7$, and $15.2 \mathrm{~mm}]$ diameter strands, respectively).

Based on the higher breaking strength, welding strand ends is not recommended. If this change is made to ASTM A1061 ${ }^{[6]}$, it is necessary that the precision of the revised standard be determined from a dataset excluding results from Laboratory 6 . The calculations that produced the results in Table 4 to Table 7 were repeated, omitting results from Laboratory 6. The resulting precision statistics are in Appendix F.

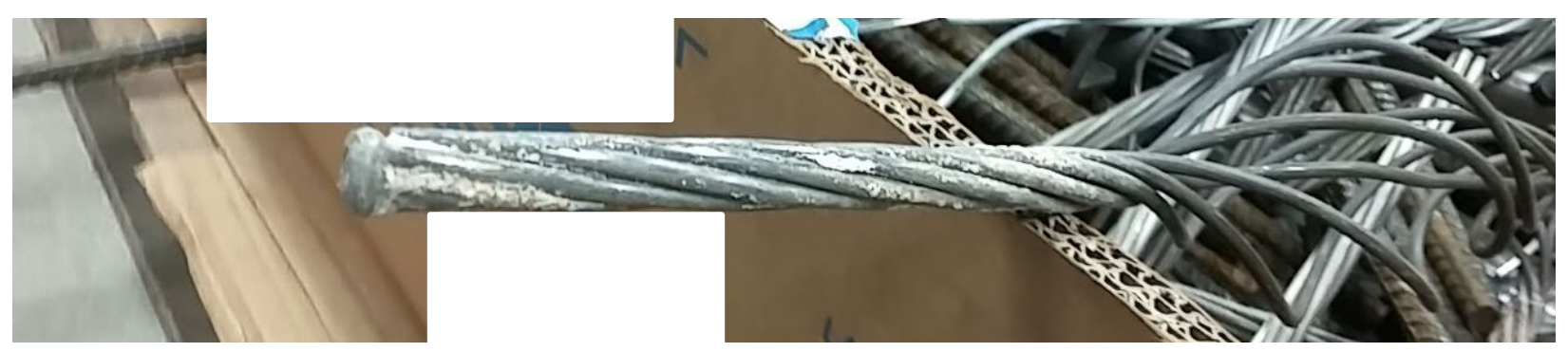

Figure 16 - Photograph of welded strand end (portions of background blocked to hide brand identification) 


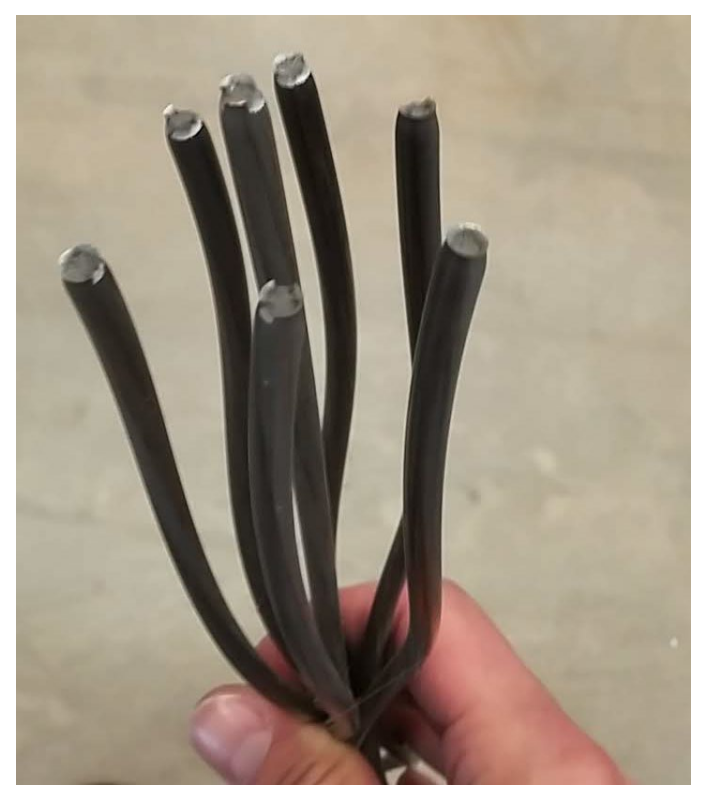

Figure 17 - Photograph of strand that exhibited nominally simultaneous fracture of seven wires

Table 11 - Effects of welding strand ends

\begin{tabular}{|c|c|c|c|c|c|c|c|}
\hline \multirow{2}{*}{$\begin{array}{c}\text { Strand } \\
\text { Diameter } \\
\text { in. [mm] }\end{array}$} & \multirow[t]{2}{*}{ Statistical Parameter } & \multicolumn{2}{|c|}{$\begin{array}{l}\text { Yield Strength } \\
\text { lbf [kN] }\end{array}$} & \multicolumn{2}{|c|}{$\begin{array}{c}\text { Elongation } \\
\% \\
\end{array}$} & \multicolumn{2}{|c|}{$\begin{array}{c}\text { Breaking Strength } \\
\text { lbf }[\mathrm{kN}]\end{array}$} \\
\hline & & Lab 6 & $\mathrm{PM}^{\mathrm{a}}$ & Lab 6 & Away ${ }^{b}$ & Lab 6 & Away ${ }^{b}$ \\
\hline \multirow{4}{*}{$\begin{array}{l}0.375 \\
{[9.5]}\end{array}$} & Number of Laboratories, $P_{L}$ & $1^{\mathrm{c}}$ & 7 & $1^{\mathrm{c}}$ & $3^{c}$ & $1^{\mathrm{c}}$ & 9 \\
\hline & Mean of Valid Results, Ibf [kN] & $\begin{array}{c}22930 \\
{[102.0]}\end{array}$ & $\begin{array}{l}23130 \\
{[102.9]}\end{array}$ & 6.083 & 6.858 & $\begin{array}{l}26130 \\
{[116.2]}\end{array}$ & $\begin{array}{l}25710 \\
{[114.4]}\end{array}$ \\
\hline & $\operatorname{COV}^{d}, \%$ & 1.53 & 1.44 & 0.84 & 19.7 & 0.59 & 0.99 \\
\hline & $p$-value ${ }^{\mathrm{e}}$ & \multicolumn{2}{|c|}{0.42} & \multicolumn{2}{|c|}{0.13} & \multicolumn{2}{|c|}{0.024} \\
\hline \multirow{4}{*}{$\begin{array}{l}0.500 \\
{[12.7]}\end{array}$} & Number of Laboratories, $P_{L}$ & $1^{\mathrm{c}}$ & 7 & $1^{\mathrm{c}}$ & $3^{c}$ & $1^{\mathrm{c}}$ & 10 \\
\hline & Mean of Valid Results, Ibf $[\mathrm{kN}]$ & $\begin{array}{l}38850 \\
{[172.8]}\end{array}$ & $\begin{array}{l}38840 \\
{[172.8]}\end{array}$ & 6.940 & 6.976 & $\begin{array}{c}44600 \\
{[198.4]}\end{array}$ & $\begin{array}{c}43870 \\
{[195.1]}\end{array}$ \\
\hline & $\operatorname{cov}^{d}, \%$ & 0.48 & 1.04 & 3.41 & 20.2 & 0.22 & 0.67 \\
\hline & $p$-value ${ }^{\mathrm{e}}$ & \multicolumn{2}{|c|}{0.95} & \multicolumn{2}{|c|}{0.94} & \multicolumn{2}{|c|}{0.000074} \\
\hline \multirow{4}{*}{$\begin{array}{l}0.600 \\
{[15.2]}\end{array}$} & Number of Laboratories, $P_{L}$ & $1^{\mathrm{c}}$ & 7 & $1^{\mathrm{c}}$ & $3^{c}$ & $1^{\mathrm{c}}$ & 13 \\
\hline & Mean of Valid Results, Ibf [kN] & $\begin{array}{l}55890 \\
{[247.2]}\end{array}$ & $\begin{array}{l}55870 \\
{[248.5]}\end{array}$ & 6.650 & 6.348 & $\begin{array}{l}62800 \\
{[279.3]}\end{array}$ & $\begin{array}{l}62000 \\
{[275.8]}\end{array}$ \\
\hline & $\operatorname{cov}^{d}, \%$ & 0.54 & 1.41 & 1.28 & 19.0 & 0.23 & 0.54 \\
\hline & $p$-value $\mathrm{e}^{\mathrm{e}}$ & \multicolumn{2}{|c|}{0.27} & \multicolumn{2}{|c|}{0.51} & \multicolumn{2}{|c|}{0.019} \\
\hline
\end{tabular}

${ }^{a}$ Valid yield strength results obtained using the preload method, excluding results from laboratory 6

${ }^{\mathrm{b}}$ Results from specimens fracturing away from the grips

${ }^{\mathrm{c}}$ Interpret results based on fewer than six laboratories with caution, as they may not be representative of larger populations of laboratories

${ }^{\mathrm{d}}$ Coefficient of variation

${ }^{\mathrm{e}}$ Result from a two-tailed Student's t-test; values $\leq 0.05$ indicate that differences are statistically significant 


\section{6 $\quad 0.2 \%$ Offset Method for Determining Yield Strength}

There is interest in whether it would be appropriate for the $0.2 \%$ offset method to be used as an approved method for determining strand yield strength. This new method may be advantageous if higherstrength strand reinforcement becomes available in the marketplace. Although outside the scope of the original study, an effort was made to compare yield strengths calculated using the preload, elastic modulus extrapolation, and $0.2 \%$ offset methods.

For this comparison, it was necessary to have point-by-point force and elongation data. Five of the 19 participating laboratories submitted such data. Of the five, three submitted data obtained in a manner consistent with ASTM A $1061^{[6]}$ requirements (the other two used extensometers that were not approved to be used for testing strand because of gauge length and precision requirements). The comparisons in this section are made using the point-by-point data submitted by three laboratories with approved extensometers (laboratories 6, 9, and 11). These data include test results from 23 specimens, representing 6, 8, and 9 results from tests of $0.375,0.500$, and 0.600 in. $[9.5,12.7$, and $15.2 \mathrm{~mm}]$ diameter strands, respectively.

The yield strength was calculated for each specimen using the preload, elastic modulus extrapolation, and $0.2 \%$ offset methods. The preload method calculation was done by:

- Identifying the elongation at a force equal to $10 \%$ of the required minimum breaking strength,

- $\quad$ Setting that elongation equal to $0.1 \%$, and

- Identifying the force corresponding to $1 \%$ elongation.

The elastic modulus extrapolation method calculation was done by:

- Calculating the slope of a line drawn through data collected between 20 and $65 \%$ of the required minimum breaking strength (this slope is the elastic modulus),

- Extrapolating that line to find the $\mathrm{x}$-axis intercept,

- Setting that $\mathrm{x}$-axis intercept equal to zero elongation, and

- Identifying the force corresponding to $1 \%$ elongation. 
Finally, the $0.2 \%$ offset method calculation was done using the same elastic modulus and $\mathrm{x}$-axis intercept (zero elongation) identified using the elastic modulus extrapolation method. A line was then drawn with an $\mathrm{x}$-axis intercept at $0.2 \%$ elongation and a slope equal to the elastic modulus. The force corresponding to the intersection of this line and the force-elongation data was taken as the yield strength.

The yield strengths calculated with the three methods for each of the 23 tests are listed in Table 12 . Table 12 also lists the mean and coefficient of variation for several subgroups of the data, including for results from each laboratory for each strand diameter and method, for all results obtained for a single strand diameter and method. Finally, Table 12 lists the coefficient of variation (by method), which was calculated by first dividing each yield strength obtained with a given method by the mean of the results for that strand diameter and method, and then calculating the coefficient of variation of the normalized values. This approach assumes that results for each strand diameter have the same distribution type, which is believed to be a reasonable approximation.

The yield strengths in Table 12 calculated with the $0.2 \%$ offset method were consistently larger than the yield strengths calculated with the other methods $(4.6,1.6$, and $1.8 \%$ larger for $0.375,0.500$, and 0.600 in. [9.5, 12.7, and $15.2 \mathrm{~mm}$ ] diameter strand, respectively). A two-tailed Student's t-test was used, assuming unequal variances, to determine the statistical significance of these differences. Comparisons were made between pairs of methods (preload versus elastic modulus extrapolation, elastic modulus extrapolation versus $0.2 \%$ offset, and preload versus $0.2 \%$ offset) for each strand diameter. The calculated $p$-values are listed in Table 13, which shows that the differences between the preload and elastic modulus extrapolation methods were not statistically significant (consistent with the findings in Section 4.5.2), but that the differences were statistically significant between the $0.2 \%$ offset method and the other two. This consistent and significant difference in yield strength exists because the $0.2 \%$ offset method consistently identified a yield point at elongations greater than $1 \%$ (Figure 18). The extent of the increase is, therefore, a function of the shape of the force-elongation curve and likely varies for different types and heats of strand. 
It was also found that results obtained with the $0.2 \%$ offset method were more scattered than the other results. This is shown in Table 12, where the coefficient of variation (by method) was calculated to be 0.011 for the $0.2 \%$ offset method and 0.008 for the other methods. From the perspective of maximizing precision, and based only on these limited data, it is not recommended that the $0.2 \%$ offset method be included in ASTM A1061 ${ }^{[6]}$ as a third alternative method for determining yield strength. 
Table 12 - Calculated yield strength by method based on submitted point-by-point data

\begin{tabular}{|c|c|c|c|c|c|c|c|c|c|c|}
\hline \multirow[b]{2}{*}{$\begin{array}{l}\text { Lab. } \\
\text { No. }\end{array}$} & \multirow{2}{*}{$\begin{array}{c}\text { Method } \\
\text { Strand } \\
\text { Diameter } \\
\text { in. [mm] }\end{array}$} & \multicolumn{3}{|c|}{ Preload } & \multicolumn{3}{|c|}{$\begin{array}{l}\text { Elastic Modulus } \\
\text { Extrapolation }\end{array}$} & \multicolumn{3}{|c|}{$0.2 \%$ Offset $^{a}$} \\
\hline & & $\begin{array}{l}0.375 \\
{[9.5]}\end{array}$ & $\begin{array}{l}0.500 \\
{[12.7]}\end{array}$ & $\begin{array}{l}0.600 \\
{[15.2]}\end{array}$ & $\begin{array}{l}0.375 \\
{[9.5]}\end{array}$ & $\begin{array}{l}0.500 \\
{[12.7]}\end{array}$ & $\begin{array}{l}0.600 \\
{[15.2]}\end{array}$ & $\begin{array}{l}0.375 \\
{[9.5]}\end{array}$ & $\begin{array}{l}0.500 \\
{[12.7]}\end{array}$ & $\begin{array}{l}0.600 \\
{[15.2]}\end{array}$ \\
\hline \multirow{5}{*}{6} & $\begin{array}{c}\text { Test 1, lbf } \\
{[\mathrm{kN}]}\end{array}$ & $\begin{array}{l}22650 \\
{[100.7]}\end{array}$ & $\begin{array}{l}39089 \\
{[173.9]}\end{array}$ & $\begin{array}{l}55695 \\
{[247.7]}\end{array}$ & $\begin{array}{l}22650 \\
{[100.7]}\end{array}$ & $\begin{array}{l}39089 \\
{[173.9]}\end{array}$ & $\begin{array}{l}55759 \\
{[248.0]}\end{array}$ & $\begin{array}{l}23730 \\
{[105.6]}\end{array}$ & $\begin{array}{c}39854 \\
{[177.3]}\end{array}$ & $\begin{array}{c}56534 \\
{[251.5]}\end{array}$ \\
\hline & $\begin{array}{c}\text { Test 2, lbf } \\
{[\mathrm{kN}]}\end{array}$ & $\begin{array}{l}23050 \\
{[102.5]}\end{array}$ & $\begin{array}{c}38982 \\
{[173.4]}\end{array}$ & $\begin{array}{l}55960 \\
{[248.9]}\end{array}$ & $\begin{array}{l}23130 \\
{[102.9]}\end{array}$ & $\begin{array}{l}39021 \\
{[173.6]}\end{array}$ & $\begin{array}{l}55960 \\
{[248.9]}\end{array}$ & $\begin{array}{l}24040 \\
{[106.9]}\end{array}$ & $\begin{array}{l}39629 \\
{[176.3]}\end{array}$ & $\begin{array}{l}57350 \\
{[255.1]}\end{array}$ \\
\hline & $\begin{array}{c}\text { Test 3, lbf } \\
{[\mathrm{kN}]}\end{array}$ & $\begin{array}{l}23250 \\
{[103.4]}\end{array}$ & $\begin{array}{l}38750 \\
{[172.4]}\end{array}$ & $\begin{array}{l}55370 \\
{[246.3]}\end{array}$ & $\begin{array}{l}23350 \\
{[103.9]}\end{array}$ & $\begin{array}{l}38750 \\
{[172.4]}\end{array}$ & $\begin{array}{l}55370 \\
{[246.3]}\end{array}$ & $\begin{array}{l}24530 \\
{[109.1]}\end{array}$ & $\begin{array}{c}39370 \\
{[175.1]}\end{array}$ & $\begin{array}{c}56610 \\
{[251.8]}\end{array}$ \\
\hline & $\begin{array}{l}\text { Mean, Ibf } \\
{[\mathrm{kN}]}\end{array}$ & $\begin{array}{l}22983 \\
{[102.2]}\end{array}$ & $\begin{array}{l}38940 \\
{[173.2]}\end{array}$ & $\begin{array}{l}55675 \\
{[247.6]}\end{array}$ & $\begin{array}{l}23043 \\
{[102.5]}\end{array}$ & $\begin{array}{l}38953 \\
{[173.3]}\end{array}$ & $\begin{array}{l}55696 \\
{[247.7]}\end{array}$ & $\begin{array}{l}24100 \\
{[107.2]}\end{array}$ & $\begin{array}{c}39618 \\
{[176.2]}\end{array}$ & $\begin{array}{c}56831 \\
{[252.8]}\end{array}$ \\
\hline & $\operatorname{cov}^{b}$ & 0.0133 & 0.0044 & 0.0053 & 0.0155 & 0.0046 & 0.0054 & 0.0167 & 0.0061 & 0.0079 \\
\hline \multirow{5}{*}{9} & $\begin{array}{c}\text { Test 1, lbf } \\
{[\mathrm{kN}]}\end{array}$ & - & $\begin{array}{l}38135 \\
{[169.6]}\end{array}$ & $\begin{array}{l}56063 \\
{[249.4]}\end{array}$ & - & $\begin{array}{l}38269 \\
{[170.2]}\end{array}$ & $\begin{array}{l}56123 \\
{[249.6]}\end{array}$ & - & $\begin{array}{c}38522 \\
{[171.3]}\end{array}$ & $\begin{array}{r}56181 \\
{[249.9]} \\
\end{array}$ \\
\hline & $\begin{array}{c}\text { Test 2, lbf } \\
{[\mathrm{kN}]}\end{array}$ & - & - & $\begin{array}{l}55304 \\
{[246.0]}\end{array}$ & - & - & $\begin{array}{l}55357 \\
{[246.2]}\end{array}$ & - & - & $\begin{array}{c}56092 \\
{[249.5]}\end{array}$ \\
\hline & $\begin{array}{c}\text { Test 3, lbf } \\
{[\mathrm{kN}]}\end{array}$ & - & $\begin{array}{c}38137 \\
{[169.6]}\end{array}$ & $\begin{array}{l}55204 \\
{[245.5]}\end{array}$ & - & $\begin{array}{l}38249 \\
{[170.1]}\end{array}$ & $\begin{array}{l}55175 \\
{[245.4]}\end{array}$ & - & $\begin{array}{c}38609 \\
{[171.7]}\end{array}$ & $\begin{array}{c}55944 \\
{[248.8]}\end{array}$ \\
\hline & $\begin{array}{c}\text { Mean, Ibf } \\
{[\mathrm{kN}]}\end{array}$ & - & $\begin{array}{r}38136 \\
{[169.6]}\end{array}$ & $\begin{array}{l}55524 \\
{[247.0]}\end{array}$ & - & $\begin{array}{r}38259 \\
{[170.2]}\end{array}$ & $\begin{array}{l}55552 \\
{[247.1]}\end{array}$ & - & $\begin{array}{l}38566 \\
{[171.5]}\end{array}$ & $\begin{array}{r}56072 \\
{[249.4]}\end{array}$ \\
\hline & $\mathrm{cov}^{\mathrm{b}}$ & - & 0.0000 & 0.0085 & - & 0.0004 & 0.0091 & - & 0.0016 & 0.0021 \\
\hline \multirow{5}{*}{11} & $\begin{array}{c}\text { Test 1, lbf } \\
{[\mathrm{kN}]}\end{array}$ & $\begin{array}{l}22960 \\
{[102.1]}\end{array}$ & $\begin{array}{c}38819 \\
{[172.7]}\end{array}$ & $\begin{array}{l}54982 \\
{[244.6]}\end{array}$ & $\begin{array}{c}23001 \\
{[102.3]}\end{array}$ & $\begin{array}{l}38867 \\
{[172.9]}\end{array}$ & $\begin{array}{l}55052 \\
{[244.9]}\end{array}$ & $\begin{array}{l}24100 \\
{[107.2]}\end{array}$ & $\begin{array}{l}39557 \\
{[175.9]}\end{array}$ & $\begin{array}{l}56531 \\
{[251.4]}\end{array}$ \\
\hline & $\begin{array}{c}\text { Test 2, Ibf } \\
{[\mathrm{kN}]}\end{array}$ & $\begin{array}{l}23319 \\
{[103.7]}\end{array}$ & $\begin{array}{l}38946 \\
{[173.2]}\end{array}$ & $\begin{array}{l}56097 \\
{[249.5]}\end{array}$ & $\begin{array}{c}23374 \\
{[104.0]}\end{array}$ & $\begin{array}{l}39018 \\
{[173.6]}\end{array}$ & $\begin{array}{l}56237 \\
{[250.1]}\end{array}$ & $\begin{array}{l}24357 \\
{[108.3]}\end{array}$ & $\begin{array}{l}39676 \\
{[176.5]}\end{array}$ & $\begin{array}{r}57533 \\
{[255.9]} \\
\end{array}$ \\
\hline & $\begin{array}{c}\text { Test 3, Ibf } \\
{[\mathrm{kN}]}\end{array}$ & $\begin{array}{l}23107 \\
{[102.8]}\end{array}$ & $\begin{array}{c}38742 \\
{[172.3]}\end{array}$ & $\begin{array}{l}55753 \\
{[248.0]}\end{array}$ & $\begin{array}{r}23160 \\
{[103.0]}\end{array}$ & $\begin{array}{l}38791 \\
{[172.5]}\end{array}$ & $\begin{array}{l}55787 \\
{[248.1]}\end{array}$ & $\begin{array}{l}24114 \\
{[107.3]}\end{array}$ & $\begin{array}{l}39557 \\
{[175.9]}\end{array}$ & $\begin{array}{r}56955 \\
{[253.3]}\end{array}$ \\
\hline & $\begin{array}{c}\text { Mean, Ibf } \\
{[\mathrm{kN}]}\end{array}$ & $\begin{array}{l}23129 \\
{[102.9]}\end{array}$ & $\begin{array}{l}38836 \\
{[172.7]}\end{array}$ & $\begin{array}{l}55611 \\
{[247.4]}\end{array}$ & $\begin{array}{l}23178 \\
{[103.1]}\end{array}$ & $\begin{array}{c}38892 \\
{[173.0]}\end{array}$ & $\begin{array}{l}55692 \\
{[247.7]}\end{array}$ & $\begin{array}{l}24190 \\
{[107.6]}\end{array}$ & $\begin{array}{l}39597 \\
{[176.1]}\end{array}$ & $\begin{array}{r}57006 \\
{[253.6]}\end{array}$ \\
\hline & $\operatorname{cov}^{b}$ & 0.0078 & 0.0027 & 0.0103 & 0.0081 & 0.0030 & 0.0107 & 0.0060 & 0.0017 & 0.0088 \\
\hline \multicolumn{2}{|c|}{ Mean c, lbf [kN] } & $\begin{array}{l}23056 \\
{[102.6]}\end{array}$ & $\begin{array}{l}38700 \\
{[172.1]}\end{array}$ & $\begin{array}{l}55603 \\
{[247.3]}\end{array}$ & $\begin{array}{l}23111 \\
{[102.8]}\end{array}$ & $\begin{array}{l}38757 \\
{[172.4]}\end{array}$ & $\begin{array}{c}55647 \\
{[247.5]}\end{array}$ & $\begin{array}{l}24145 \\
{[107.4]}\end{array}$ & $\begin{array}{c}39347 \\
{[175.0]}\end{array}$ & $\begin{array}{l}56637 \\
{[251.9]}\end{array}$ \\
\hline \multicolumn{2}{|c|}{$\operatorname{COV}$ (by column) $^{d}$} & 0.0094 & 0.0089 & 0.0068 & 0.0105 & 0.0079 & 0.0072 & 0.0104 & 0.0119 & 0.0092 \\
\hline \multicolumn{2}{|c|}{$\begin{array}{c}\text { COV } \\
\text { (by method) }\end{array}$} & \multicolumn{3}{|c|}{0.0083} & \multicolumn{3}{|c|}{0.0084} & \multicolumn{3}{|c|}{0.0105} \\
\hline
\end{tabular}

${ }^{a}$ Yield strength was defined as the force corresponding to the intersection of the force-elongation data and a line drawn from $0.2 \%$ elongation with a slope equal to the elastic modulus; the elastic modulus extrapolation method was used to determine the elastic modulus and identify the point of zero elongation

${ }^{b}$ Coefficient of variation

${ }^{\mathrm{c}}$ Mean of results obtained for specimens with a single strand diameter using a single method

${ }^{d}$ Coefficient of variation of results obtained for specimens with a single strand diameter using a single method

${ }^{\mathrm{e}}$ Coefficient of variation by method was calculated by: (1) dividing each yield strength obtained with a given method by the mean of the results for that strand diameter and method, and (2) calculating the coefficient of variation of the normalized values 
Table 13 - Statistical significance ( $p$-values) of differences in yield strengths obtained with preload, elastic modulus extrapolation, and $0.2 \%$ offset methods

\begin{tabular}{c|c|c|c} 
& A vs. B $^{\text {a }}$ & B vs. C ${ }^{\text {a }}$ & A vs. C $^{\text {a }}$ \\
\hline $\begin{array}{c}0.375 \text { in. [9.5 mm] } \\
\text { Diameter Strand }\end{array}$ & 0.72 & 0.000060 & 0.000030 \\
\hline $\begin{array}{c}0.500 \text { in. [12.7 mm] } \\
\text { Diameter Strand }\end{array}$ & 0.75 & 0.017 & 0.011 \\
\hline $\begin{array}{c}0.600 \text { in. [15.2 mm] } \\
\text { Diameter Strand }\end{array}$ & 0.83 & 0.00067 & 0.00040 \\
\hline Finding: & $\begin{array}{c}\text { No statistically } \\
\text { significant difference }\end{array}$ & $\begin{array}{c}\text { Statistically significant } \\
\text { difference }\end{array}$ & $\begin{array}{c}\text { Statistically significant } \\
\text { difference }\end{array}$
\end{tabular}

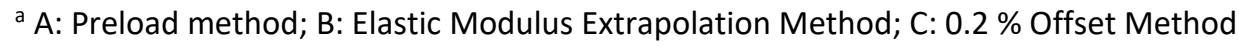

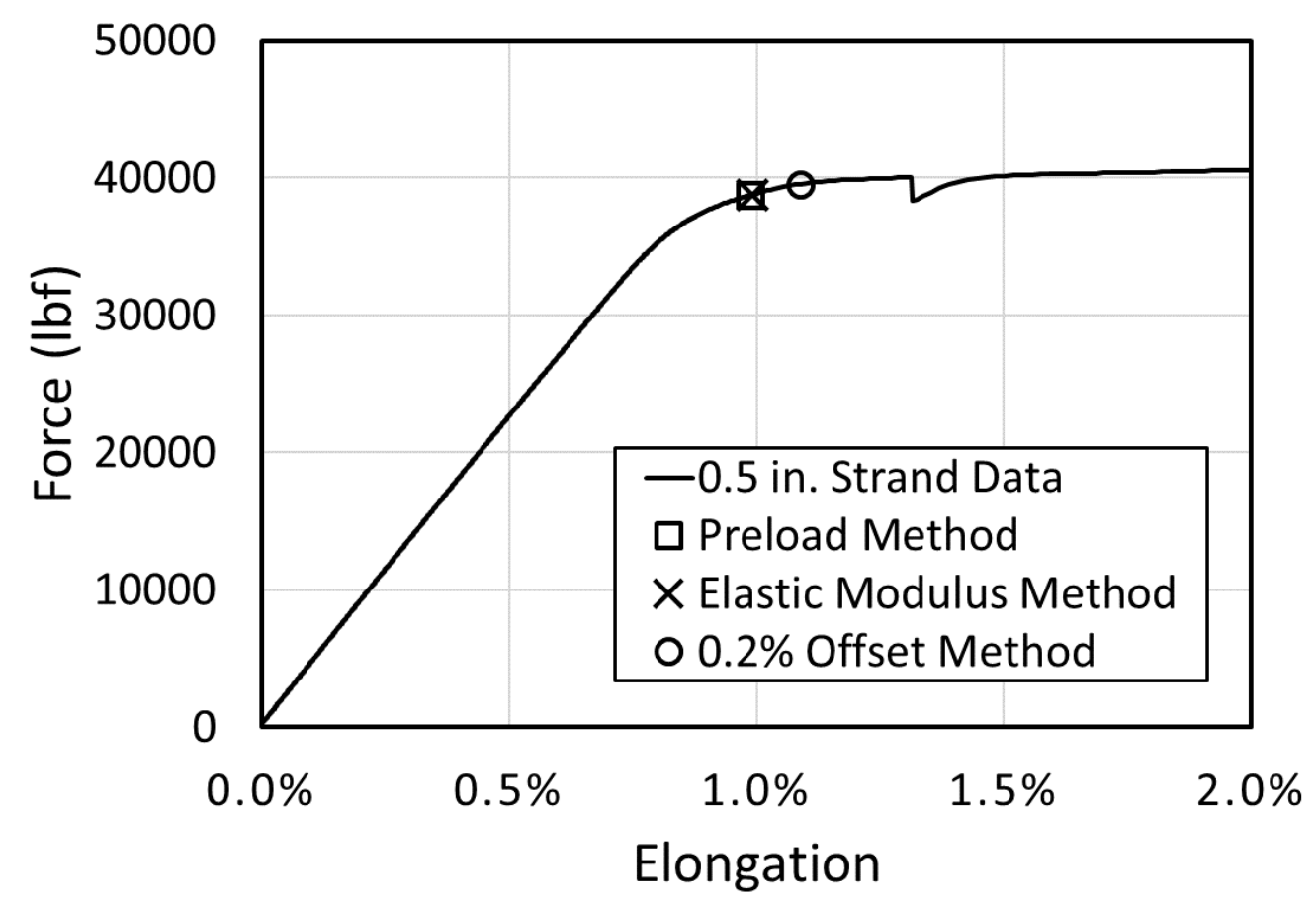

Figure 18 - Yield strengths determined with different methods for specimen 3 of the 0.5 in. diameter strand tested by laboratory $11[1 \mathrm{in} .=25.4 \mathrm{~mm}, 1000 \mathrm{lbf}=4.448 \mathrm{kN}]$ 


\section{RECOMMENDED CHANGES TO ASTM A1061}

In the following sections, changes to ASTM A1061 ${ }^{[6]}$ are proposed. Each section is considered separately and a brief justification for the proposed changes is provided. In this chapter proposed additions are underlined and proposed deletions are struck-out. Sections where no changes are proposed are not reproduced.

\subsection{Terminology, Section 3 of ASTM A1061}

\subsubsection{Proposed changes}

3.1.1 breaking forcestrength, $n$-maximum force at or after which one or more wires fracture.

3.1.5 yield forcestrength, $n$-measured force at $1.0 \%$ extension under load (EUL).

Modify terminology throughout the standard if adopted.

\subsubsection{Rationale}

This is a recommended editorial change, but it is not considered critical. Strength is an ambiguous term that sometimes implies a stress and other times a force or a moment. Use of "force" is clear.

\subsection{Sampling, Section 6 of ASTM A1061}

\subsubsection{Proposed changes}

6.1 Unless otherwise... strand being tested. The ends of strand samples shall not be welded before the strand is tested.

\subsubsection{Rationale}

This change is suggested because results from a laboratory that welds the ends of strand samples (such that all wires are joined at both ends of the sample) exhibited 1.3 to $5.7 \%$ larger breaking strengths for specimens with different strand diameters. This increase in strength was statistically significant (see Section 4.5.5). If this change is adopted, results from Laboratory 6 must be removed from the dataset used 
to calculated the precision of the ASTM A1061 ${ }^{[6]}$ methods. Precision statistics were recalculated omitting Laboratory 6 (Appendix F).

\subsection{Gripping Devices, Section 7 of ASTM A1061}

\subsubsection{Proposed changes}

7.1.1 Standard V-Grips with Serrated Teeth (Note 1).

\section{$7.1 .1 .2 \ldots$}

7.1.2.3 Special Grips with Smooth, Semi Cylindrical Grooves (Note 2, Fig. 1)-The grips can be used as is or in conjunction with an abrasive slurry applied to the grooves of the grips and the gripped portion of the test specimen to prevent slippage. The slurry consists of abrasive such as Grade 3-F aluminum oxide and a carrier such as water or glycerin. Alternatively, a gritty coating may be affixed to the smooth grip surface, such as a welded tungsten-carbide coating.

\section{$7.1 .34 \ldots$}

\subsubsection{Rationale}

This change is recommended because $78 \%$ of specimens tested with standard V-grips without a cushioning material between the grips and the strand fractured near the grips (Section 4.1.1). Although tests with the strand fracturing near the grips cannot be used to disqualify a strand, it was reported to research team members that some laboratories improperly disqualify strand regardless of fracture location. This change is not believed to be unduly onerous because use of a cushioning material can easily be implemented without modifying laboratory equipment.

The committee might consider also permitting use of special grips with semi-cylindrical grooves with a tungsten-carbide textured coating. Several laboratories use these grips even though they are not currently permitted. Among results submitted to the research team, strand specimens fractured less frequently near this type of grip relative to specimens tested with standard V-grips with serrated teeth (Section 4.1.1). 


\subsection{Preload Method for Yield Strength, Section 9.1.1 of ASTM A1061}

\subsubsection{Proposed changes}

9.1.1 Preload Method-After loading the specimen in the test frame, apply and hold an initial load force of $10 \%$ of the required minimum breaking strength to the specimen. Next, attach the extensometer described in 5.2 and adjust it to a reading of $0.1 \%$ of the extensometer gauge length. Continue loading until the extensometer indicates a total extension of $1.0 \%$ of the extensometer gauge length (a change in extension equal to $0.9 \%$ of the extensometer gauge length, relative to the reading of $0.1 \%$ of gauge length, is required to obtain a total extension of $1 \%$ of the gauge length including the $0.1 \%$ extension during pre-loading). Record the load at $1.0 \%$ extension as the yield strength. The extensometer remains attached to the strand until at least $1.05 \%$ EUL is reached to ensure the yield strength is accurately measured and recorded; typically, the extensometer is then removed from the specimen to avoid possible extensometer damage due to strand rupture.

\subsubsection{Rationale}

The changes to the first sentence are editorial. First, "force" is more appropriate than "load" in this instance. Second, it is not possible to "hold [a force]... to the specimen". The change to the second sentence is proposed to distinguish between the extensometer gauge length used here and the distance between jaws used for elongation measurement. Some laboratories failed to correctly distinguish between the two. The last change, to the third sentence, is the most important proposed change to this section. Several laboratories misread this requirement and applied incorrect increments of elongation to the specimen, resulting in incorrect reported yield strengths.

\subsection{Elastic Modulus Extrapolation Method for Yield Strength, Section 9.1.2 of ASTM A1061}

\subsubsection{Proposed changes}

9.1.2 Elastic Modulus Extrapolation Method-Use a computerized data acquisition system... after $65 \%$ of the minimum breaking strength is reached. Data corresponding to at least $70 \%$ of the range 
between $20 \%$ and $65 \%$ of the minimum breaking strength (inclusive) shall be used for the linear regression used to calculate the elastic modulus. Between $20 \%$ and $65 \%$ of the minimum breaking strength, the linear regression shall collect data over at least $70 \%$ of this range to ensure sufficient data is included to generate the elastic modulus value. Once the elastic modulus is determined measured, the... zero force point. This is the origin from which the $1.0 \%$ EUL shall be determined. Record yield strength as the load corresponding to $1.0 \%$ extension on the force-elongation curve. The extensometer...

\subsubsection{Rationale}

Two changes to Section 9.1.2 are proposed. The first is an editorial revision aimed at clarifying the text stating that at least $70 \%$ of the data collected between 20 and $65 \%$ of the required minimum breaking strength shall be used to calculate the elastic modulus. The second change is proposed to mirror the text in Section 9.1.1 of ASTM A1061 ${ }^{[6]}$ that states which value is to be reported as the yield strength. This latter change is not strictly necessary given the definition of yield strength in ASTM A1061 ${ }^{[6]}$ Section 3.1.5.

\subsection{Methods for Determining Elongation, Section 9.2 of ASTM A1061}

Major changes are needed to this section to address the extreme variability of elongation measurements reported in Chapter 4. Changes are also needed to improve clarity and remove contradictions with the aim of reducing the frequency that laboratories measure elongation in a manner that is not compliant with ASTM A1061 ${ }^{[6]}$. Due to the number and importance of issues that need to be addressed, specific line-by-line changes to Section 9.2 of ASTM A1061-16 $6^{[6]}$ are not proposed. Instead, a list of questions and problems made apparent by the results of the current study are described.

\subsubsection{Problems with Section 9.2}

1. Although Section 9.2 states that elongation may be measured with a "Class D extensometer..., a linear dial gauge, or ruler", the wording of 9.2.1 seems to only permit use of an extensometer that can be attached to the specimen. It needs to be clear which tools can be used for each method. 
Likewise, an extensometer attached to the specimen cannot be used to measure changes in jaw-tojaw distance, as required in 9.2.2.

\subsubsection{Problems with Section 9.2.1}

1. The name of Section 9.2.1, the "Pre-Load Method", is spelled differently from the name of Section 9.1.1, the "Preload Method".

2. Because of the names of Sections 9.1.1 and 9.2.1, many technicians believe they are using the preload method for elongation (Section 9.2.1) after they used the preload method for yield strength (Section 9.1.1). This cannot be, however, because Sections 9.1.1 and 9.2.1 require the elongation at $10 \%$ of the required minimum breaking strength be set to $0.1 \%$ and $0 \%$, respectively. The two preload methods are therefore incompatible if conducted in strict accordance with the standard. Additionally, Section 9.2.2 is titled the "Elongation after measuring yield strength method", implying that the Section 9.2.2 method applies if yield strength is measured regardless of method.

3. It is not clear how a dial gauge or ruler is to be used for the preload method. Section 9.2 states they are permitted tools, but 9.2.1 states the tool must be attached. It is also not clear whether the instrument must be attached to the specimen or whether it can be attached to the cross-frame. If the intent is to have it attached to the specimen, it is not clear how to attach a ruler.

4. Section 9.2.1 needs to clearly state how to calculate elongation when using the preload method. There is text describing the calculation near the end of Section 9.2.2, but that does not apply when the preload method (Section 9.2.1) is employed. Many questions arise from this ambiguity. For instance, if a ruler or dial gauge is used for the preload method, what is the gauge length for calculating elongation?

\subsubsection{Problems with Section 9.2.2}

1. The user has latitude to remove the extensometer used to determine yield strength at any EUL larger than $1.05 \%$. At a minimum, this value should be specified with some stated tolerance. 
2. The user has latitude to use either jaw separation or crosshead movement to quantify the increment of separation after yield strength. A single method should be clearly required.

3. It is not clear how a Class D extensometer, which is presumably attached to the specimen, is used to measure jaw-to-jaw separation. If jaw-to-jaw separation is to be the basis of the elongation calculation, use of a Class D extensometer affixed to the specimen must be explicitly prohibited.

4. The last sentence needs to more clearly describe what the reference gauge length is. Several laboratories used the jaw separation at $0.1 \%$ elongation as the reference point.

5. More broadly, the method described in Section 9.2.2 cannot be automated because the jaw-to-jaw distance after yield strength determination is required as an input. Most laboratories choose to automate this test and therefore modify the procedures in a manner that is both in violation of the standard requirements and more convenient. Few laboratories actually measure jaw separation while the strand is loaded.

\subsection{Fracture Location, Section 9.3.1 of ASTM A1061}

\subsubsection{Proposed changes}

9.3.1 Fracture Location-If a... the results shall be accepted (Note 4). Test results from specimens that fracture within secondary chucking devices shall be considered invalid regardless of whether

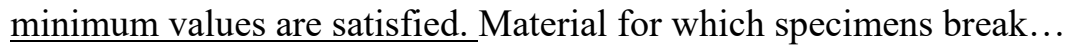

Note 4-Wire or strand fracture occurring within $0.25 \mathrm{in}$. [6.0 $\mathrm{mm}$ ] of the grips is affected by stress concentrations due to the gripping system. Consequently, values from these test results should be considered conservative. Conversely, values from tests where fracture occurs within secondary gripping devices may not be conservative. A break ... and will often indicate a shear-type failure (a near $45^{\circ}$ fracture profile). Necking (or "cupping") at the fracture point is not evidence that the gripping device had no effect on test results and should not be used as a basis for determining test validity. 


\subsubsection{Rationale}

Two changes are proposed to Section 9.3.1. Results from tests where a specimen fractures in the secondary chucking devices must be considered invalid because 1) chucking devices are not permitted to act as a primary gripping device for testing purposes (see Section 7.1.4 of ASTM A1061 ${ }^{[6]}$ ), and 2) in such cases the actual gauge length for elongation will be much longer than the jaw-to-jaw distance, resulting in an unconservative measurement of elongation. The other proposed change, to Note 4, is intended to correct a misconception held by technicians at several participating laboratories that strand fracture location is irrelevant if necking is observed at the fracture location. Regardless of the shape of the fracture surface, the requirements of Section 9.3.1 should be satisfied.

\subsection{Precision and Bias, Section 11.1 of ASTM A1061}

\subsubsection{Proposed changes}

11.1 No statement is made... statistical analysis for precision at this time. Precision--An interlaboratory study of the mechanical characterization of multi-wire steel prestressing strand was conducted in accordance with Practice E691, involving nineteen laboratories. Three diameters of strand were considered $(0.375 \mathrm{in} .[9.5 \mathrm{~mm}], 0.5 \mathrm{in} .[12.7 \mathrm{~mm}]$, and $0.6 \mathrm{in} .[15.2 \mathrm{~mm}])$, with each laboratory testing between three and five specimens for each strand diameter; except that four of the nineteen participating laboratories were not equipped to test the smallest diameter $(0.375$ in. [9.5 mm]). Eight laboratories did not return results for one of the mechanical parameters (elastic modulus). Measurement of relaxation properties was outside the scope of the study. See ASTM Research Report No. A01-XXXX. The precision statistics obtained for each of the measured mechanical parameters are provided in Table 4 (yield strength), Table 5 (elastic modulus), Table 6 (elongation), and Table 7 (breaking strength). The terms repeatability limit and reproducibility limit are used as specified in Practice E177. 


\subsubsection{Rationale}

See Section 4.4 of this report.

If a change is made to ASTM A1061 ${ }^{[6]}$ that prohibits welding the ends of strand specimens prior to testing, as recommended in Section 5.2 of this report, the precision statistics given in Appendix F should be used in place of those in Table 4 to Table 7. 


\section{SUMMARY AND CONCLUSIONS}

An interlaboratory study involving 19 laboratories was conducted to quantify the precision of the ASTM A $1061^{[6]}$ methods for measuring strand yield strength, elastic modulus, elongation, and breaking strength. Specimens were 0.375, 0.500, and 0.600-in. [9.5, 12.7, and 15.2-mm] diameter Grade 270 [1860] low-relaxation seven-wire steel prestressing strands compliant with ASTM A416 ${ }^{[2]}$. The results were used to examine how the method is implemented in practice and how precise the results are when the procedures described in ASTM A1061 ${ }^{[6]}$ are correctly implemented. Several changes to ASTM A1061 ${ }^{[6]}$ were proposed aimed at improving the clarity of the standard. The following conclusions were drawn:

1. Rates of compliance among participating laboratories with ASTM A1061 ${ }^{[6]}$ requirements were low for several measures, indicating need for modifications to the standard to clarify and simplify requirements. Among laboratories reporting results, 74, 82, 32, and $100 \%$ reported at least one result that was classified as valid for identifying yield strength, elastic modulus, elongation, and breaking strength, respectively.

2. Precision: Measurements of yield strength and breaking strength had low variability, resulting in a precision, in terms of reproducibility limit, that was less than $4 \%$ of the mean value. Measurements of elastic modulus were more scattered, with a reproducibility limit up to $9 \%$ of the mean value for some strand diameters. Elongation measurements were highly scattered, resulting in recommended reproducibility limits between 51 and $54 \%$ of the mean reported value for different strand diameters. Variability among reported results was not correlated with strand size for any test outcome. Recommended repeatability and reproducibility limits are provided in Chapter 4.

3. Yield strengths determined using the preload and elastic modulus extrapolation methods exhibited no statistically significant difference. There was, however, a large difference between the two methods in terms of the percentage of submitted results classified as valid, with 91 and $50 \%$ of results classified as valid for the preload and elastic modulus extrapolation methods, respectively. 
4. Strand fracture within the grips or within a distance of 0.25 in. [6 mm] of the grips results in negligible changes in breaking strength and large reductions in measured elongation. Strand fracture near grips resulted in a statistically significant $(p=0.050$ and 0.016$)$ reduction in elongation of approximately $15 \%$ for 0.375 and 0.500 in. [9.5 and $12.7 \mathrm{~mm}$ ] diameter strand, and a $7 \%$ reduction for $0.600 \mathrm{in}$. [15.2 $\mathrm{mm}]$ strand that was not statistically significant $(p=0.37)$.

5. The type of grip used has a large influence on the percentage of specimens that fracture near the grips. V-grips without cushioning material resulted in the highest frequency of fracture near the grips $(78 \%)$, and it is recommended that this type of grip be prohibited unless used with cushioning material. All other permitted methods resulted in fewer than $30 \%$ of specimens fracturing near the grips. Several laboratories used cylindrical grips with a gritty tungsten-carbide coating welded to the surface. Though not permitted by the standard, this type of grip resulted in $35 \%$ of specimens fracturing near the grips.

6. A limited study of point-by-point data submitted by three laboratories showed that use of the 0.2 $\%$ offset method to determine yield strength consistently results in a larger calculated yield strength and greater variability than either the preload or elastic modulus extrapolation methods. The increase was between 1 and $5 \%$, differences that were statistically significant ( $p$-values were between 0.00003 and 0.017 , see Table 13). The extent of the increase is a function of the shape of the force-elongation curve of the strand and will likely vary for different types and heats of strand.

7. Welding the ends of strands, which was done by one laboratory to obtain simultaneous fracture of all strand wires, has no effect on yield strength or elongation. Welding strand ends did, however, result in 1.3 to $5.7 \%$ increase in breaking strength for different strand diameters, results that were statistically significant $(p=0.024,0.000074$, and 0.019 for $0.375,0.500$, and 0.600 in. $[9.5,12.7$, and $15.2 \mathrm{~mm}$ ] diameter strands). This should be prohibited to improve consistency in results. 


\section{REFERENCES}

1. ASTM International. (2017). ASTM A370-17 Standard Test Methods and Definitions for Mechanical Testing of Steel Products, ASTM International, West Conshohocken, PA.

2. ASTM International. (2017). ASTM A416/A416M-17a Standard Specification for Low-Relaxation, Seven-Wire Steel Strand for Prestressed Concrete, ASTM International, West Conshohocken, PA.

3. ASTM International. (2016). ASTM A779/A779M-16 Standard Specification for Steel Strand, SevenWire, Uncoated, Compacted for Prestressed Concrete, ASTM International, West Conshohocken, PA.

4. ASTM International. (2017). ASTM A886/A886M-17, Standard Specification for Steel Strand, Indented, Seven-Wire Stress-Relieved for Prestressed Concrete, ASTM International, West Conshohocken, PA.

5. ASTM International. (2018). ASTM A910/A910M-18, Standard Specification for Uncoated, Weldless, 2-Wire and 3-Wire Steel Strand for Prestressed Concrete, ASTM International, West Conshohocken, PA.

6. ASTM International. (2016). ASTM A1061/A1061M-16 Standard Test Method for Testing Multi-Wire Steel Prestressing Strand, ASTM International, West Conshohocken, PA.

7. ASTM International. (2016). ASTM E83-16 Standard Practice for Verification and Classification of Extensometer Systems, ASTM International, West Conshohocken, PA.

8. ASTM International. (2014). ASTM E177-14 Standard Practice for Use of the Terms Precision and Bias in ASTM Test Methods, ASTM International, West Conshohocken, PA.

9. ASTM International. (2016). ASTM E691-16 Standard Practice for Conducting an Interlaboratory Study to Determine the Precision of a Test Method, ASTM International, West Conshohocken, PA.

10. Johnson, R. A., Miller, I., and Freund, J. E. (2005). "Probability and Statistics for Engineers, 7th ed." Pearson Prentice Hall, Englewood Cliffs, New Jersey, 634 pp. 


\section{APPENDIX A: NOTATION}

EUL $=$ Extension under load

$h \quad=\quad$ Between-laboratory consistency statistic (ASTM E177 ${ }^{[8]}$ )

$k=$ Within-laboratory consistency statistic (ASTM E177 ${ }^{[8]}$ )

$L_{O}=$ Separation between grips measured when loading is paused to remove the extensometer after reaching the yield strength

$n_{i}=\quad$ Number of results reported by $i^{\text {th }}$ laboratory

$p=$ Probability that datasets being compared are sourced from the same population as determined using a Student's T-Test assuming unequal variances. When less than 0.05 , differences between datasets are judged herein to be statistically significant.

$P_{L} \quad=\quad$ Number of laboratories

$r=$ Repeatability limit - the value below which the absolute difference between two individual test results obtained under repeatability conditions may be expected to occur with a probability of approximately 0.95 (95\%) (ASTM E177 ${ }^{[8]}$ )

$R=$ Reproducibility limit - the value below which the absolute difference between two test results obtained under reproducibility conditions may be expected to occur with a probability of approximately 0.95 (95\%) (ASTM E177 $\left.{ }^{[8]}\right)$

$s_{i}=$ Standard deviation of results reported by $i^{\text {th }}$ laboratory

$s_{i}{ }^{2}=$ Variance of results reported by $i^{\text {th }}$ laboratory

$s_{L}=$ Between laboratory standard deviation - the sample standard deviation attributable to differences of test result means among laboratories (ASTM E177 ${ }^{[8]}$ )

$s_{r}=$ Repeatability standard deviation - the standard deviation of test results obtained under repeatability conditions (ASTM E177 ${ }^{[8]}$ )

$S_{R}=$ Reproducibility standard deviation - the standard deviation of test results obtained under reproducibility conditions (ASTM E177 ${ }^{[8]}$ )

$s_{\bar{x}} \quad=\quad$ Standard deviation of laboratory means

$x=$ Individual test result - the value of a characteristic obtained by carrying out a specified test method (ASTM E177 ${ }^{[8]}$ )

$\bar{x}_{i}=$ Mean of results reported by $\mathrm{i}^{\text {th }}$ laboratory

$\overline{\bar{x}} \quad=\quad$ Mean of laboratory means 
APPENDIX B: RESULTS REPORTING FORMS AND QUESTIONNAIRE SENT TO LABORATORIES 


\section{Protocol, Results Reporting, and Questionnaire Inter-Laboratory Study for ASTM A1061}

\section{ILS Coordinator and point of contact for any ILS-related questions:}

Remy Lequesne, P.E., Ph.D.

University of Kansas

2150 Learned Hall

$1530 \mathrm{~W} 15^{\text {th }}$ Street

Lawrence, KS 66045

p. 785.864 .8649

e.rlequesne@ku.edu

\section{Shipment Contents:}

Five (5) samples of 0.500 in. diameter strand

Five (5) samples of 0.600 in. diameter strand

Test Protocol and Questionnaire

\section{Instructions:}

1) Conduct three (3) valid tensile tests on samples of each strand diameter - a total of six (6) valid tests are required ${ }^{1}$. Please report all values using a minimum of six (6) significant figures, if possible.

2) Each test must be run in accordance with ASTM A1061/A1061M-16 (attached). Relaxation properties (ASTM A1061 §9.4) do not need to be reported (this is outside of the scope of this study).

3) Complete the attached questionnaire to the best of your ability.

4) When complete, send the following to the ILS coordinator:

a. Completed questionnaire

b. Test results for each sample, including: yield strength, modulus, breaking strength, and elongation

c. All data collected during testing

d. A photo of the test setup

\footnotetext{
${ }^{1}$ If tests are invalid (due to strand failures within the grips or other causes), additional tests are required until three valid tests are obtained. For this reason, five samples of each strand diameter have been provided. If additional samples are needed, contact the ILS coordinator - additional samples can be shipped as necessary.
} 
Results Reporting 2,3

\begin{tabular}{|l|c|}
\hline Sample Number & 1 \\
\hline Strand diameter & $0.5 \mathrm{in}$. \\
\hline Gauge length & $3.5 \%$ \\
\hline Minimum specified elongation & $41300 \mathrm{lb}$ \\
\hline Minimum specified breaking strength & $37170 \mathrm{lb}$ \\
\hline Minimum specified yield strength & \\
\hline
\end{tabular}

1) Yield Strength (ASTM A1061 §9.1), choose 1.1 or 1.2:

1.1) Preload Method (ASTM A1061 §9.1.1):

\begin{tabular}{|l|l|}
\hline $\begin{array}{l}1.1(a) \text { Initial load at which the extensometer } \\
\text { was attached }\end{array}$ & \\
\hline $1.1(\mathrm{~b})$ Initial reading of the extensometer & \\
\hline $\begin{array}{l}1.1(\mathrm{c}) \text { Extensometer reading at which the } \\
\text { yield strength was recorded }\end{array}$ & \\
\hline $1.1(\mathrm{~d})$ Recorded yield strength & \\
\hline
\end{tabular}

1.2) Elastic Modulus Extrapolation Method (ASTM A1061 §9.1.2):

\section{2(a) Cross-sectional area of strand}

1.2(b) The range of data points used for the linear regression analysis in terms of minimum breaking strength

1.2(c) Calculated modulus of elasticity

1.2(d) Yield strength

2) Elongation (ASTM A1061 §9.2), choose 2.1 or 2.2:

2.1) Preload Method (ASTM A1061 §9.2.1):

\section{1(a) Initial load at which the extensometer was attached}

\footnotetext{
${ }^{2}$ Tests are to be conducted per A1061/A1061M-16. Report results using a minimum of 6 digits if possible.

3 Provide units for all reported values
} 


\section{1(b) Initial reading of the extensometer}

2.1(c) Final reading of the extensometer

2.1(d) Total percent elongation

2.2) Elongation After Measuring Yield Strength Method (ASTM A1061 §9.2.2):

\begin{tabular}{|l|l|}
\hline $\begin{array}{l}\text { 2.2(a) Initial distance between jaws after } \\
\text { measuring yield strength }\end{array}$ & \\
\hline 2.2 (b) Final distance between jaws & \\
\hline $\begin{array}{l}\text { 2.2(c) Incremental movement of test frame } \\
\text { crosshead or jaws }\end{array}$ & \\
\hline $2.2($ d) Percent change in jaw to jaw distance & \\
\hline 2.2(e) Total percent elongation & \\
\hline $\begin{array}{l}2.2(f) \text { Does recorded elongation correspond } \\
\text { to wire failure? }\end{array}$ & \\
\hline
\end{tabular}

3) Breaking Strength:

\begin{tabular}{l} 
3(a) Breaking strength \\
\hline $\begin{array}{l}\text { 3(b) Distance between the fracture point and } \\
\text { the grips }\end{array}$ \\
3(c) Is the answer to 3(a) less than 0.25 in.? \\
\hline $\begin{array}{l}\text { 3(d) If yes to 3(c), is the recorded breaking } \\
\text { strength less than the specified minimum? }\end{array}$ \\
$\begin{array}{l}\text { 3(e) If yes to 3(c), is the yield strength less } \\
\text { than the specified minimum? }\end{array}$ \\
\hline $\begin{array}{l}\text { 3(f) If yes to 3(c), is the final elongation value } \\
\text { less than the specified minimum? }\end{array}$ \\
\hline $\begin{array}{l}\text { 3(g) If yes to 3(c), is there is any evidence of } \\
\text { specimen slipping out of the grips? }\end{array}$
\end{tabular}

If any responses to $3(\mathrm{~d})$ through $3(\mathrm{~g})$ are YES, the test is invalid. An additional test is required. Comments: 


\section{Personnel:}

\section{Questionnaire}

Q1) Name(s) of Laboratory Personnel Conducting Testing:

\section{Apparatus:}

Q2) When were the tensile testing machine and extensometers last calibrated?

Q3) Does the extensometer being used to measure yield strength qualify as Class B-1? See ASTM E3-11(2017), which is attached.

Q4) What is the gauge length of the extensometer?

Q5) What type of instrument is being used to measure elongation?

Q5.1) If a ruler is used, what is the precision of the ruler?

Q5.2) If an extensometer is used, does it qualify as Class D? See ASTM E3-11(2017), attached.

\section{Gripping device:}

Q6) What is the primary method of gripping used in the tensile testing machine?

a) Standard V-grips with serrated teeth (go to Q7)

b) Special grips with smooth, cylindrical grooves (go to Q8)

c) Other (go to Q9)

Q7) If 6(a) was selected:

7.1) What is used between the grooves and the test specimen?

7.2) What is the number of teeth per inch? 
Q8) If 6(b) was selected: are the strands or grips pre-treated prior to testing? How?

Q9) Please describe the devices used to grip the strand:

Q10) Are chucking devices, or post-tensioning anchorages, used as a secondary gripping device?

Q11) What is the (clear) distance between grips at the start of testing?

\section{Speed of testing: (Per A370-17)}

Q12) Is the speed of testing controlled by the crosshead displacement rate (e.g. in./min)?

Q12.1) If yes, what is the speed of testing from $1 / 2$ of the yield point up to the yield point?

Q12.2) If yes, what is the speed of testing from the yield point up to the ultimate load?

Q13) Is the testing machine equipped with a device to indicate the rate of loading (often in terms of stress/time)?

Q13.1) If yes, what is the speed of testing (in terms of $\mathrm{psi} / \mathrm{min}$ or similar)?

Additional Comments:

B - 6 
APPENDIX C: SAMPLE RESPONSE REPORTING FORM FROM LABORATORY 11

FOR SAMPLE 2

$\mathrm{C}-1$ 


\begin{tabular}{|l|c|}
\hline Sample Number & 2 \\
\hline Strand diameter & $0.375 \mathrm{in}$. \\
\hline Gauge length & $3.5 \%$ \\
\hline Minimum specified elongation & $23000 \mathrm{lb}$ \\
\hline Minimum specified breaking strength & $20700 \mathrm{lb}$ \\
\hline Minimum specified vield strength & 20 \\
\hline
\end{tabular}

1) Yield Strength (ASTM A1061 §9.1), choose 1.1 or 1.2:

1.1) Preload Method (ASTM A1061 \$9.1.1):

\begin{tabular}{|l|}
\hline $\begin{array}{l}1.1(a) \text { Initial load at which the extensometer } \\
\text { was attached }\end{array}$ \\
\hline $\begin{array}{l}1.1(b) \text { Initial reading of the extensometer } \\
\text { 1.1(c) Extensometer reading at which the } \\
\text { yield strength was recorded }\end{array}$ \\
\hline $1.1(d)$ Recorded yield strength
\end{tabular}

1.2) Elastic Modulus Extrapolation Method (ASTM A1061 §9.1.2):

\begin{tabular}{|l|c|}
\hline $1.2(a)$ Cross-sectional area of strand & 0858 \\
\hline $\begin{array}{l}\text { 1.2(b) The range of data points used for the } \\
\text { linear regression analysis in terms of } \\
\text { minimum breaking strength }\end{array}$ & 290 \\
\hline $1.2($ c) Calculated modulus of elasticity & 235 \\
\hline $1.2($ d) Yield strength & 29 \\
\hline
\end{tabular}

2) Elongation (ASTM A1061 §9.2), choose 2.1 or 2.2:

2.1) Preload Method (ASTM A1061 §9.2.1):

2.1(a) Initial load at which the extensometer was attached

2.1(b) Initial reading of the extensometer

2.1(c) Final reading of the extensometer 
2.1(d) Total percent elongation

2.2) Elongation After Measuring Yield Strength Method (ASTM A1061 §9.2.2):

\begin{tabular}{|l|l|}
\hline $\begin{array}{l}\text { 2.2(a) Initial distance between jaws after } \\
\text { measuring yield strength }\end{array}$ & \\
\hline 2.2(b) Final distance between jaws & \\
\hline $\begin{array}{l}\text { 2.2(c) Incremental movement of test frame } \\
\text { crosshead or jaws }\end{array}$ & \\
\hline 2.2 (d) Percent change in jaw to jaw distance & \\
\hline $2.2($ e) Total percent elongation & 5 \\
\hline $\begin{array}{l}2.2(f) \text { Does recorded elongation correspond } \\
\text { to wire failure? }\end{array}$ & 4 \\
\hline
\end{tabular}

3) Breaking Strength:

\begin{tabular}{|c|c|}
\hline 3(a) Breaking strength & 25820 \\
\hline $\begin{array}{l}\text { 3(b) Distance between the fracture point and } \\
\text { the grips }\end{array}$ & $\angle 0<6.1^{\prime \prime}$ \\
\hline $3(c)$ Is the answer to $3(a)$ less than 0.25 in.? & Y \\
\hline $\begin{array}{l}3(d) \text { If yes to } 3(c) \text {, is the recorded breaking } \\
\text { strength less than the specified minimum? }\end{array}$ & N \\
\hline $\begin{array}{l}3(\mathrm{e}) \text { If yes to } 3(\mathrm{c}) \text {, is the vield strength less } \\
\text { than the specified minimum? }\end{array}$ & $N$ \\
\hline $\begin{array}{l}3(f) \text { If yes to } 3(c) \text {, is the final elongation value } \\
\text { less than the specified minimum? }\end{array}$ & $N$ \\
\hline $\begin{array}{l}3(\mathrm{~g}) \text { If yes to } 3(\mathrm{c}), \text { is there is any evidence of } \\
\text { specimen slipping out of the grips? }\end{array}$ & $N$ \\
\hline
\end{tabular}

If any responses to $3(\mathrm{~d})$ through $3(\mathrm{~g})$ are YES, the test is invalid. An additional test is required.

Comments: 
APPENDIX D: EXCERPTS OF ASTM E691-18 DESCRIBING STATISTICAL METHODS OF ANALYSIS 
to serve as a familiarization procedure for those without sufficient experience with the method (see 9.3). The results of this pilot run also give the task group an indication of how well each laboratory will perform in terms of promptness and following the protocol. Laboratories with poor performance should be encouraged and helped to take corrective action.

13.2 All steps of the procedures described in this practice should be followed in detail to ensure that these directions are understood, and to disclose any weaknesses in the protocol or the test method.

\section{Full Scale Run}

\subsection{Material Preparation and Distribution:}

14.1.1 Sample Preparation and Labelling-Prepare enough of each material to supply at least $10 \%$ more than needed by the number of laboratories committed to the ILS. Label each test unit or test specimen with a letter for the material and a sequential number. Thus, for ten laboratories and two test results for each laboratory the test units for Material B would be numbered from B1 to B22, or, if five test specimens per test unit are required, the test specimens may be numbered B1 to B110.

14.1.2 Randomization-For each material independently, allocate the specified number of test units or test specimens to each laboratory, using a random number table, or a suitable computerized randomization based on random numbers. See Guide E1402 for a discussion of randomization.

14.1.3 Shipping-Ensure that the test units are packaged properly to arrive in the desired condition. When the material is sensitive to the conditions to which it is exposed (light, heat, humidity, etc.), place special directions for opening the package on a label outside the package. Clearly indicate the name of the person who has been designated as ILS supervisor at the laboratory on the address of each package. Follow each laboratory's instructions for ensuring prompt delivery of the package.

14.1.4 Follow-up-Once the test units have been shipped, the ILS coordinator should call each laboratory ILS supervisor within a week to ten days to confirm that all test units have arrived safely. If the task group has decided to intermingle test units from different materials in the order of testing, the testing should not start until all the test units have arrived at the laboratory so they can be tested in the specified order.

14.1.5 Replacement Sets of Test Units-As the ILS progresses, a laboratory may discover that the test method was not used properly on some test units. The laboratory ILS supervisor should discuss this with the ILS coordinator, who may send a replacement set of test units, replace the misused test units, or do nothing, as may seem desirable.

14.2 Checking Progress-From time to time, at intervals appropriate to the magnitude of the ILS, the coordinator should call each ILS supervisor to ascertain how the testing is progressing. By comparing the progress of all laboratories, the coordinator can determine whether some laboratories are lagging considerably behind the others and so advise these laboratories.

14.3 Data Inspection-The completed data sheets should be examined by the coordinator immediately upon receipt in order to detect unusual values or other deficiencies that should be questioned. Replacement sets of test units or of specific test units may be sent when there is missing or obviously erroneous data. The task group can decide later whether or not the additional data should be used in the estimation of the precision of the test method.

\section{CALCULATION AND DISPLAY OF STATISTICS}

\section{Calculation of the Statistics}

15.1 Overview-The analysis and treatment of the ILS test results have three purposes, to determine whether the collected data are adequately consistent to form the basis for a test method precision statement, to investigate and act on any data considered to be inconsistent, and to obtain the precision statistics on which the precision statement can be based. The statistical analysis of the data for estimates of the precision statistics is simply a one-way analysis of variance (within- and between-laboratories) carried out separately for each level (material). Since such an analysis can be invalidated by the presence of severe outliers, it is necessary to first examine the consistency of the data. Appendix X1 gives background theory on these procedures. The following paragraphs show, in terms of a numerical example, how the entire program is carried out:

15.1.1 The calculations are illustrated with test results from an ILS in which the concentration of glucose in serum (see Table 1) was measured at five different concentration levels by eight laboratories. Each laboratory obtained three test results at each concentration level. A second example of an ILS is given

TABLE 1 Glucose in Serum ILS Test Result Data

\begin{tabular}{|c|c|c|c|c|c|}
\hline \multirow{2}{*}{ Laboratory } & \multicolumn{5}{|c|}{ Material } \\
\hline & $A$ & $B$ & $C$ & $D$ & $E$ \\
\hline \multirow[t]{3}{*}{1} & 41.03 & 78.28 & 132.66 & 193.71 & 292.78 \\
\hline & 41.45 & 78.18 & 133.83 & 193.59 & 294.09 \\
\hline & 41.37 & 78.49 & 133.10 & 193.65 & 292.89 \\
\hline \multirow[t]{3}{*}{2} & 41.17 & 77.78 & 132.92 & 190.88 & 292.27 \\
\hline & 42.00 & 80.38 & 136.90 & 200.14 & 309.40 \\
\hline & 41.15 & 79.54 & 136.40 & 194.30 & 295.08 \\
\hline \multirow[t]{3}{*}{3} & 41.01 & 79.18 & 132.61 & 192.71 & 295.53 \\
\hline & 40.68 & 79.72 & 135.80 & 193.28 & 290.14 \\
\hline & 42.66 & 80.81 & 135.36 & 190.28 & 292.34 \\
\hline \multirow[t]{3}{*}{4} & 39.37 & 84.08 & 138.50 & 195.85 & 295.19 \\
\hline & 42.37 & 78.60 & 148.30 & 196.36 & 295.44 \\
\hline & 42.63 & 81.92 & 135.69 & 199.43 & 296.83 \\
\hline \multirow[t]{3}{*}{5} & 41.88 & 78.16 & 131.90 & 192.59 & 293.93 \\
\hline & 41.19 & 79.58 & 134.14 & 191.44 & 292.48 \\
\hline & 41.32 & 78.33 & 133.76 & 195.12 & 294.28 \\
\hline \multirow[t]{3}{*}{6} & 43.28 & 78.66 & 137.21 & 195.34 & 297.74 \\
\hline & 40.50 & 79.27 & 135.14 & 198.26 & 296.80 \\
\hline & 42.28 & 81.75 & 137.50 & 198.13 & 290.33 \\
\hline \multirow[t]{3}{*}{7} & 41.08 & 79.76 & 130.97 & 194.66 & 287.29 \\
\hline & 41.27 & 81.45 & 131.59 & 191.99 & 293.76 \\
\hline & 39.02 & 77.35 & 134.92 & 187.13 & 289.36 \\
\hline \multirow[t]{3}{*}{8} & 43.36 & 80.44 & 135.46 & 197.56 & 298.46 \\
\hline & 42.65 & 80.80 & 135.14 & 195.99 & 295.28 \\
\hline & 41.72 & 79.80 & 133.63 & 200.82 & 296.12 \\
\hline
\end{tabular}


in Appendix X2 for a test method measuring pentosans in wood pulp that involved seven laboratories and nine materials.

15.1.2 For extended calculations it is usually necessary to retain extra significant digits in order to ensure that statistically important information is not lost in calculation by rounding off too soon. As a general rule, retain at least two more digits in the averages than in the reported test results and at least three significant figures in the standard deviations.

15.1.3 While the calculations described in this section are arranged for use of a hand calculator, they also can be readily programmed for the computer. A spreadsheet can be easily adapted to these calculations, and Appendix X3 illustrates an example spreadsheet for the glucose in serum ILS.

15.2 Table of ILS Test Results-The test results received from the laboratories are usually best arranged in rows and columns as in Table 1. Each column contains the data obtained from all laboratories for one material, and each row contains the data from one laboratory for all materials. The test results from one laboratory on one material constitute a cell. Thus, the cell for Laboratory 2 and Material C contains the test results 132.92, 136.90 and 136.40. This cell is called C2, by material and laboratory. It helps in the interpretation of the data to arrange the materials in increasing order of the measured values.

15.3 Worksheets - Generally, it facilitates the calculations to prepare a separate calculation worksheet for each material, using Table 2 as a model but making appropriate changes for different numbers of laboratories, and test results per material. Enter the test result data for one material (from one column of Table 1) on a worksheet. Also enter the results of the following calculations for that material on the same worksheet, as illustrated in Table 2. Work on only one material at a time.
15.4 Cell Statistics:

15.4.1 Cell Average, $\bar{x}$-Calculate the cell average for each laboratory using the following equation:

$$
\bar{x}=\sum_{1}^{n} x / n
$$

where:

$\bar{x}=$ the average of the test results in one cell,

$x=$ the individual test results in one cell, and

$n=$ the number of test results in one cell.

Thus from Table 2 for Material C, Laboratory 2 (that is, for Cell C2):

$$
\bar{x}=\frac{(132.92+136.90+136.40)}{3}=135.407
$$

15.4.2 Cell Standard Deviation, $s$-Calculate the standard deviation of the test results in each cell using the following equation:

$$
s=\sqrt{\sum_{1}^{n}(x-\bar{x})^{2} /(n-1)}
$$

The symbols have the same meaning as for Eq 1. Thus for Cell C2:

$$
s=\sqrt{\frac{\left[(-2.487)^{2}+(1.493)^{2}+(0.994)^{2}\right]}{(3-1)}}=\sqrt{\frac{9.400448}{2}}=2.168
$$

While Eq 2 shows the underlying calculation of the cell standard deviation, inexpensive pocket calculators are available that calculate both the average and the standard deviation directly. Check to be sure the calculator uses $(n-1)$ as the

\begin{tabular}{|c|c|c|c|c|c|c|c|c|}
\hline \multirow{2}{*}{$\begin{array}{c}\text { Laboratory } \\
\text { Number }\end{array}$} & \multicolumn{3}{|c|}{ Test Results, $x$} & \multirow{2}{*}{$\bar{x}$} & \multirow{2}{*}{$s$} & \multirow{2}{*}{$d$} & \multirow{2}{*}{$h$} & \multirow{2}{*}{$k$} \\
\hline & 1 & 2 & 3 & & & & & \\
\hline 1 & 132.66 & 133.83 & 133.10 & 133.197 & 0.591 & -1.946 & -0.73 & 0.22 \\
\hline 2 & 132.92 & 136.90 & 136.40 & 135.407 & 2.168 & 0.264 & 0.10 & 0.79 \\
\hline 3 & 132.61 & 135.80 & 135.36 & 134.590 & 1.729 & -0.553 & -0.21 & 0.63 \\
\hline 4 & 138.50 & 148.30 & 135.69 & 140.830 & 6.620 & 5.687 & 2.14 & 2.41 \\
\hline 5 & 131.90 & 134.14 & 133.76 & 133.267 & 1.199 & -1.876 & -0.71 & 0.44 \\
\hline 6 & 137.21 & 135.14 & 137.50 & 136.617 & 1.287 & 1.474 & 0.55 & 0.47 \\
\hline 7 & 130.97 & 131.59 & 134.92 & 132.493 & 2.124 & -2.650 & -1.00 & 0.77 \\
\hline 8 & 135.46 & 135.14 & 133.63 & 134.743 & 0.977 & -0.400 & -0.15 & 0.36 \\
\hline
\end{tabular}
divisor in $\mathrm{Eq} 2$, not $n$, and has adequate precision of calculation.

TABLE 2 Interlaboratory Study Worksheet for Glucose in Serum Initial Preparation of Test Result Data for Material $C$

Average of cell averages, $\overline{\bar{x}}=135.1429$

Standard deviation of cell averages, $s_{\bar{x}}=2.6559$

Repeatability standard deviation, $s_{r}=2.7483$

Between-Laboratory standard deviation, $s_{L}=2.1298$

Reproducibility standard deviation, $s_{R}=3.4770$

\footnotetext{
where:

$x=$ individual test result (see 15.3),

$\bar{x}=$ cell average (see 15.4.1)

$s=$ cell standard deviation (see 15.4.2),

$\overline{\overline{\mathrm{x}}}=$ average of cell averages (see 15.5.1),

$d=$ cell deviation (see 15.5.2),

$s_{\bar{x}}=$ standard deviation of cell averages (see 15.5.3),

$s_{r}=$ repeatability standard deviation (see 15.6.1),

$s_{L}=$ between-laboratory standard deviation (see 15.6.2),

$s_{R}=$ reproducibility standard deviation (see 15.6.3),

$h=$ between-laboratory consistency (see 15.7.1), and

$k=$ within-laboratory consistency (see 15.7.2).
} 
15.5 Intermediate Statistics:

15.5.1 Average of the Cell Averages, $\overline{\bar{x}}$-Calculate the average of all the cell averages for the one material using Eq 3.

$$
\overline{\bar{x}}=\sum_{1}^{p} \bar{x} / p
$$

where:

$\overline{\bar{x}} \quad=$ the average of the cell averages for one material,

$\bar{x}=$ the individual cell averages, and

$p=$ the number of laboratories in the ILS.

Thus for Material C:

$$
\overline{\bar{x}}=\frac{1081.1432}{8}=135.1429
$$

15.5.2 Cell Deviation, $d$-For each laboratory calculate the cell deviation by subtracting the average of the cell averages from the cell average using the following equation:

$$
d=\bar{x}-\overline{\bar{x}}
$$

Thus for Cell C2:

$$
d=135.407-135.143=0.264
$$

15.5.3 Standard Deviation of the Cell Averages, $s_{\bar{x}}$ Calculate this statistic using the following equation:

$$
s_{\bar{x}}=\sqrt{\sum_{1}^{p} d^{2} /(p-1)}
$$

Thus for Material C:

$$
s_{\bar{x}}=\sqrt{\frac{49.376634}{(8-1)}}=\sqrt{7.053805}=2.6559
$$

15.6 Precision Statistics-While there are other precision statistics, introduced later in this practice, the fundamental precision statistics of the ILS are the repeatability standard deviation and the reproducibility standard deviation. The other statistics are calculated from these standard deviations.

15.6.1 Repeatability Standard Deviation, $s_{r}$-Calculate this statistic using the following equation:

$$
s_{r}=\sqrt{\sum_{1}^{p} s^{2} / p}
$$

where:

$s_{r}=$ the repeatability standard deviation,

$s=$ the cell standard deviation ( $p$ of them from Eq 2), and

$p=$ the number of laboratories.

TABLE 3 Glucose in Serum- $h^{A}$

\begin{tabular}{crrrrr}
\hline \multirow{2}{*}{ Laboratory } & \multicolumn{5}{c}{ Material } \\
\cline { 2 - 6 } & $\mathrm{A}$ & $\mathrm{B}$ & $\mathrm{C}$ & \multicolumn{1}{c}{$\mathrm{D}$} & \multicolumn{1}{c}{$\mathrm{E}$} \\
\hline 1 & -0.39 & -1.36 & -0.73 & -0.41 & -0.46 \\
2 & -0.13 & -0.45 & 0.10 & 0.15 & 1.64 \\
3 & -0.11 & 0.22 & -0.21 & -1.01 & -0.68 \\
4 & -0.10 & 1.85 & 2.14 & 0.96 & 0.49 \\
5 & -0.09 & -0.99 & -0.71 & -0.64 & -0.34 \\
6 & 0.83 & 0.21 & 0.55 & 0.97 & 0.17 \\
7 & -1.75 & -0.16 & -1.00 & -1.33 & -1.62 \\
8 & 1.75 & 0.67 & -0.15 & 1.31 & 0.79 \\
\hline
\end{tabular}

${ }^{A}$ Critical value $=2.15$.
TABLE 4 Glucose in Serum- $\boldsymbol{k}^{A}$

\begin{tabular}{cccccc}
\hline \multirow{2}{*}{ Laboratory } & \multicolumn{5}{c}{ Material } \\
\cline { 2 - 6 } & $\mathrm{A}$ & $\mathrm{B}$ & $\mathrm{C}$ & $\mathrm{D}$ & $\mathrm{E}$ \\
\hline 1 & 0.21 & 0.11 & 0.22 & 0.02 & 0.18 \\
2 & 0.46 & 0.89 & 0.79 & 1.78 & 2.33 \\
3 & 1.00 & 0.56 & 0.63 & 0.61 & 0.69 \\
4 & 1.70 & 1.85 & 2.41 & 0.74 & 0.22 \\
5 & 0.34 & 0.52 & 0.44 & 0.72 & 0.24 \\
6 & 1.32 & 1.09 & 0.47 & 0.63 & 1.03 \\
7 & 1.17 & 1.38 & 0.77 & 1.45 & 0.84 \\
8 & 0.77 & 0.34 & 0.36 & 0.94 & 0.42 \\
\hline
\end{tabular}

${ }^{A}$ Critical value $=2.06$.

Thus for Material C:

$$
s_{r}=\sqrt{\frac{60.425223}{8}}=\sqrt{7.553153}=2.7483
$$

15.6.2 Between Laboratory Variance, $s_{L}^{2}$, and Standard Deviation $s_{L}$-Calculate this variance and standard deviation using the following equations:

$$
\begin{gathered}
s_{L}^{2}=s_{\tilde{x}}^{2}-s_{r}^{2} / n \\
s_{L}=\sqrt{s_{L}^{2}}
\end{gathered}
$$

If $s_{L}^{2}$ is negative, set $s_{\mathrm{L}}^{2}=0$ and $\mathrm{s}_{L}=0$.

Thus for Material C:

$$
\begin{gathered}
s_{L}^{2}=2.6559^{2}-2.7483^{2} / 3=7.053805-2.517718=4.536087 \\
s_{L}=\sqrt{4.536087}=2.1298
\end{gathered}
$$

15.6.2.1 The data for Material A illustrate the case of negative estimate for $s_{L}^{2}$ (see Table 8 for the required statistics $s_{\overline{\mathrm{x}}}$ and $s_{r}$ for Material A).

Thus for Material A:

$$
\begin{gathered}
s_{L}^{2}=0.6061^{2}-1.0632^{2} / 3=-0.009441, \\
\text { set } s_{L}^{2}=0, \\
\text { and set } s_{L}=0 .
\end{gathered}
$$

Note 3-This situation may occur when the laboratories are in excellent agreement, in which case both $s_{\overline{\mathrm{x}}}{ }^{2}$ and $s_{r}{ }^{2} / n$ in Eq 7 tend to become estimates of the variance of laboratory averages, and their difference will fluctuate around zero, causing the estimate $s_{L}^{2}$ to take on negative values at times. Because variances cannot be negative (being proportional to a sum of squared deviations from an average), any negative estimate of the between laboratory variance must be set to zero.

15.6.3 Reproducibility Standard Deviation, $s_{R}$-Calculate this statistic using the following equation:

$$
s_{R}=\sqrt{s_{L}^{2}+s_{r}^{2}}
$$

Thus for Material C:

$$
s_{R}=\sqrt{4.536087+2.7483^{2}}=3.4770
$$

Thus for Material A:

$$
s_{R}=\sqrt{0+1.0632^{2}}=1.0632 \text {, thus } s_{R}=s_{r}
$$

15.7 Consistency Statistics, $h$ and $k$ :

15.7.1 For each cell, calculate a value of $h$ using the following equation:

$$
h=d / s_{\bar{x}}
$$


TABLE 5 Critical Values of $\boldsymbol{h}$ and $\boldsymbol{k}$ at the $0.5 \%$ Significance Level

\begin{tabular}{|c|c|c|c|c|c|c|c|c|c|c|}
\hline \multirow{2}{*}{$\begin{array}{c}\text { Critical } \\
\text { value of } \\
h\end{array}$} & \multirow{2}{*}{$\begin{array}{c}\text { Number } \\
\text { of labs } \\
p\end{array}$} & \multicolumn{9}{|c|}{$\begin{array}{c}\text { Critical values of } k \\
\text { Number of replicates per lab, } n\end{array}$} \\
\hline & & 2 & 3 & 4 & 5 & 6 & 7 & 8 & 9 & 10 \\
\hline 1.15 & 3 & 1.72 & 1.67 & 1.61 & 1.56 & 1.52 & 1.49 & 1.47 & 1.44 & 1.42 \\
\hline 1.49 & 4 & 1.95 & 1.82 & 1.73 & 1.66 & 1.60 & 1.56 & 1.53 & 1.50 & 1.47 \\
\hline 1.74 & 5 & 2.11 & 1.92 & 1.79 & 1.71 & 1.65 & 1.60 & 1.56 & 1.53 & 1.50 \\
\hline 1.92 & 6 & 2.22 & 1.98 & 1.84 & 1.75 & 1.68 & 1.63 & 1.59 & 1.55 & 1.52 \\
\hline 2.05 & 7 & 2.30 & 2.03 & 1.87 & 1.77 & 1.70 & 1.65 & 1.60 & 1.57 & 1.54 \\
\hline 2.15 & 8 & 2.36 & 2.06 & 1.90 & 1.79 & 1.72 & 1.66 & 1.62 & 1.58 & 1.55 \\
\hline 2.23 & 9 & 2.41 & 2.09 & 1.92 & 1.81 & 1.73 & 1.67 & 1.62 & 1.59 & 1.56 \\
\hline 2.29 & 10 & 2.45 & 2.11 & 1.93 & 1.82 & 1.74 & 1.68 & 1.63 & 1.59 & 1.56 \\
\hline 2.34 & 11 & 2.49 & 2.13 & 1.94 & 1.83 & 1.75 & 1.69 & 1.64 & 1.60 & 1.57 \\
\hline 2.38 & 12 & 2.51 & 2.14 & 1.96 & 1.84 & 1.76 & 1.69 & 1.64 & 1.60 & 1.57 \\
\hline 2.41 & 13 & 2.54 & 2.15 & 1.96 & 1.84 & 1.76 & 1.70 & 1.65 & 1.61 & 1.58 \\
\hline 2.44 & 14 & 2.56 & 2.16 & 1.97 & 1.85 & 1.77 & 1.70 & 1.65 & 1.61 & 1.58 \\
\hline 2.47 & 15 & 2.57 & 2.17 & 1.98 & 1.86 & 1.77 & 1.71 & 1.66 & 1.62 & 1.58 \\
\hline 2.49 & 16 & 2.59 & 2.18 & 1.98 & 1.86 & 1.77 & 1.71 & 1.66 & 1.62 & 1.58 \\
\hline 2.51 & 17 & 2.60 & 2.19 & 1.99 & 1.86 & 1.78 & 1.71 & 1.66 & 1.62 & 1.59 \\
\hline 2.53 & 18 & 2.61 & 2.20 & 1.99 & 1.87 & 1.78 & 1.72 & 1.66 & 1.62 & 1.59 \\
\hline 2.54 & 19 & 2.62 & 2.20 & 2.00 & 1.87 & 1.78 & 1.72 & 1.67 & 1.62 & 1.59 \\
\hline 2.56 & 20 & 2.63 & 2.21 & 2.00 & 1.87 & 1.79 & 1.72 & 1.67 & 1.63 & 1.59 \\
\hline 2.57 & 21 & 2.64 & 2.21 & 2.00 & 1.88 & 1.79 & 1.72 & 1.67 & 1.63 & 1.59 \\
\hline 2.58 & 22 & 2.65 & 2.21 & 2.01 & 1.88 & 1.79 & 1.72 & 1.67 & 1.63 & 1.59 \\
\hline 2.59 & 23 & 2.66 & 2.22 & 2.01 & 1.88 & 1.79 & 1.72 & 1.67 & 1.63 & 1.59 \\
\hline 2.60 & 24 & 2.66 & 2.22 & 2.01 & 1.88 & 1.79 & 1.73 & 1.67 & 1.63 & 1.60 \\
\hline 2.61 & 25 & 2.67 & 2.23 & 2.01 & 1.88 & 1.79 & 1.73 & 1.67 & 1.63 & 1.60 \\
\hline 2.62 & 26 & 2.67 & 2.23 & 2.02 & 1.89 & 1.80 & 1.73 & 1.68 & 1.63 & 1.60 \\
\hline 2.62 & 27 & 2.68 & 2.23 & 2.02 & 1.89 & 1.80 & 1.73 & 1.68 & 1.63 & 1.60 \\
\hline 2.63 & 28 & 2.68 & 2.23 & 2.02 & 1.89 & 1.80 & 1.73 & 1.68 & 1.63 & 1.60 \\
\hline 2.64 & 29 & 2.69 & 2.24 & 2.02 & 1.89 & 1.80 & 1.73 & 1.68 & 1.64 & 1.60 \\
\hline 2.64 & 30 & 2.69 & 2.24 & 2.02 & 1.89 & 1.80 & 1.73 & 1.68 & 1.64 & 1.60 \\
\hline Secti & 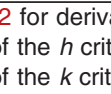 & 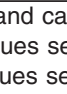 & & & & & & & & \\
\hline
\end{tabular}

TABLE 6 Glucose in Serum- $h^{A, B}$

\begin{tabular}{crrrrr}
\hline \multirow{2}{*}{ Laboratory } & \multicolumn{5}{c}{ Material } \\
\cline { 2 - 6 } & $\mathrm{A}$ & $\mathrm{B}$ & $\mathrm{C}$ & \multicolumn{1}{c}{$\mathrm{D}$} & \multicolumn{1}{c}{$\mathrm{E}$} \\
\hline 1 & -0.39 & -1.36 & -0.88 & -0.41 & -0.46 \\
2 & -0.13 & -0.45 & 0.39 & 0.15 & 1.64 \\
3 & -0.11 & 0.22 & -0.08 & -1.01 & -0.68 \\
4 & -0.10 & 1.85 & 1.59 & 0.96 & 0.49 \\
5 & -0.09 & -0.99 & -0.84 & -0.64 & -0.34 \\
6 & 0.83 & 0.21 & 1.09 & 0.97 & 0.17 \\
7 & -1.75 & -0.16 & -1.28 & -1.33 & -1.62 \\
8 & 1.75 & 0.67 & 0.01 & 1.31 & 0.79 \\
\hline
\end{tabular}

${ }^{A}$ Recalculated values after correcting Cell C4 (see 20.1.4 and 20.1.5).

${ }^{B}$ Critical value $=2.15$.

where:

$h=$ the between-laboratory consistency statistic,

$d=$ the cell deviation (that is, the deviation of the cell average from the average of the cell averages, from 15.5.2), and

$s_{\bar{x}}=$ the standard deviation of the cell averages (from 15.5.3).

Thus for Cell C2:
TABLE 7 Glucose in Serum- $\boldsymbol{k}^{A, B}$

\begin{tabular}{cccccc}
\hline \multirow{2}{*}{ Laboratory } & \multicolumn{5}{c}{ Material } \\
\cline { 2 - 6 } & $\mathrm{A}$ & $\mathrm{B}$ & $\mathrm{C}$ & $\mathrm{D}$ & $\mathrm{E}$ \\
\hline 1 & 0.21 & 0.11 & 0.38 & 0.02 & 0.18 \\
2 & 0.46 & 0.89 & 1.40 & 1.78 & 2.33 \\
3 & 1.00 & 0.56 & 1.12 & 0.61 & 0.69 \\
4 & 1.70 & 1.85 & 1.02 & 0.74 & 0.22 \\
5 & 0.34 & 0.52 & 0.78 & 0.72 & 0.24 \\
6 & 1.32 & 1.09 & 0.83 & 0.63 & 1.03 \\
7 & 1.17 & 1.38 & 1.38 & 1.45 & 0.84 \\
8 & 0.77 & 0.34 & 0.63 & 0.94 & 0.42 \\
\hline
\end{tabular}

${ }^{A}$ Recalculated values after correcting Cell C4 (see 20.1.4 and 20.1.5).

${ }^{B}$ Critical value $=2.06$.

$$
h=\frac{0.264}{2.6559}=0.10
$$

Retain two decimal places in the computed values of $h$.

15.7.2 For each cell, use the following equation to calculate a value of $k$.

$$
k=s / s_{r}
$$




\section{TABLE 8 Glucose in Serum-Precision Statistics}

Note 1 -This table (with the column for $s_{\bar{x}}$ omitted) is a useful format for the presentation of the precision of a test method as required by Section A21 of the Form and Style of ASTM Standards.

\begin{tabular}{crrrrrr}
\hline $\begin{array}{c}\text { Mate- } \\
\text { rial }\end{array}$ & $\bar{x}$ & $s_{\bar{x}}$ & $s_{r}$ & $s_{R}$ & $r$ & $R$ \\
\hline A & 41.5183 & 0.6061 & 1.0632 & 1.0632 & 2.98 & 2.98 \\
B & 79.6796 & 1.0027 & 1.4949 & 1.5796 & 4.19 & 4.42 \\
C & 134.7264 & 1.7397 & 1.5434 & 2.1482 & 4.33 & 6.02 \\
D & 194.7170 & 2.5950 & 2.6251 & 3.3657 & 7.35 & 9.42 \\
E & 294.4920 & 2.6931 & 3.9350 & 4.1923 & 11.02 & 11.74 \\
\hline
\end{tabular}

where:

$k=$ the within-laboratory consistency statistic,

$s \quad=$ the cell standard deviation for one laboratory (from 15.4.2), and

$s_{r}=$ the repeatability standard deviation of the material (from 15.6.1).

Thus for Cell C2:

$$
k=\frac{2.168}{2.7483}=0.79
$$

Retain two decimal places in the computed values of $k$.
15.8 Other Materials-Repeat the steps described in 15.4 through 15.7 for each material, entering the calculation results on separate worksheets.

\section{Tabular and Graphical Display of Statistics}

16.1 Material Order-It is often useful to arrange the worksheets in order of increasing values of $\overline{\bar{x}}$, the material averages. This order may facilitate interpretation.

16.2 Tables-From the Table 2 results for each material, prepare tables of $h$ and $k$ as shown in Table 3 and Table 4 for the glucose in serum example.

16.3 Graphs-Prepare bar graphs for $h$ and $k$ with materials grouped by laboratory as in Fig. 1 and Fig. 2, respectively. Arrange the laboratories and materials within and between each grouping in the same order as used in Table 1 . Thus the materials will be arranged in order of increasing $x$ from left to right, and the laboratories in order of laboratory code number.

\section{DATA CONSISTENCY}

\section{Flagging Inconsistent Results}

17.1 Critical Values of the Consistency Statistics-Table 5 lists critical values of the $h$ and $k$ consistency statistics at the $0.5 \%$ significance level. The critical values for $h$ (first column)

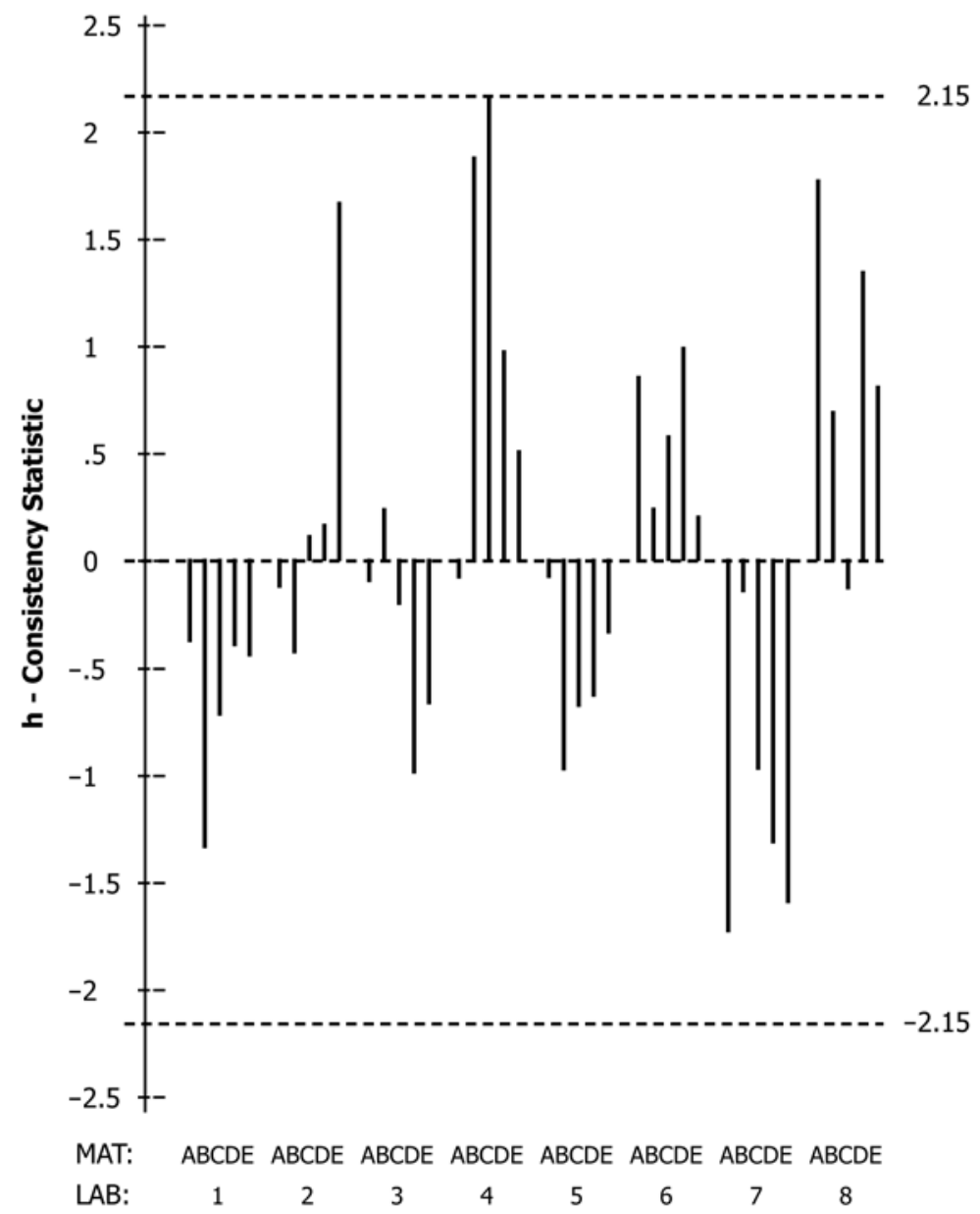

FIG. 1 Glucose in Serum: $h$-Materials within Laboratories 


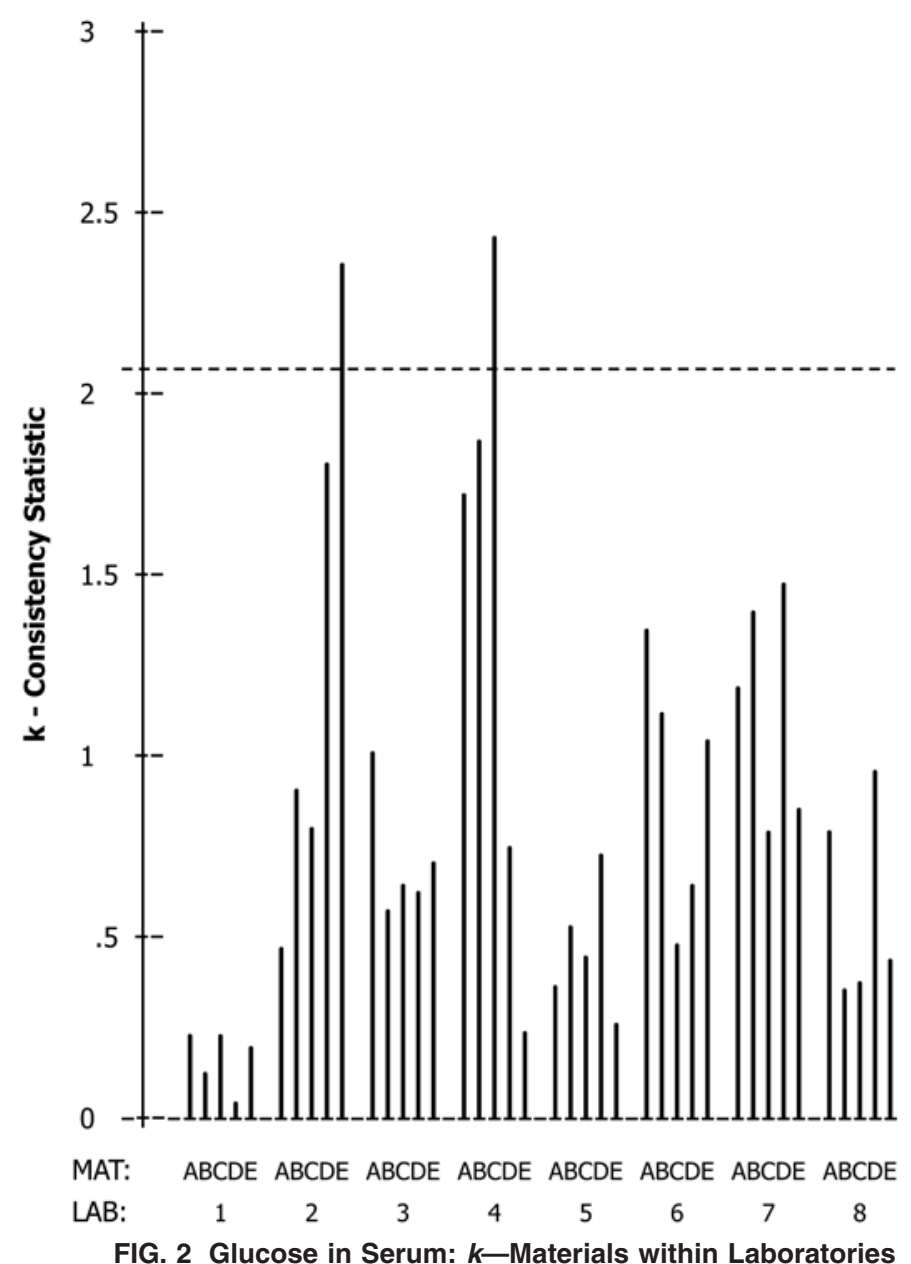

depend on the number of laboratories ( $p$, second column) participating in the ILS and the critical values for $k$ (columns headed 2 through 10) depend both on the number of laboratories $(p)$ and on the number of replicate test results $(n)$ per laboratory per material. The $0.5 \%$ level was chosen based on the judgment and experience that the $1.0 \%$ resulted in too many cells being flagged and the $0.1 \%$ level in too few. For further discussion see Appendix X1.

17.1.1 Obtain from Table 5 the appropriate critical values. For the glucose in serum example, the respective critical $h$ and $k$ values are 2.15 and 2.06. In Table 3 and Table 4 circle those values that exceed the critical values and underline those values that approach the critical values. On Fig. 1, draw horizontal lines for positive and negative values of $h$. On Fig. 2 , draw a horizontal line for $k$.

17.1.2 The $h$ and $k$ graphs and the marked tables give a picture of the overall character of the variability of the test method as well as singling out particular laboratories or cells that should be investigated.

17.2 Plots by Laboratory - In order to evaluate the differences between laboratories, use the following guidelines.

17.2.1 $h$ Graph-There are three general patterns in these plots. In one, all laboratories have both positive and negative $h$ values among the materials. In the second, the individual laboratories tend to be either positive or negative for all materials and the number of negative laboratories equals the number of positive laboratories, more or less. Neither of these patterns is unusual or requires investigation, although they may tell something about the nature of the test method variability. In the third pattern, one laboratory, with all $h$ values positive (or negative), is opposed to all the other laboratories, with substantially all the $h$ values negative (or positive). Such a pattern calls for an investigation of that laboratory.

17.2.1.1 Another kind of pattern to look for occurs within one laboratory, in which the $h$ values for low property levels are of one sign, and for high property levels are of the opposite sign. If the values are extreme, this behavior should be investigated.

17.2.2 $k$ Graph-Here the primary pattern to look for is that of one laboratory having large $k$ values (or very small $k$ values) for all or most of the materials. High $k$ values represent within-laboratory imprecision. Very small $k$ values may indicate a very insensitive measurement scale or other measurement problem.

\section{Investigation}

18.1 Clerical and Sampling Errors-Examine the laboratory report for each flagged cell. Try to locate where each test result in the flagged cell begins to deviate from the others. Is it 
in the original observations? Are the data rounded prematurely? Are the calculations correct? Then, look for signs of mislabeling of test units such that the test result for one material was reported as belonging to another material. Check these errors with the laboratories: do not assume them to be so.

\subsection{Procedural Errors:}

18.2.1 Study the laboratory reports again looking for deviations from either the test method or the protocol. For instance, variations in the number of significant digits reported in the test results may be a sign of incorrect rounding, or that the equipment in one laboratory is different from the rest. Also, study the event log for special comments relating to the flagged cells.

\section{Task Group Actions}

19.1 General-If the investigation disclosed no clerical, sampling or procedural errors, the unusual data should be retained, and the precision statistics based on them should be published. If, on the other hand, a cause was found during the investigation, the task group has several options to consider. If the laboratory clearly and seriously deviated from the test method, the test results for that laboratory must be removed from the ILS calculations. However, despite the danger of the recalcitrant laboratory having prior knowledge, it may be appropriate to ask the laboratory to retest one or more materials following the correct procedure, and then include the new set of test results in the ILS calculations. Of course, if the data have changed, recalculation of the $h$ and $k$ values must be made and the data consistency examined again.

19.2 Exception-When a large number of laboratories have participated in the ILS and no cause for some unusual cell values have been found during the investigation, it may be appropriate to delete a cell from the study if all of the other laboratories are in substantial agreement. The number of laboratories that can be considered large enough to support deletion of data without an identified cause cannot be stated exactly. Any action which results in discarding more than five percent of the ILS data likely will lead to the presentation of precision data that the test method cannot deliver in routine application.

19.3 Test Method Vagueness-One of the important things to be on the alert for during a laboratory investigation is for vagueness in the test method standard that permits a wide range of interpretation leading to loss of precision. Particular elements to check are lack of measurement tolerances, diversity of apparatus and insufficient direction for operator technique. These problems can be the basis for a revision of the standard.

\section{Glucose ILS Consistency}

20.1 Glucose in Serum-The ILS is described in 15.1.1.

20.1.1 $h$ Statistic - The overall impression given by Fig. 1 and Table 3 is one of reasonable consistency for variation among laboratories. Only Laboratory 4 stands out with large values for Materials B and C.

20.1.2 k Statistic-Laboratories 2 and 4 stand out in Fig. 2 and Table 4.

20.1.3 Cells and Test Results-Cells C4 and E2 should be investigated. A look at Table 1 reveals that the second test results of 148.30 in C4 and of 309.40 in E2 are the particular values to be investigated.

20.1.4 Action-If the data from Laboratory 4 were typed, the result 148.30 in Cell C4 could have been a typographical error. We have no way of knowing this today, many years after this study was made. We will suppose, however, that the task group did indeed call the laboratory and did find that the number should have been 138.30. However, let us suppose that for Cell E2 the task group could find no explanation of the apparently high value of 309.40. In such a case they should retain the value.

20.1.5 Recalculation-Table 6 and Table 7 show the recalculated consistency statistics resulting from correcting Cell C4.

\section{PRECISION STATEMENT INFORMATION}

\section{Repeatability and Reproducibility}

21.1 General-Once the task group has concluded which cells are sufficiently inconsistent to require action, and action has been taken, the statistics of 15.4 through 15.6 are recalculated (see also 20.1.5). Using the corrected statistics, calculate for each material the $95 \%$ repeatability and reproducibility limits (see Practice E177) according to the following Eq 12 and Eq 13:

$$
\begin{aligned}
r & =2.8 s_{r} \\
R & =2.8 s_{R}
\end{aligned}
$$

21.2 Prepare a table for the corrected precision statistics as shown in Table 8.

\subsection{Variation of Precision Statistics with Property Level:}

21.3.1 Quite often the values of $s_{r}$ and $s_{R}$ will be found to vary with the values of the property level $\overline{\bar{x}}$. This type of response can be seen in Fig. 3, that is based on Table 8. The manner in which the statistics vary with the property level should be shown in presenting the precision information in the precision statement of the test method. The statistician should recommend the most appropriate relationship to present, using Practice E177 as a guide.

21.4 Precision Statement-Table 8 (with the column for $s_{\bar{x}}$ omitted) is a useful format for the presentation of the precision statement of the test method as required by Section A21 of the "Form and Style of ASTM Standards (Bluebook)." Having obtained the required precision information in accordance with this practice, the final form of the precision statement may be prepared in accordance with Practice E177.

21.5 Conclusion-The precision statistics obtained by an ILS such as described in this practice must not be treated as exact mathematical quantities which are applicable to all circumstances and uses. The small number of laboratories and of materials included in the usual ILS guarantees that there will be times when differences greater than predicted by the ILS results will arise, sometimes with considerably greater or smaller frequency than the $95 \%$ probability limit would imply. The repeatability limit and the reproducibility limit should be considered as general guides, and the associated probability of $95 \%$ as only a rough indicator of what can be expected. If more precise information is needed in specific circumstances, 


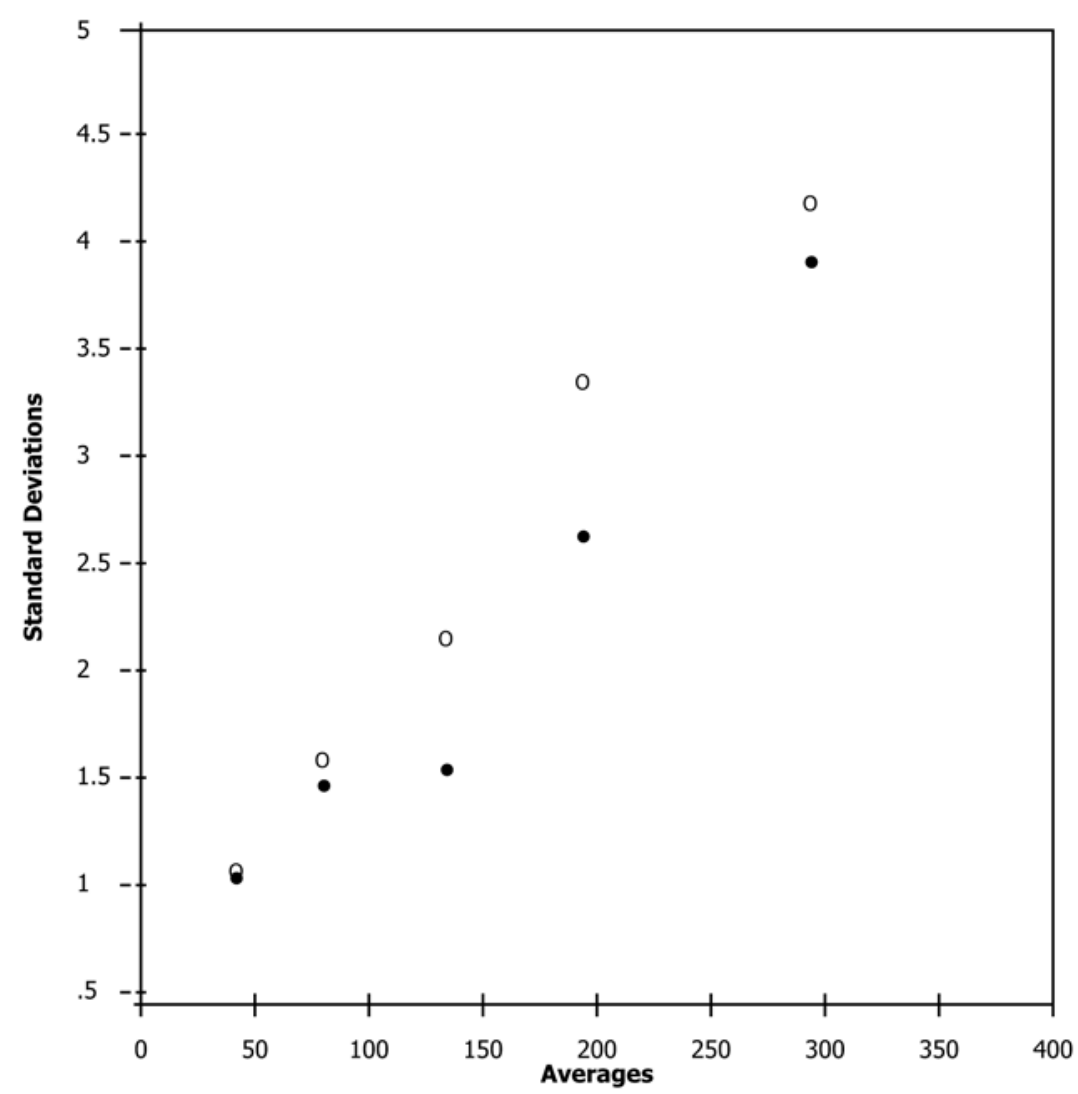

FIG. 3 Glucose in Serum: Standard Deviations of Reproducibility (0) and Repeatability (๑) Versus Average

those laboratories directly involved in a material comparison must conduct interlaboratory studies specifically aimed at the material of interest. ${ }^{4}$

\section{Keywords}

22.1 precision; repeatability; reproducibility; repeatability limit; reproducibility limit

${ }^{4}$ Following the ASTM Research Report format guide, prepare a research report on the ILS to be filed at ASTM Headquarters.

\section{APPENDIXES}

\section{(Nonmandatory Information)}

\section{X1. THEORETICAL CONSIDERATIONS}

\section{X1.1 Underlying Assumptions of ILS}

X1.1.1 Within-Laboratory Variability-The cell standard deviation is a measure of the within-laboratory variability of each individual laboratory. All laboratories are assumed to have essentially the same level of variability when following the specified repeatability conditions. This assumption is not always fulfilled. However, the shorter the period of time in which the test results for a particular material are to be obtained by the laboratories the more likely the validity of this assumption. Therefore, the laboratory cell variances can generally be pooled by averaging the squares of the cell standard deviations. The square root of this average within-laboratory variance is the repeatability standard deviation $s_{r}$.

\section{X1.1.2 Between-Laboratory Variability:}

X1.1.2.1 Variability of Laboratory Means-The test results obtained on a particular material at any particular laboratory are considered part of a population having a normal distribution with a standard deviation equal to the repeatability standard deviation but with a mean that may be different for each laboratory. The laboratory means are also assumed to vary according to a normal distribution, whose mean is estimated by the average of all ILS test results for a given material, and whose standard deviation is designated by $s_{L}$. (The effect of a single outlying laboratory on this assumption will be less if there are enough laboratories.) For the ILS calculations, $s_{L}$ is 
APPENDIX E: DRAFT OF ASTM REPORT JUSTIFYING THE PROPOSED PRECISION

STATEMENT

$\mathrm{E}-1$ 
[Date RR \# approved - ASTM to assign]

Committee A01 on Steel, Stainless Steel and Related Alloys Subcommittee A01.05 on Steel Reinforcement

Research Report: [RR \# - ASTM to assign]

\section{Interlaboratory Study to Establish Precision Statements for} ASTM A1061/A106M, Standard Test Methods for

Testing Multi-Wire Steel Prestressing Strand

Technical contacts:

Enrico Lucon

National Institute of Standards and Technology

Boulder, Colorado 80305, USA

enrico.lucon@nist.gov

Rémy Lequesne, William Collins, and David Darwin

The University of Kansas

Lawrence, Kansas 66045

rlequesne@,ku.edu; william.collins@,ku.edu; daved@,ku.edu

ASTM International

100 Barr Harbor Drive

West Conshohocken, PA 19428-2959 


\section{Introduction:}

Seven-wire low-relaxation strand conforming to ASTM A416/A416M-17 is the most widely used type of strand in prestressed concrete applications in the United States. Qualification of this type of strand for use in production requires that samples are tested in tension according to ASTM A1061/A1061M-16 to determine the yield strength, elongation, and breaking strength (though not explicitly required by ASTM A1061/A1061M-16, results from tests conducted according to the method can also be used to determine elastic modulus).

The ASTM A1061/A1061M-16 standard does not have a Precision and Bias statement. Absence of a Precision and Bias statement makes it difficult to resolve conflicts in the event that qualification testing conducted on samples from the same strand at different laboratories (e.g. at a supplier and at a commercial testing laboratory) report conflicting results.

Due to this absence, the industry has identified the pressing need for a systematic study of inter-laboratory and intra-laboratory variation in results from tests of strand conducted in accordance with ASTM A1061/A1061M-16. The results from the interlaboratory study (ILS) described herein will be used in accordance with ASTM E177-14 to develop a Precision and Bias statement for adoption in the next version of ASTM A1061/A1061M.

\section{Test Method:}

The Test Method used for this ILS is A1061/A1061M-16. To obtain a copy of A1061/A106M-16, go to ASTM's website, www.astm.org, or contact ASTM Customer Service by phone at 610-832-9585 (8:30 a.m. - 4:30 p.m. Eastern U.S. Standard Time, Monday through Friday) or by email at service@astm.org.

\section{Participating Laboratories:}

The following laboratories participated in this interlaboratory study:

\section{Bekaert Corporation}

Van Buren, AR

Caltrans - Structural Material Testing Branch Sacramento, CA

\section{CTLGroup}

Skokie, IL

\section{Georgia Department of Transportation}

Forest Park, GA

\section{Illinois Department of Transportation - Central Bureau of Materials} Springfield, IL

\section{Insteel Wire Products}

Sanderson, FL 
Insteel Wire Products

Gallatin, TN

Insteel Wire Products

Houston, TX

Missouri Department of Transportation - Central Laboratory

Jefferson City, MO

Montana Department of Transportation - Aggregate Unit Helena, MT

Nevada Department of Transportation Carson City, NV

Pennsylvania Department of Transportation Harrisburg, PA

Sumiden Wire Products

Dayton, TX

Sumiden Wire Products

Dickson, TN

Sumiden Wire Products

Stockton, CA

Tennessee Department of Transportation

Nashville, TN

Texas Department of Transportation

Austin, TX

Wiss, Janney, Elstner Associates, Inc.

Northbrook, IL

Wire Mesh Corporation

St. Matthews, SC

\section{Description of Samples:}

The ILS focused on Grade 270 low-relaxation seven-wire strand, conforming to ASTM A416/A416M17. Grade 270 strand is the dominant strand in the marketplace. Qualification of this type of strand for use in production requires that samples are tested in tension according to ASTM A1061/A1061M-16 to determine the yield strength, elongation, and breaking strength (though not explicitly required by ASTM A1061/A1061M-16, results from tests conducted according to the method can also be used to determine elastic modulus).

Discussions with strand suppliers and precast concrete manufacturers indicated that strand diameters of 0.5 and 0.6 in. are the most commonly used in structural applications, making up approximately $85 \%$ of the market share. The 0.375 in. diameter strand is commonly used in commercial precast applications and is the third most widely used strand size in the U.S. 
Prestressing 7-wire strand samples of three diameters ( 0.375 in., 0.5 in., and 0.6 in.) were supplied for use in the ILS by Sumiden Wire Products Corporation (0.375 in.), WMC - Wire Mesh Corporation (0.5 in.), and Insteel Wire Products Company (0.6 in.). Each supplier was asked to provide all the material to produce the test samples for a given diameter from a single heat, in order to minimize variability among samples.

Five samples of each strand diameter were supplied to each participating laboratory. Even though participants were asked to test 3 samples for each diameter strand, some laboratories actually tested 4 or 5 samples.

\section{Interlaboratory Study Instructions}

Each laboratory participating in the ILS was provided the test protocol, results reporting sheets, and a questionnaire, as documented in Annex A. Additionally, participants were provided copies of ASTM A370-17 (Standard Test Methods and Definitions for Mechanical Testing of Steel Products), ASTM A1061/A1061M, and ASTM E3-11(2017) (Standard Guide for Preparation of Metallographic Specimens).

The questionnaire and the reporting sheets requested detailed information on the test setup, methods used, and observations made during testing, and were prepared in accordance with ASTM E691-16 (Standard Practice for Conducting an Interlaboratory Study to Determine the Precision of a Test Method). The responses furnished by participants provided, in part, the basis for acceptance or rejection of submitted data.

\section{Description of Equipment/Apparatus ${ }^{1}$ :}

For information on the equipment/apparatus (gripping device) used by each laboratory, please see Annex B.

Four laboratories were not equipped with the grips required to test $0.375 \mathrm{in}$. diameter strands, and therefore only provided results for $0.5 \mathrm{in}$. and 0.6 in. diameter strands. Furthermore, some laboratories reported that they could not (or did not) quantify all four strand performance measures (yield strength, elongation, elastic modulus, and breaking strength). In most cases, the omitted parameter was elastic modulus. Annex $\mathrm{C}$ provides a list of the participating laboratories, along with the information concerning their capability to test the three diameter strands and to report the four strand performance measures.

\section{Data Report Forms:}

As already mentioned, each laboratory was provided with data reporting sheets for the collection of test results. Tables presenting the raw data provided by participants are provided in Annex D.

Please note: The laboratories have been randomly coded and cannot be identified herein.

\section{Statistical Analyses:}

The statistical analyses conducted on the data returned by the participating laboratories are detailed in Annex E.

\footnotetext{
${ }^{1}$ The equipment listed was used to develop a precision statement for A1061/A1061M-16. This listing is not an endorsement or certification by ASTM International.
} 


\section{Precision and Bias Statement:}

9.1 The precision of this test method is based on an interlaboratory study of ASTM A1061/A1061M, Standard Test Methods for Testing Multi-Wire Steel Prestressing Strand, that was conducted in 2018 and included 19 laboratories. Test samples were Grade 270 low-relaxation seven-wire strand of three different diameters (0.375 in., 0.5 in., and 0.6 in.). Every "test result" represents an individual determination, and all participants reported between 3 and 5 test results. Practice E691 was followed for the design and analysis of the data; the details are given in ASTM Research Report No. A01$\mathrm{XXXX}^{2}$

9.1.1 Repeatability $(r)$ - The difference between repetitive results obtained by the same operator in a given laboratory applying the same test method with the same apparatus under constant operating conditions on identical test material within short intervals of time would in the long run, in the normal and correct operation of the test method, exceed the following values only in one case in 20 .

9.1.1.1 Repeatability can be interpreted as the maximum difference between two results, obtained under repeatability conditions, that is accepted as plausible due to random causes under normal and correct operation of the test method.

9.1.1.2 Repeatability limits are listed in Tables $1-4$ below. 9.1.2 Reproducibility $(R)$ - The difference between two single and independent results obtained by different operators applying the same test method in different laboratories using different apparatus on identical test material would, in the long run, in the normal and correct operation of the test method, exceed the following values only in one case in 20.

9.1.2.1 Reproducibility can be interpreted as the maximum difference between two results, obtained under reproducibility conditions, that is accepted as plausible due to random causes under normal and correct operation of the test method.

9,1.2.2 Reproducibility limits are listed in Tables $1-4$ below.

9.1.3 The above terms (repeatability limit and reproducibility limit) are used as specified in Practice E 177.

9.1.4 Any judgment in accordance with statements 9.1.1 and 9.1.2 would have an approximate $95 \%$ probability of being correct.

${ }^{2}$ For a copy of the draft Research Report, please contact ResearchReports@astm.org (research report number assigned after balloting). 
Table 1. Precision statistics for yield strength (unit: lbf)

\begin{tabular}{|c|c|c|c|c|c|}
\hline \multirow{2}{*}{$\begin{array}{l}\text { Strand } \\
\text { Diameter } \\
\text { (in.) }\end{array}$} & Average $^{3}$ & $\begin{array}{l}\text { Repeatability } \\
\text { Standard } \\
\text { Deviation }\end{array}$ & $\begin{array}{c}\text { Reproducibility } \\
\text { Standard } \\
\text { Deviation }\end{array}$ & $\begin{array}{c}\text { Repeatability } \\
\text { Limit }\end{array}$ & $\begin{array}{l}\text { Reproducibility } \\
\text { Limit }\end{array}$ \\
\hline & $\overline{\mathbf{x}}$ & $s_{r}$ & $S_{R}$ & $r$ & $R$ \\
\hline 0.375 & 23086.9 & 208.77 & 304.94 & 584.57 & 853.84 \\
\hline 0.5 & 38791.7 & 222.74 & 350.21 & 623.67 & 980.59 \\
\hline 0.6 & 55784.7 & 397.33 & 615.66 & 1112.51 & 1723.85 \\
\hline
\end{tabular}

Table 2. Precision statistics for elongation (unit: \%)

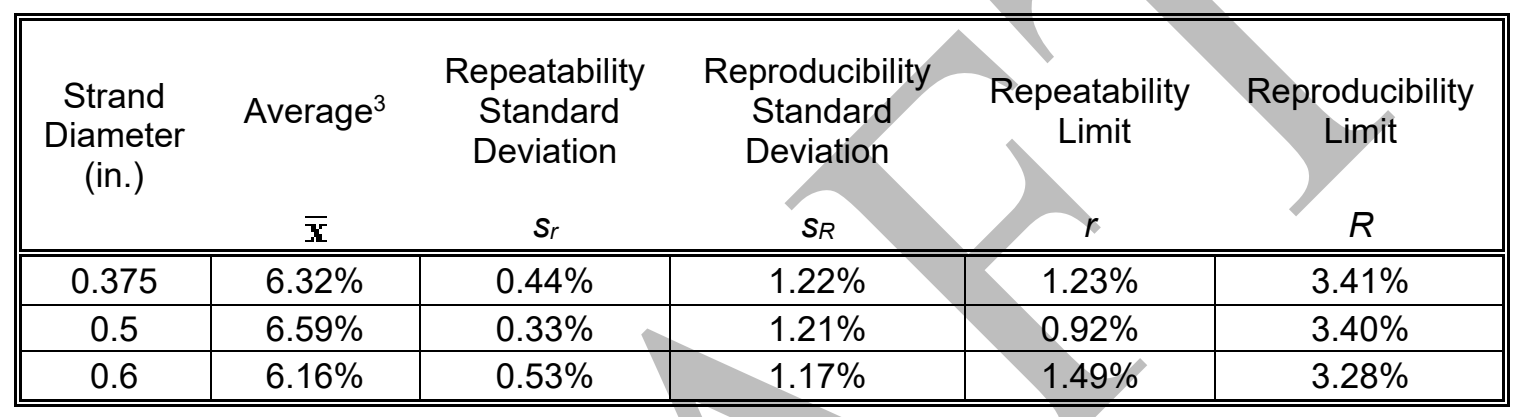

Table 3. Precision statistics for elastic modulus (unit: $10^{6} \mathrm{psi}$ )

\begin{tabular}{|c|c|c|c|c|c|}
\hline $\begin{array}{l}\text { Strand } \\
\text { Diameter } \\
\text { (in.) }\end{array}$ & $\begin{array}{c}\text { Average }^{3} \\
\overline{\mathbf{x}} \\
\end{array}$ & $\begin{array}{l}\text { epeatability } \\
\text { Standard } \\
\text { Deviation } \\
S_{r} \\
\end{array}$ & $\begin{array}{c}\text { Reproducibility } \\
\text { Standard } \\
\text { Deviation } \\
S_{R} \\
\end{array}$ & $\begin{array}{c}\text { Repeatability } \\
\text { Limit } \\
r \\
r\end{array}$ & $\begin{array}{c}\begin{array}{c}\text { Reproducibility } \\
\text { Limit }\end{array} \\
R \\
\end{array}$ \\
\hline 0.375 & 29.22 & 0.396 & 0.423 & 1.11 & 1.18 \\
\hline 0.5 & 29.62 & 0.820 & 0.943 & 2.30 & 2.64 \\
\hline 0.6 & 29.10 & 0.497 & 0.874 & 1.39 & 2.45 \\
\hline
\end{tabular}

Table 4. Precision statistics for breaking strength (unit: lbf)

\begin{tabular}{|c|c|c|c|c|c|}
\hline \multirow{2}{*}{$\begin{array}{l}\text { Strand } \\
\text { Diameter } \\
\text { (in.) }\end{array}$} & Average $^{3}$ & $\begin{array}{c}\text { Repeatability } \\
\text { Standard } \\
\text { Deviation }\end{array}$ & $\begin{array}{l}\text { Reproducibility } \\
\text { Standard } \\
\text { Deviation }\end{array}$ & $\begin{array}{c}\text { Repeatability } \\
\text { Limit }\end{array}$ & $\begin{array}{l}\text { Reproducibility } \\
\text { Limit }\end{array}$ \\
\hline & $\overline{\mathbf{x}}$ & $s_{r}$ & $S_{R}$ & $r$ & $R$ \\
\hline 0.375 & 25767.7 & 151.70 & 241.63 & "424.76 & "676.56 \\
\hline 0.5 & 43818.9 & 189.12 & 357.35 & 529.55 & 1000.58 \\
\hline 0.6 & 61966.9 & 235.67 & 452.60 & 659.87 & 1267.27 \\
\hline
\end{tabular}

\footnotetext{
${ }^{3}$ The average of the laboratories' calculated averages.
} 
9.2 Bias - At the time of the study, there was no accepted reference material suitable for determining the bias for this test method, therefore no statement on bias is made.

9.3 The precision statement was determined through statistical examination of 647 results (values of yield strength, elongation, elastic modulus, and breaking strength), from 19 laboratories, on 3 diameter strands ( $0.375 \mathrm{in}$., $0.5 \mathrm{in}$., and $0.6 \mathrm{in}$.). The valid results used for the establishment of the precision statement were 426 (65.8\% of the reported results).

9.4 To judge the equivalency of two test results, it is recommended to choose the material closest in characteristics to the test material.

ASTM International takes no position respecting the validity of any patent rights asserted in connection with any item mentioned in this research report. Users of this research report are expressly advised that determination of the validity of any such patent rights, and the risk of infringement of such rights, are entirely their own responsibility.

This research report is copyrighted by ASTM International, 100 Barr Harbor Drive, PO Box C700, West Conshohocken, PA 19428-2959, United States. Individual reprints (single or multiple copies) of this research report may be obtained by contacting ASTM at the above address or at 610-832-9585 (phone), 610-832-9555 (fax), or serviceastm.org (e-mail); or through the ASTM website (www.astm.org)

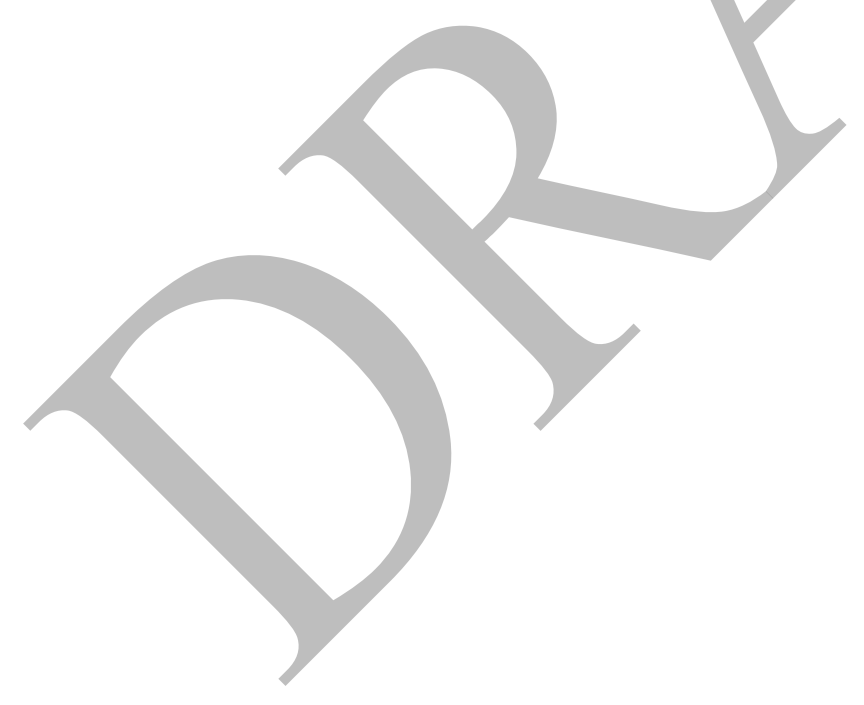




\title{
Annex A: Test Protocol, Results Reporting Forms, and Questionnaire
}

\section{ILS Coordinator and point of contact for any ILS-related questions:}

\author{
Rémy Lequesne \\ University of Kansas \\ 2150 Learned Hall \\ $1530 \mathrm{~W} 15^{\text {th }}$ Street \\ Lawrence, KS 66045 \\ p. 785.864.8649 \\ e. rlequesne@ku.edu
}

\section{Shipment Contents:}

Five (5) samples of 0.375 in. diameter strand

Five (5) samples of 0.500 in. diameter strand

Five (5) samples of 0.600 in. diameter strand

Test Protocol, Results Reporting Forms, and Questionnaire

\section{Instructions:}

1) Conduct three (3) valid tensile tests on samples of each strand diameter - a total of nine (9) valid tests are required ${ }^{1}$. Please report all values using a minimum of six (6) significant figures, if possible.

2) Each test must be run in accordance with ASTM A1061/A1061M-16 (attached). Relaxation properties (ASTM A1061 \$9.4) do not need to be reported (this is outside of the scope of this study).

3) Complete the attached questionnaire to the best of your ability.

4) When complete, send the following to the ILS coordinator:

a. Completed questionnaire

b. Test results for each sample (i.e.: yield strength, modulus, breaking strength, and elongation)

c. All data collected during testing.

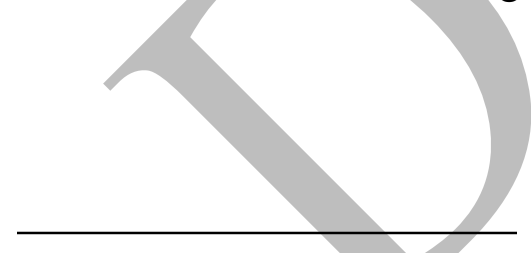

\footnotetext{
${ }^{1}$ If tests are invalid (due to strand failures within the grips or other causes), additional tests are required until three valid tests are obtained. For this reason, five samples of each strand diameter have been provided. If additional samples are needed, contact the ILS coordinator - additional samples can be shipped as necessary.
} 


\section{Results Reporting ${ }^{2,3}$}

\begin{tabular}{|l|c|}
\hline Sample Number & \\
\hline Strand diameter ${ }^{4}$ & $0.375 \mathrm{in}$. \\
\hline Gauge length & $3.5 \%$ \\
\hline Minimum specified elongation & $23000 \mathrm{lbf}$ \\
\hline Minimum specified breaking strength & $20700 \mathrm{lbf}$ \\
\hline Minimum specified yield strength & \\
\hline
\end{tabular}

1) Yield Strength (ASTM A1061 §9.1), choose 1.1 or 1.2:

1.1) Preload Method (ASTM A1061 §9.1.1):

1.1(a) Initial load at which the extensometer was attached

1.1(b) Initial reading of the extensometer

1.1(c) Extensometer reading at which the yield strength was recorded

1.1(d) Recorded yield strength

1.2) Elastic Modulus Extrapolation Method (ASTM A1061 §9.1.2):

\begin{tabular}{|l|l|}
\hline 1.2 (a) Cross-sectional area of strand & \\
\hline $\begin{array}{l}1.2(\mathrm{~b}) \text { The range of data points used for the } \\
\text { linear regression analysis in terms of } \\
\text { minimum breaking strength }\end{array}$ & \\
\hline $1.2(\mathrm{c})$ Calculated modulus of elasticity & \\
\hline $1.2(\mathrm{~d})$ Yield strength & \\
\hline
\end{tabular}

2) Elongation (ASTM A1061 §9.2), choose 2.1 or 2.2:

2.1) Preload Method (ASTM A1061 §9.2.1):

2.1(a) Initial load at which the extensometer was attached

2.1(b) Initial reading of the extensometer

\footnotetext{
${ }^{2}$ Tests are to be conducted per A1061/A1061M-16. Report results using a minimum of 6 digits if possible.

${ }^{3}$ Provide units for all reported values; $\quad{ }^{4}$ Separate sheets are provided for different diameter strands.
} 


\begin{tabular}{|l|l|}
\hline 2.1(c) Final reading of the extensometer & \\
\hline $2.1(\mathrm{~d})$ Total percent elongation & \\
\hline
\end{tabular}

2.2) Elongation After Measuring Yield Strength Method (ASTM A1061 §9.2.2):

\begin{tabular}{|l|l|}
\hline $\begin{array}{l}\text { 2.2(a) Initial distance between jaws after } \\
\text { measuring yield strength }\end{array}$ & \\
\hline 2.2(b) Final distance between jaws & \\
\hline $\begin{array}{l}\text { 2.2(c) Incremental movement of test frame } \\
\text { crosshead or jaws }\end{array}$ & \\
\hline 2.2(d) Percent change in jaw to jaw distance & \\
\hline 2.2(e) Total percent elongation & \\
\hline $\begin{array}{l}\text { 2.2(f) Does recorded elongation correspond to } \\
\text { wire failure? }\end{array}$ & \\
\hline
\end{tabular}

3) Breaking Strength:

\begin{tabular}{|l|l|}
\hline 3(a) Breaking strength \\
\hline $\begin{array}{l}\text { 3(b) Distance between the fracture point and } \\
\text { the grips }\end{array}$ \\
\hline 3(c) Is the answer to 3(b) less than 0.25 in.? & \\
\hline $\begin{array}{l}\text { 3(d) If yes to 3(c), is the recorded breaking } \\
\text { strength less than the specified minimum? }\end{array}$ & \\
\hline $\begin{array}{l}\text { 3(e) If yes to 3(c), is the yield strength less } \\
\text { than the specified minimum? }\end{array}$ & \\
\hline $\begin{array}{l}\text { 3(f) If yes to 3(c), is the final elongation } \\
\text { value less than the specified minimum? }\end{array}$ & \\
\hline $\begin{array}{l}\text { 3(g) If yes to 3(c), is there is any evidence of } \\
\text { specimen slipping out of the grips? }\end{array}$ & \\
\hline
\end{tabular}

If any responses to 3(d) through 3(g) are YES, the test is invalid. Please run an additional test. Comments: 


\section{Questionnaire}

\section{Personnel:}

Q1) Name(s) of Laboratory Personnel Conducting Testing:

\section{Apparatus:}

Q2) When were the tensile testing machine and extensometers last calibrated?

Q3) Does the extensometer being used to measure yield strength qualify as Class B-1?

See ASTM E3-11(2017), which is attached.

Q4) What is the gauge length of the extensometer?

Q5) What type of instrument is being used to measure elongation?

Q5.1) If a ruler is used, what is the precision of the ruler?

Q5.2) If an extensometer is used, does it qualify as Class D? See ASTM E3-11(2017), attached.

\section{Gripping device:}

Q6) What is the primary method of gripping used in the tensile testing machine?

a) Standard V-grips with serrated teeth (go to Q7)

b) Special grips with smooth, cylindrical grooves (go to Q8)

c) Other (go to Q9)

Q7) If 6(a) was selected:

7.1) What is used between the grooves and the test specimen?

7.2) What is the number of teeth per inch? 
Q8) If 6(b) was selected: are the strands or grips pre-treated prior to testing? How?

Q9) Please describe the devices used to grip the strand:

Q10) Are chucking devices, or post-tensioning anchorages, used as a secondary gripping device?

Q11) What is the (clear) distance between grips at the start of testing?

\section{Speed of testing: (Per A370-17)}

Q12) Is the speed of testing controlled by the crosshead displacement rate (e.g. in./min)?

Q12.1) If yes, what is the speed of testing from $1 / 2$ of the yield point up to the yield point?

Q12.2) If yes, what is the speed of testing from the yield point up to the ultimate load?

Q13) Is the testing machine equipped with a device to indicate the rate of loading (often in terms of stress/time)?

Q13.1) If yes, what is the speed of testing (in terms of $\mathrm{psi} / \mathrm{min}$ or similar)?

Additional Comments: 


\section{Annex B: List of participating laboratories and corresponding gripping devices used for testing}

\begin{tabular}{|c|c|}
\hline Laboratory & Description of Gripping Device \\
\hline Bekaert Corporation & $\begin{array}{l}\text { Hydraulic compressing grips with inserts appropriate for } \\
\text { each strand size }\end{array}$ \\
\hline Insteel Wire Products - Florida & $\begin{array}{l}\text { Hydraulic jaw assembly with } 10 \text { " smooth grip inserts for } \\
\text { each strand size }\end{array}$ \\
\hline Insteel Wire Products - Tennessee & Wedge grips and a wet sand slurry \\
\hline Insteel Wire Products - Texas & $\begin{array}{l}\text { Hydraulic powered wedge shaped jaws with aluminum } \\
\text { inserts }\end{array}$ \\
\hline Sumiden Wire Products - Dayton & Size specific hydraulic side-action grips \\
\hline Sumiden Wire Products - Dickson & Standard V-grips with serrated teeth \\
\hline Sumiden Wire Products - Stockton & Standard V-grips with serrated teeth \\
\hline Wire Mesh Corporation - St. Matthews & $\begin{array}{l}\text { Tinius Olsen } 10 \text { " smooth cylindrical grips with } 100 \text { grit } \\
\text { media used to pretreat the strands/grips }\end{array}$ \\
\hline CTL Group & Mechanical V-grips with customized anti-slip device \\
\hline WJE & Sand-wedge grip \\
\hline $\begin{array}{l}\text { Caltrans-Structural Material Testing } \\
\text { Branch }\end{array}$ & Standard V-grip with serrated teeth \\
\hline $\begin{array}{l}\text { Georgia Department of } \\
\text { Transportation }\end{array}$ & Hydraulic gripping device \\
\hline $\begin{array}{l}\text { Illinois Department of Transportation, } \\
\text { Central Bureau of Materials }\end{array}$ & Tinius Olsen 10" smooth cylindrical grips \\
\hline $\begin{array}{l}\text { Missouri Department of } \\
\text { Transportation- Central Laboratory }\end{array}$ & $\begin{array}{l}\text { V-grips with serrated teeth and chucks for the ends of the } \\
\text { wire }\end{array}$ \\
\hline $\begin{array}{l}\text { Montana Department of } \\
\text { Transportation/ Aggregate Unit }\end{array}$ & Standard V-grips with serrated teeth \\
\hline Nevada Department of Transportation & Cylindrical grips with a surface alloy coating \\
\hline Pennsylvania & $\begin{array}{l}\text { Grips with smooth semi-circular grooves used with slurry } \\
\text { per A1061-7.1.3 }\end{array}$ \\
\hline $\begin{array}{l}\text { Tennessee Department of } \\
\text { Transportation }\end{array}$ & $\begin{array}{l}\text { Grips with semi-cylindrical groove combined with an } \\
\text { abrasive slurry }\end{array}$ \\
\hline $\begin{array}{l}\text { Texas Department of Transportation- } \\
\text { Construction Division }\end{array}$ & $\begin{array}{l}\text { Notched gripping plates made in house that bolt together. } \\
\text { Bolts tightened with pneumatic impact drill }\end{array}$ \\
\hline
\end{tabular}




\section{Annex C: Capability of participating laboratories to grip various strand diameters and obtain tension test results}

\begin{tabular}{|c|c|c|c|c|c|c|c|}
\hline Name & $\begin{array}{l}0.375 \\
\text { in. }\end{array}$ & $\begin{array}{l}0.5 \\
\text { in. }\end{array}$ & $\begin{array}{l}0.6 \\
\text { in. }\end{array}$ & $\begin{array}{c}\text { Yield } \\
\text { Strength }\end{array}$ & Elongation & $\begin{array}{l}\text { Breaking } \\
\text { Strength } \\
\end{array}$ & $\begin{array}{r}\text { Elastic } \\
\text { Modulus }\end{array}$ \\
\hline Bekaert Corporation & Yes & Yes & Yes & Yes & Yes & Yes & $\overline{\text { Yes }}$ \\
\hline $\begin{array}{l}\text { Insteel Wire Products - } \\
\text { Florida }\end{array}$ & Yes & Yes & Yes & Yes & Yes & Yes & No \\
\hline $\begin{array}{l}\text { Insteel Wire Products - } \\
\text { Tennessee }\end{array}$ & Yes & Yes & Yes & Yes & Yes & Yes & No \\
\hline $\begin{array}{l}\text { Insteel Wire Products - } \\
\text { Texas }\end{array}$ & Yes & Yes & Yes & Yes & Yes & Yes & No \\
\hline $\begin{array}{l}\text { Sumiden Wire Products - } \\
\text { Dayton }\end{array}$ & Yes & Yes & Yes & Yes & Yes & Yes & Yes \\
\hline $\begin{array}{l}\text { Sumiden Wire Products - } \\
\text { Dickson }\end{array}$ & Yes & Yes & Yes & Yes & es & Yes & Yes \\
\hline $\begin{array}{l}\text { Sumiden Wire Products - } \\
\text { Stockton }\end{array}$ & Yes & Yes & Yes & Yes & Yes & Yes & Yes \\
\hline $\begin{array}{l}\text { Wire Mesh Corporation - } \\
\text { St. Matthews }\end{array}$ & Yes & Yes & Yes & Yes & Yes & Yes & Yes \\
\hline CTL Group & Yes & Yes & Yes & Yes & Yes & Yes & No \\
\hline WJE & Yes & Yes & Yes & Yes & Yes & Yes & Yes \\
\hline $\begin{array}{l}\text { Caltrans-Structural } \\
\text { Material Testing Branch }\end{array}$ & Yes & Yes & Yes & Yes & Yes & Yes & Yes \\
\hline $\begin{array}{l}\text { Georgia Department of } \\
\text { Transportation }\end{array}$ & No & Yes & Yes & Yes & Yes & Yes & No \\
\hline $\begin{array}{l}\text { Illinois Department of } \\
\text { Transportation }\end{array}$ & No & Yes & Yes & Yes & Yes & Yes & Yes \\
\hline $\begin{array}{l}\text { Missouri Department of } \\
\text { Transportation }\end{array}$ & Yes & Yes & Yes & Yes & Yes & Yes & Yes \\
\hline $\begin{array}{l}\text { Montana Department of } \\
\text { Transportation/ Aggregate } \\
\text { Unit }\end{array}$ & Yes & Yes & Yes & Yes & Yes & Yes & No \\
\hline $\begin{array}{l}\text { Nevada Department of } \\
\text { Transportation }\end{array}$ & No & Yes & Yes & Yes & Yes & Yes & No \\
\hline $\begin{array}{l}\text { Pennsylvania Department } \\
\text { of Transportation }\end{array}$ & Yes & Yes & Yes & Yes & Yes & Yes & No \\
\hline $\begin{array}{l}\text { Tennessee Department of } \\
\text { Transportation }\end{array}$ & No & Yes & Yes & Yes & Yes & Yes & Yes \\
\hline $\begin{array}{l}\text { Texas Department of } \\
\text { Transportation }\end{array}$ & Yes & Yes & Yes & Yes & Yes & Yes & Yes \\
\hline
\end{tabular}




\section{Annex D: Raw ILS Data [invalid data highlighted with pink background]}

Table D.1 - Strand diameter: 0.375 in.

\begin{tabular}{|c|c|c|c|c|}
\hline & & & & \\
\hline Random Lab ID & Yield, Ibf & Elongation & Elastic Modulus, $10^{6} \mathrm{psi}$ & Breaking Strength, Ibf \\
\hline 2 & 23626 & $3.63 \%$ & 28.5 & 25352 \\
\hline 2 & 23850 & $3.89 \%$ & 28.8 & 25483 \\
\hline 2 & 23692 & $3.66 \%$ & 30 & 25213 \\
\hline 3 & 23109 & $7.61 \%$ & 28.8 & 25795 \\
\hline 3 & 23109 & $7.56 \%$ & 28.9 & 25791 \\
\hline 3 & 23056 & $6.62 \%$ & 28.8 & 25672 \\
\hline 4 & 22566 & $8.80 \%$ & & 25817 \\
\hline 4 & 22747 & $8.00 \%$ & & 25873 \\
\hline 4 & 22978 & $7.50 \%$ & & 26006 \\
\hline 6 & 22550 & $6.04 \%$ & 28.633 & 26000 \\
\hline 6 & 23000 & $6.14 \%$ & 29.296 & 26100 \\
\hline 6 & 23240 & $6.07 \%$ & 29.3 & 26300 \\
\hline 7 & 22600 & $7.50 \%$ & & 25600 \\
\hline 7 & 22800 & $6.98 \%$ & . & 25400 \\
\hline 7 & 23000 & $7.31 \%$ & & 25600 \\
\hline 8 & 23515 & $4.95 \%$ & & 26165 \\
\hline 8 & 23074 & $5.73 \%$ & & 25829 \\
\hline 8 & 23068 & $4.95 \%$ & & 25763 \\
\hline 10 & 23379 & $8.10 \%$ & 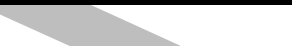 & 25998 \\
\hline 10 & 23100 & $8.27 \%$ & 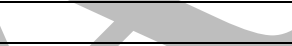 & 25863 \\
\hline 10 & 23565 & $8.35 \%$ & 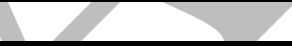 & 25862 \\
\hline 11 & 22987 & $5.50 \%$ & 29 & 25871 \\
\hline 11 & 23355 & $5.00 \%$ & 29.6 & 25820 \\
\hline 11 & 23107 & $4.90 \%$ & 29.2 & 25692 \\
\hline 12 & 22850 & $5.20 \%$ & & 25463 \\
\hline 12 & 23227 & $6.80 \%$ & & 25818 \\
\hline 12 & 23047 & $6.30 \%$ & 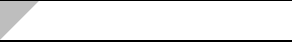 & 25627 \\
\hline 12 & 23136 & $6.40 \%$ & & 25849 \\
\hline 12 & 23283 & $6.00 \%$ & & 25800 \\
\hline 13 & 23290 & $7.01 \%$ & 29.5 & 25912 \\
\hline 13 & 23294 & $6.38 \%$ & 29.5 & 25916 \\
\hline 13 & 22978 & $6.56 \%$ & 29.5 & 25638 \\
\hline 13 & 22684 & $7.32 \%$ & 29.4 & 25626 \\
\hline 14 & 23119 & $5.92 \%$ & 29.6 & 26079 \\
\hline 14 & 23100 & $6.28 \%$ & 29.5 & 26143 \\
\hline 14 & 23078 & $6.19 \%$ & 29.6 & 26015 \\
\hline 16 & 22831 & $5.90 \%$ & 28.8 & 25509 \\
\hline 16 & 22953 & $5.87 \%$ & 28.6 & 25677 \\
\hline 16 & 22803 & $6.00 \%$ & 29.1 & 25574 \\
\hline 17 & 24249 & $5.10 \%$ & & 25960 \\
\hline 17 & 24473 & $5.47 \%$ & & 26030 \\
\hline 17 & 23918 & $5.07 \%$ & & 25620 \\
\hline 17 & 23801 & $5.28 \%$ & & 25770 \\
\hline 17 & 23082 & $6.21 \%$ & & 25580 \\
\hline
\end{tabular}




\begin{tabular}{|c|c|c|c|c|}
\hline Random Lab ID & Yield, Ibf & Elongation & Elastic Modulus, $10^{6} \mathrm{psi}$ & Breaking Strength, Ibf \\
\hline 18 & 23100 & $8.15 \%$ & & 25700 \\
\hline 18 & 23100 & $7.68 \%$ & & 25800 \\
\hline 18 & 22800 & $4.89 \%$ & & 25000 \\
\hline 18 & 23000 & $7.94 \%$ & & 25700 \\
\hline 18 & 23300 & $6.58 \%$ & & 25600 \\
\hline 19 & 23541 & $8.40 \%$ & 29.1 & 25807 \\
\hline 19 & 23304 & $9.30 \%$ & 27.8 & 25734 \\
\hline 19 & 23178 & $9.10 \%$ & 29 & 25636 \\
\hline
\end{tabular}

Table D.2 - Strand diameter: 0.5 in.

\begin{tabular}{|c|c|c|c|c|}
\hline & & & & \\
\hline Random Lab ID & Yield, Ibf & Elongation & Elastic Modulus, $10^{6} \mathrm{psi}$ & Breaking Strength, lbf \\
\hline 1 & 39010 & $4.60 \%$ & & 43700 \\
\hline 1 & 38690 & $4.10 \%$ & $\Delta$ & 43500 \\
\hline 1 & 38860 & $4.70 \%$ & & 43700 \\
\hline 2 & 39140 & $4.94 \%$ & 29.3 & 43136 \\
\hline 2 & 39170 & $5.19 \%$ & 29.2 & 43244 \\
\hline 2 & 40128 & $5.14 \%$ & 28.7 & 43491 \\
\hline 3 & 39111 & $5.63 \%$ & 29.1 & 43348 \\
\hline 3 & 38271 & $6.44 \%$ & 27.1 & 43245 \\
\hline 3 & 38509 & $7.19 \%$ & 27.4 & 43823 \\
\hline 4 & 38616 & $7.29 \%$ & 27.7 & 43768 \\
\hline 4 & 38268 & $8.80 \%$ & 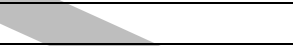 & 43950 \\
\hline 4 & 38555 & $8.30 \%$ & 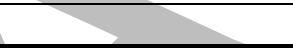 & 44032 \\
\hline 5 & 39663 & $6.60 \%$ & T. & 43892 \\
\hline 5 & 38476 & $6.70 \%$ & 29.7 & 43876 \\
\hline 5 & 39258 & $6.20 \%$ & 32.3 & 43777 \\
\hline 6 & 39010 & $7.16 \%$ & 29.407 & 44700 \\
\hline 6 & 38900 & $6.97 \%$ & 29.248 & 44600 \\
\hline 6 & 38650 & $6.69 \%$ & 29.085 & 44500 \\
\hline 7 & 38200 & $7.38 \%$ & & 44000 \\
\hline 7 & 38400 & $7.44 \%$ & & 44000 \\
\hline 7 & 38400 & $7.44 \%$ & & 43200 \\
\hline 8 & 39043 & $5.47 \%$ & & 44151 \\
\hline 8 & 38877 & $5.21 \%$ & & 43761 \\
\hline 8 & 38905 & $4.95 \%$ & & 43922 \\
\hline 9 & 38267 & $8.21 \%$ & 28.7 & 43773 \\
\hline 9 & 38673 & $8.28 \%$ & 29.6 & 44079 \\
\hline 9 & 38269 & $7.88 \%$ & 28.6 & 43926 \\
\hline 10 & 39130 & $7.95 \%$ & & 43953 \\
\hline 10 & 39355 & $6.58 \%$ & & 43409 \\
\hline 10 & $38774^{4}$ & $7.94 \%$ & & 43698 \\
\hline 11 & 38838 & $5.60 \%$ & 29.1 & 43867 \\
\hline 11 & 38973 & $5.50 \%$ & 29.2 & 43898 \\
\hline 11 & 38761 & $5.40 \%$ & 28.9 & 43771 \\
\hline
\end{tabular}

${ }^{4}$ Although considered valid, this value was omitted from precision calculations because only one valid result was obtained from laboratory 10 for yield strength of 0.500 in. strand. 


\begin{tabular}{|c|c|c|c|c|}
\hline Random Lab ID & Yield, Ibf & Elongation & Elastic Modulus, $10^{6} \mathrm{psi}$ & Breaking Strength, Ibf \\
\hline 12 & 38641 & $5.50 \%$ & & 43224 \\
\hline 12 & 38780 & $6.50 \%$ & & 43832 \\
\hline 12 & 38778 & $6.50 \%$ & & 43144 \\
\hline 12 & 38718 & $6.60 \%$ & & 43496 \\
\hline 12 & 38754 & $5.70 \%$ & & 43132 \\
\hline 13 & 38865 & $6.62 \%$ & 29.5 & 44015 \\
\hline 13 & 39129 & $7.75 \%$ & 31.3 & 43964 \\
\hline 13 & 39267 & $7.13 \%$ & 31.4 & 44010 \\
\hline 13 & 39015 & $7.45 \%$ & 29.6 & 44018 \\
\hline 13 & 38890 & $6.79 \%$ & 29.7 & 43998 \\
\hline 14 & 38530 & $6.12 \%$ & 29.1 & 44232 \\
\hline 14 & 38698 & $6.32 \%$ & 29.1 & 44354 \\
\hline 14 & 38627 & $6.48 \%$ & 29.2 & 44346 \\
\hline 15 & 38776 & $7.34 \%$ & 29.83 & 44042 \\
\hline 15 & 38939 & $7.37 \%$ & 29.65 & 44184 \\
\hline 15 & 39483 & $6.46 \%$ & 28.85 & 44104 \\
\hline 16 & 38209 & $6.60 \%$ & 29.1 & 43366 \\
\hline 16 & 38118 & $6.53 \%$ & 29.2 & 43349 \\
\hline 16 & 38155 & $6.63 \%$ & 29.3 & 43273 \\
\hline 17 & 39351 & $6.22 \%$ & & 43950 \\
\hline 17 & 39121 & $5.38 \%$ & & 43710 \\
\hline 17 & 39365 & $5.21 \%$ & & 43630 \\
\hline 17 & 39495 & $4.97 \%$ & & 43660 \\
\hline 17 & 39855 & $5.88 \%$ & & 44190 \\
\hline 18 & 38700 & $7.95 \%$ & & 43900 \\
\hline 18 & 38500 & $8.27 \%$ & & 43900 \\
\hline 18 & 38900 & $7.19 \%$ & 7 & 43800 \\
\hline 18 & 38600 & $8.20 \%$ & & 43700 \\
\hline 18 & 38500 & $8.05 \%$ & 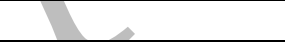 & 43700 \\
\hline 19 & 39043 & $8.30 \%$ & 28.9 & 43640 \\
\hline 19 & 39053 & $9.00 \%$ & 29.4 & 43725 \\
\hline 19 & 38909 & $8.90 \%$ & 29.1 & 43644 \\
\hline
\end{tabular}

Table D.3 - Strand diameter: 0.6 in.

\begin{tabular}{|c|c|c|c|c|}
\hline Random Lab ID & Yield, Ibf & Elongation & Elastic Modulus, $10^{6} \mathrm{psi}$ & Breaking Strength, lbf \\
\hline 1 & 55470 & $6.20 \%$ & & 62100 \\
\hline 1 & 55540 & $6.30 \%$ & & 62100 \\
\hline 1 & 55350 & $5.60 \%$ & & 62300 \\
\hline 2 & 57835 & $4.39 \%$ & & 61578 \\
\hline 2 & 56806 & $6.20 \%$ & 29.2 & 61712 \\
\hline 2 & 57967 & $4.64 \%$ & 27.4 & 61529 \\
\hline 2 & 56584 & $5.69 \%$ & 28.7 & 61588 \\
\hline 3 & 55479 & $7.15 \%$ & 27.3 & 61639 \\
\hline 3 & 54953 & $6.36 \%$ & 27 & 61632 \\
\hline 3 & 55389 & $6.57 \%$ & 27.7 & 61443 \\
\hline 4 & 54927 & $6.00 \%$ & & 61952 \\
\hline 4 & 55808 & $7.50 \%$ & & 62133 \\
\hline 4 & 55966 & $7.80 \%$ & & 62277 \\
\hline
\end{tabular}




\begin{tabular}{|c|c|c|c|c|}
\hline Random Lab ID & Yield, Ibf & Elongation & Elastic Modulus, $10^{6} \mathrm{psi}$ & Breaking Strength, Ibf \\
\hline 5 & 56124 & $6.00 \%$ & 30.92 & 61753 \\
\hline 5 & 56274 & $8.10 \%$ & 30.97 & 62364 \\
\hline 5 & 55879 & $8.40 \%$ & 30.55 & 61778 \\
\hline 6 & 55630 & $6.59 \%$ & 28.881 & 62900 \\
\hline 6 & 55860 & $6.71 \%$ & 28.674 & 62700 \\
\hline 6 & 55270 & $6.55 \%$ & 28.496 & 62800 \\
\hline 7 & 55400 & $7.24 \%$ & & 62400 \\
\hline 7 & 55000 & $7.25 \%$ & & 62200 \\
\hline 7 & 55200 & $7.12 \%$ & & 62200 \\
\hline 8 & 55671 & $4.95 \%$ & & 62353 \\
\hline 8 & 55606 & $4.95 \%$ & & 62418 \\
\hline 8 & 56231 & $5.21 \%$ & & 62164 \\
\hline 9 & 56233 & $10.21 \%$ & 28.9 & 61975 \\
\hline 9 & 55520 & $9.37 \%$ & 28.5 & 62202 \\
\hline 9 & 55717 & $8.49 \%$ & 28 & 62114 \\
\hline 10 & 54677 & $6.19 \%$ & & 61499 \\
\hline 10 & 55928 & $6.56 \%$ & & 61695 \\
\hline 10 & 55899 & $7.25 \%$ & & 61836 \\
\hline 11 & 54970 & $4.80 \%$ & 28 & 61481 \\
\hline 11 & 56126 & $4.40 \%$ & 29.4 & 61935 \\
\hline 11 & 55753 & $4.60 \%$ & 28.8 & 61520 \\
\hline 12 & 56119 & $7.70 \%$ & & 62689 \\
\hline 12 & 55609 & $5.90 \%$ & & 62753 \\
\hline 12 & 55960 & $6.60 \%$ & & 62639 \\
\hline 12 & 55314 & $5.50 \%$ & 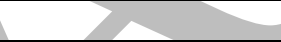 & 62179 \\
\hline 12 & 54828 & $6.30 \%$ & & 62002 \\
\hline 13 & 55985 & $7.04 \%$ & 29.2 & 61884 \\
\hline 13 & 54784 & $7.12 \%$ & 28.8 & 62090 \\
\hline 13 & 55876 & $6.90 \%$ & 29.1 & 61868 \\
\hline 13 & 56231 & $6.77 \%$ & 29.2 & 61619 \\
\hline 13 & 55989 & $7.37 \%$ & 29.2 & 62128 \\
\hline 14 & 55107 & $6.23 \%$ & 28.7 & 62395 \\
\hline 14 & 55485 & $6.57 \%$ & 28.9 & 62620 \\
\hline 14 & 55418 & $6.23 \%$ & 28.9 & 62226 \\
\hline 15 & 55728 & $8.05 \%$ & 29.11 & 62482 \\
\hline 15 & 56009 & $7.86 \%$ & 28.9 & 62123 \\
\hline 15 & 55864 & $7.43 \%$ & 29.55 & 62576 \\
\hline 16 & 55727 & $5.97 \%$ & 29.6 & 61221 \\
\hline 16 & 55369 & $6.17 \%$ & 28.9 & 61632 \\
\hline 16 & 55652 & $6.23 \%$ & 29.7 & 61351 \\
\hline 17 & 56901 & $6.15 \%$ & & 62250 \\
\hline 17 & 56651 & $4.08 \%$ & & 60680 \\
\hline 17 & 56930 & $4.92 \%$ & & 61780 \\
\hline 17 & 57194 & $3.58 \%$ & & 60960 \\
\hline 17 & 56516 & $4.71 \%$ & & 61460 \\
\hline 18 & 56100 & $7.52 \%$ & & 61900 \\
\hline 18 & 55500 & $6.57 \%$ & & 61600 \\
\hline 18 & 55500 & $6.51 \%$ & & 61800 \\
\hline 18 & 55000 & $7.33 \%$ & & 61500 \\
\hline 18 & 55600 & $6.20 \%$ & & 61500 \\
\hline
\end{tabular}




\begin{tabular}{|c|c|c|c|c|}
\hline Random Lab ID & Yield, Ibf & Elongation & Elastic Modulus, $10^{6} \mathrm{psi}$ & Breaking Strength, Ibf \\
\hline 19 & 55856 & $8.70 \%$ & 29.1 & 61477 \\
\hline 19 & 56512 & $8.50 \%$ & 29.4 & 61571 \\
\hline 19 & 56113 & $8.50 \%$ & 28.5 & 61403 \\
\hline
\end{tabular}

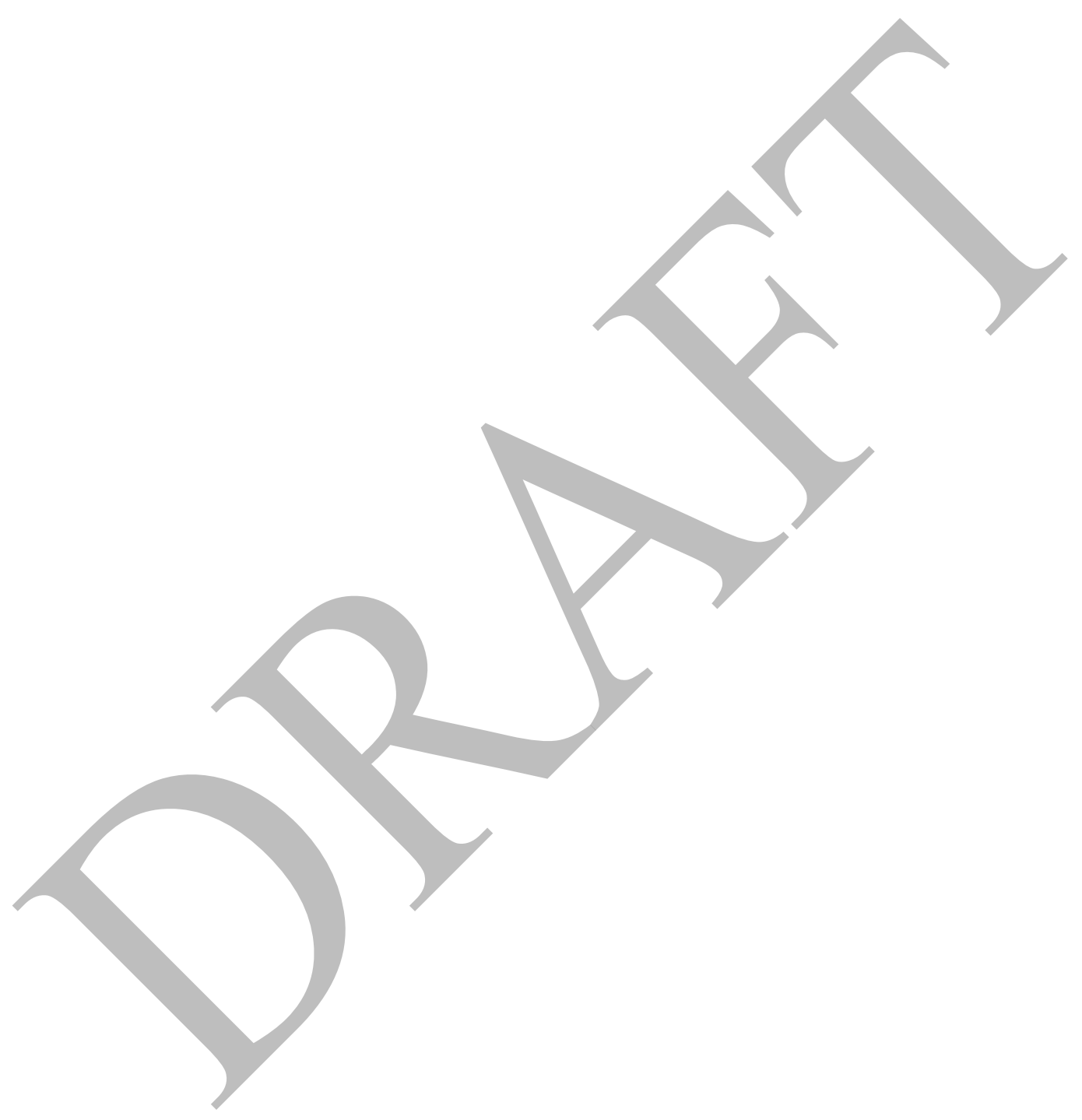

E - 20 


\section{Annex E: Statistical Data Summary}

The raw data presented in Annex D were examined by the ILS Coordinator, and invalid data (highlighted with a pink background in Tables D.1 to D.3) were removed. Data were judged invalid if they were:

- Clearly erroneous test results, corresponding to physically impossible values (less than $1 \%$ of the whole database).

- Obtained from tests conducted not in strict accordance with the ASTM A1061/A1061M procedures (as noted by members of the research team while observing tests, when applicable). Examples of violations include:

- Incorrect range of strains selected in the application of the preload method for determining yield strength (A1061/A1061M, Section 9.1.1). [2 labs]

- Invalid elastic modulus due to selection of incorrect stress range in the application of the extrapolation method for determining yield strength (A1061/A1061M, Section 9.1.2). [2 labs]

- Elastic modulus set to a fixed value instead of being calculated in the application of the extrapolation method for establishing yield. [1 lab]

- Incorrect gauge length used in the calculation of strains. [1 lab]

- Slippage of the extensometer during tests. [1 lab]

- Extensometer used with a gauge length shorter than the lay length of $0.5 \mathrm{in}$. and $0.6 \mathrm{in}$. diameter strand samples. [1 lab]

- Extensometer not meeting the requirements of ASTM E83 for B-1 classification. [1 lab]

- For the case of elongation, obtained from tests where procedures for determining yield strength were deemed invalid because:

- Extensometer gauge lengths were shorter than 24 in. [2 labs]

- Incorrect gauge lengths were used to calculate strain from measured crosshead displacement values. [2 labs]

- Elongation values were reported from the acquisition software immediately after breakage, when crosshead displacement values can be erratic due to the energy released by strand fracture. [1 lab]

Out of 647 reported test results, 221 (34\%) were classified invalid by the ILS Research Team. The remaining 426 valid results (114 yield strength values, 60 elongation values, 68 elastic modulus values, and 184 breaking strength values ${ }^{5}$ ) were analyzed in accordance with the statistical procedures of ASTM E691-18 (Standard Practice for Conducting an Interlaboratory Study to Determine the Precision of a Test Method).

Note that:

- The minimum number of laboratories required by E691-18 to produce an acceptable statement of precision for a Test Method is 6 (Section 9.1.2).

- The minimum number of materials (strand diameters in this ILS), representing different test levels, recommended by E691-18 (Section 10.2.2), is 3.

- The number of test results on each material recommended by E691-18 (Section 11.1) is 3 or 4 and not less than 2 for a physical test.

${ }^{5}$ All the reported breaking strength values were classified as valid. 
Since for this ILS:

- the minimum number of laboratories providing valid test results for any of the mechanical properties was 6 (elongation for 0.375 in., 0.5 in., and 0.6 in. diameter strand; elastic modulus for $0.375 \mathrm{in}$. diameter strand),

- the number of strand diameters (i.e., materials) tested was 3, and

- between 3 and 5 test results were reported by all participants for a specific strand diameter and at least 2 valid results were obtained from each laboratory included in the analyses,

the ILS described in this Research Report can be used to determine the precision of Test Methods A1061/A1061M in accordance with Standard Practice ASTM E691-18.

\section{E1 Calculation of the Statistics}

For each laboratory/mechanical property/strand diameter (representing a cell), the following cell statistics, intermediate statistics, precision statistics, and consistency statistics ${ }^{6}$ were calculated from the valid results:

- average value (\$15.4.1),

- $\quad$ standard deviation $(\$ 15.4 .2)$,

- average of the cell averages (\$15.5.1),

- cell deviation (\$15.5.2),

- standard deviation of the cell averages (\$15.5.3),

- repeatability standard deviation (\$15.6.1),

- between laboratory standard deviation (\$15.6.2),

- reproducibility standard deviation (\$15.6.3),

- consistency statistics, $h$ and $k(\S 15.7)$.

\section{E2 Assessment of Data Consistency}

The consistency statistics, $h$ (between-laboratory consistency statistic) and $k$ (within-laboratory consistency statistic), were used to identify ("flag") any inconsistent result that should have been removed from the analyses before establishing the precision of Test Methods A1061/A1061M.

The critical values of $h$ and $k$ at the $0.5 \%$ significance level are listed in Table 5 of ASTM E691-18.

Note that, while $h_{\text {critical }}$ only depends on the number of laboratories providing valid results, $k_{\text {critical }}$ also depends on the number of replicate test results per laboratory per material (n). ASTM E691-18 only covers the situation where $n$ is the same for all cells, whereas in this ILS $n$ ranged from 3 to 5 (number of valid tests performed by each laboratory for a given strand diameter). Consequently, different values of $k_{\text {critical }}$ were used for each cell in order to assess the within-laboratory data consistency.

\section{E2.1 Between-Laboratory Consistency ( $h$ Graphs)}

The $h$ bar graphs by laboratory are shown in Figure 1 (yield strength), Figure 2 (elongation), Figure 3 (elastic modulus), and Figure 4 (breaking strength). Any laboratory whose bar exceeded the critical value of $h$ deviated excessively from the general trend of ILS results.

\footnotetext{
${ }^{6}$ For every statistic, the relevant section of ASTM E691-18 is indicated below.
} 


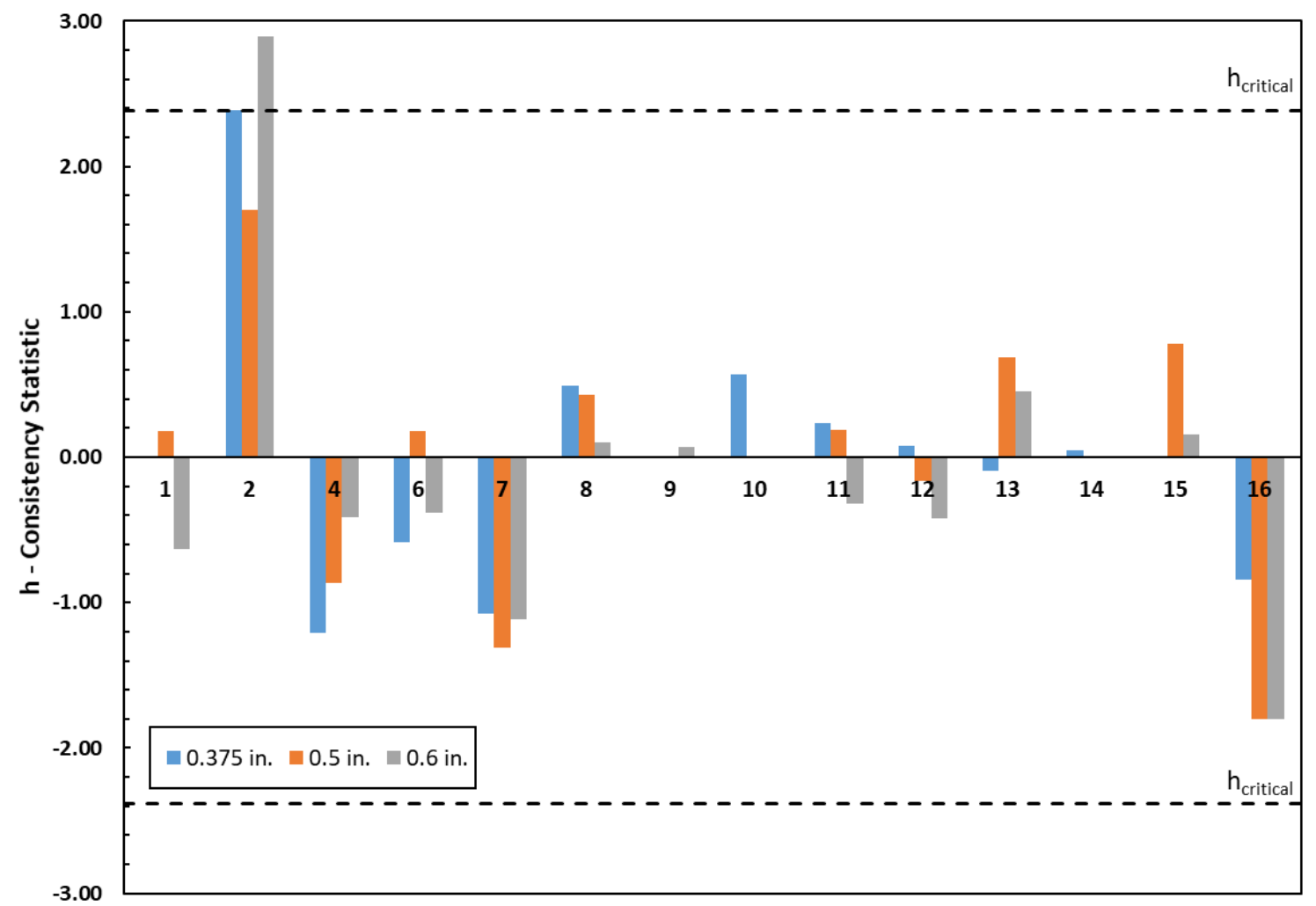

Figure 1 -Between-laboratory consistency (h) graph for yield strength.

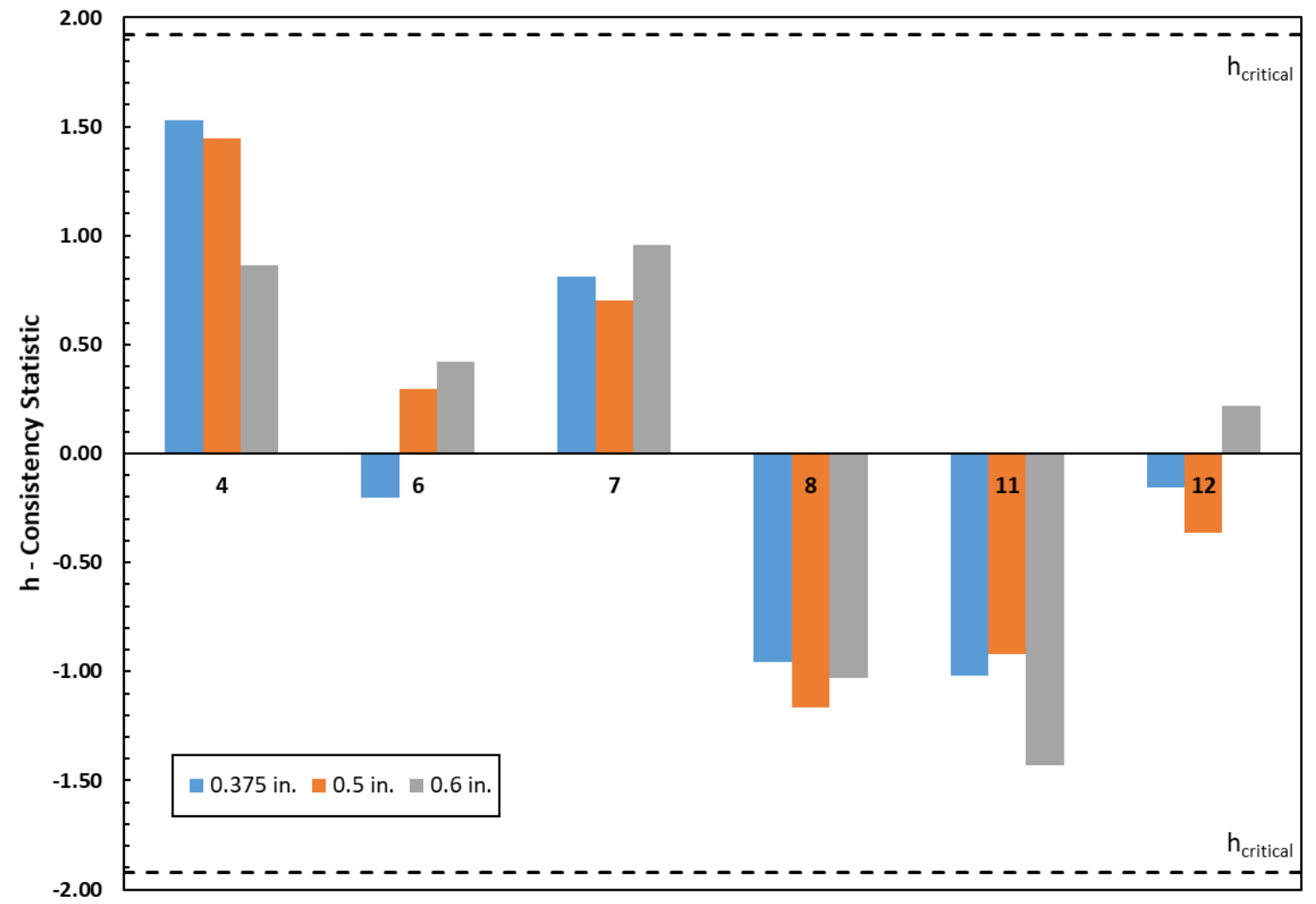

Figure 2 -Between-laboratory consistency (h) graph for elongation. 


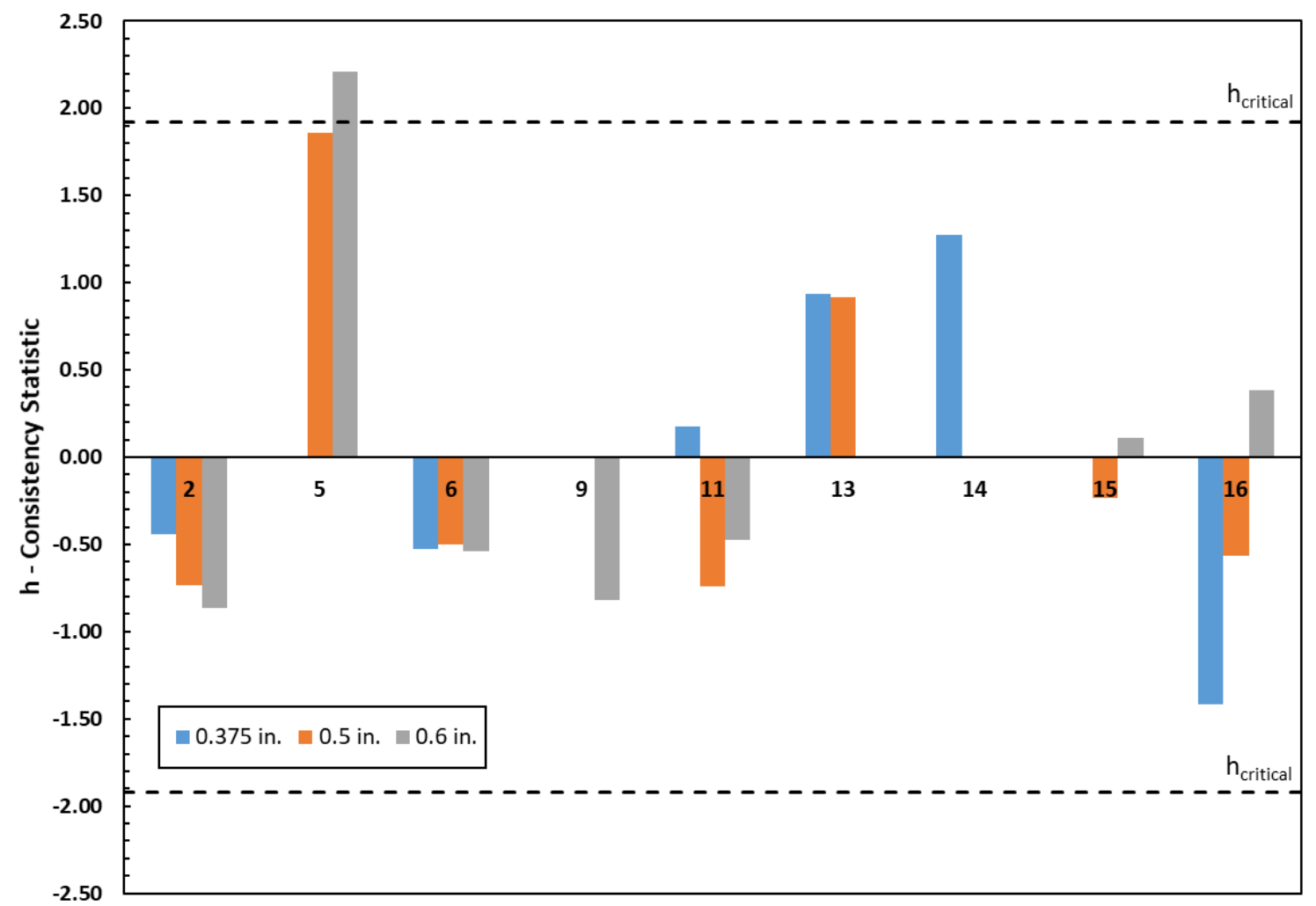

Figure 3-Between-laboratory consistency (h) graph for elastic modulus.

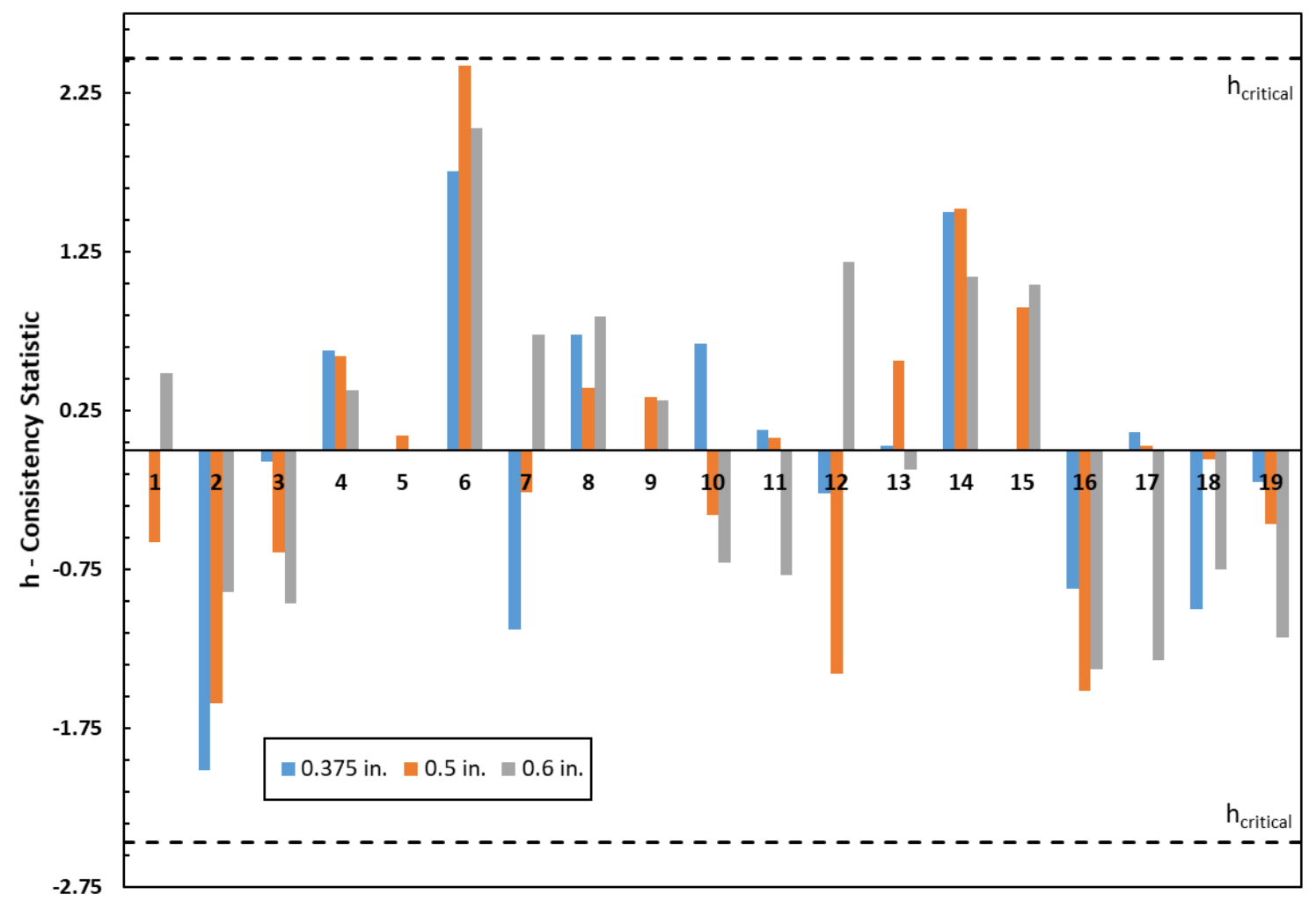

Figure 4 - Between-laboratory consistency (h) graph for breaking strength. 


\section{E2.2 Within-Laboratory Consistency ( $k$ Graphs)}

The $k$ bar graphs by laboratory are shown in Figure 5 (yield strength), Figure 6 (elongation), Figure 7 (elastic modulus), and Figure 8 (breaking strength). Any laboratory whose bar exceeded the critical value of $k$ deviated excessively from the general trend of ILS results. As explained before, a unique value of $k_{\text {critical }}$ for all labs and strand diameters cannot be illustrated in the figures, since the number of reported values was not constant; we have decided to visualize $k_{\text {critical }}$ only in the cases it was exceeded.

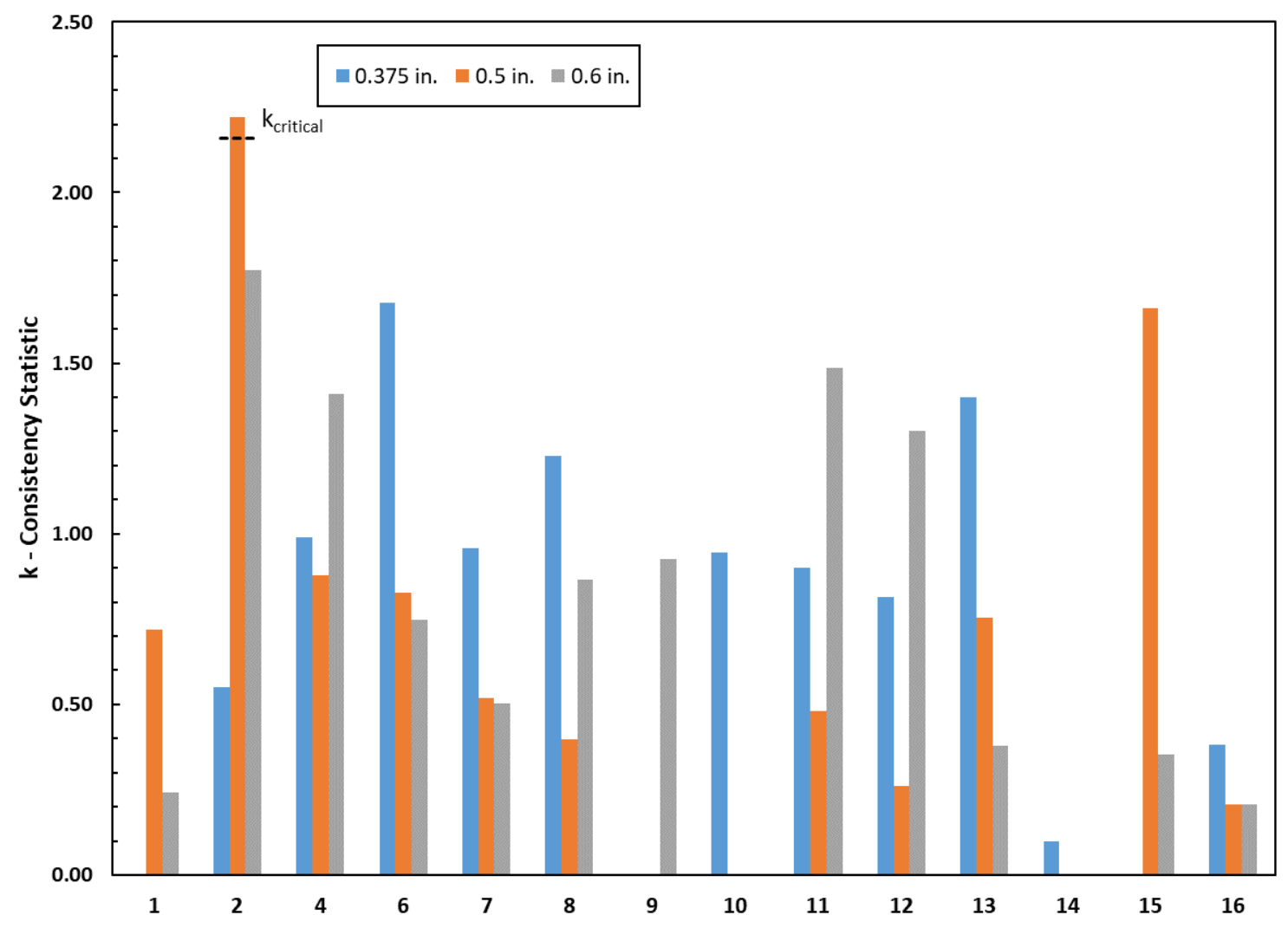

Figure 5 -Within-laboratory consistency $(k)$ graph for yield strength. Lab 2 exceeded the critical value for 0.375 in.



E -25 


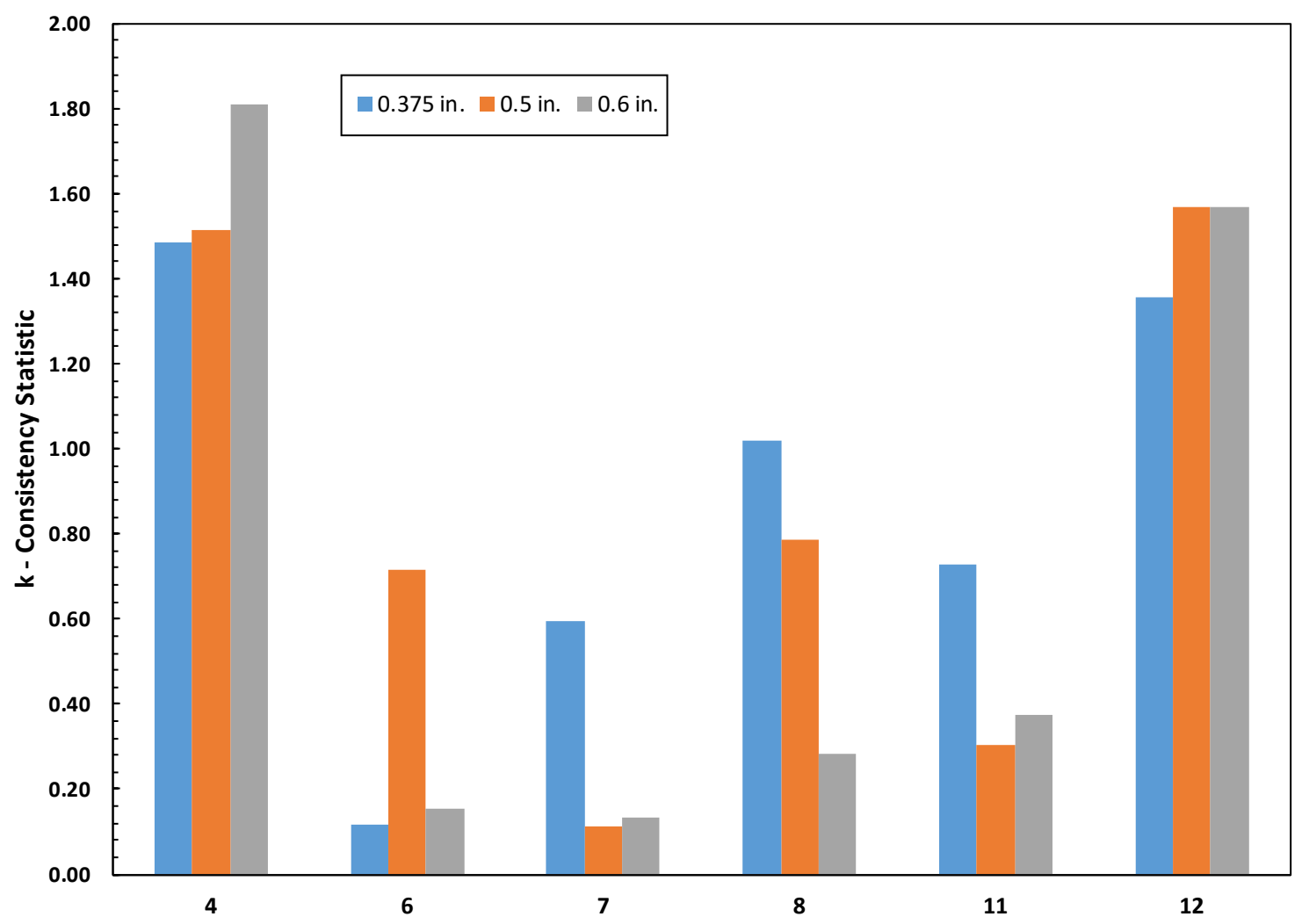

Figure 6 - Within-laboratory consistency (k) graph for elongation. No lab exceeded the critical values.

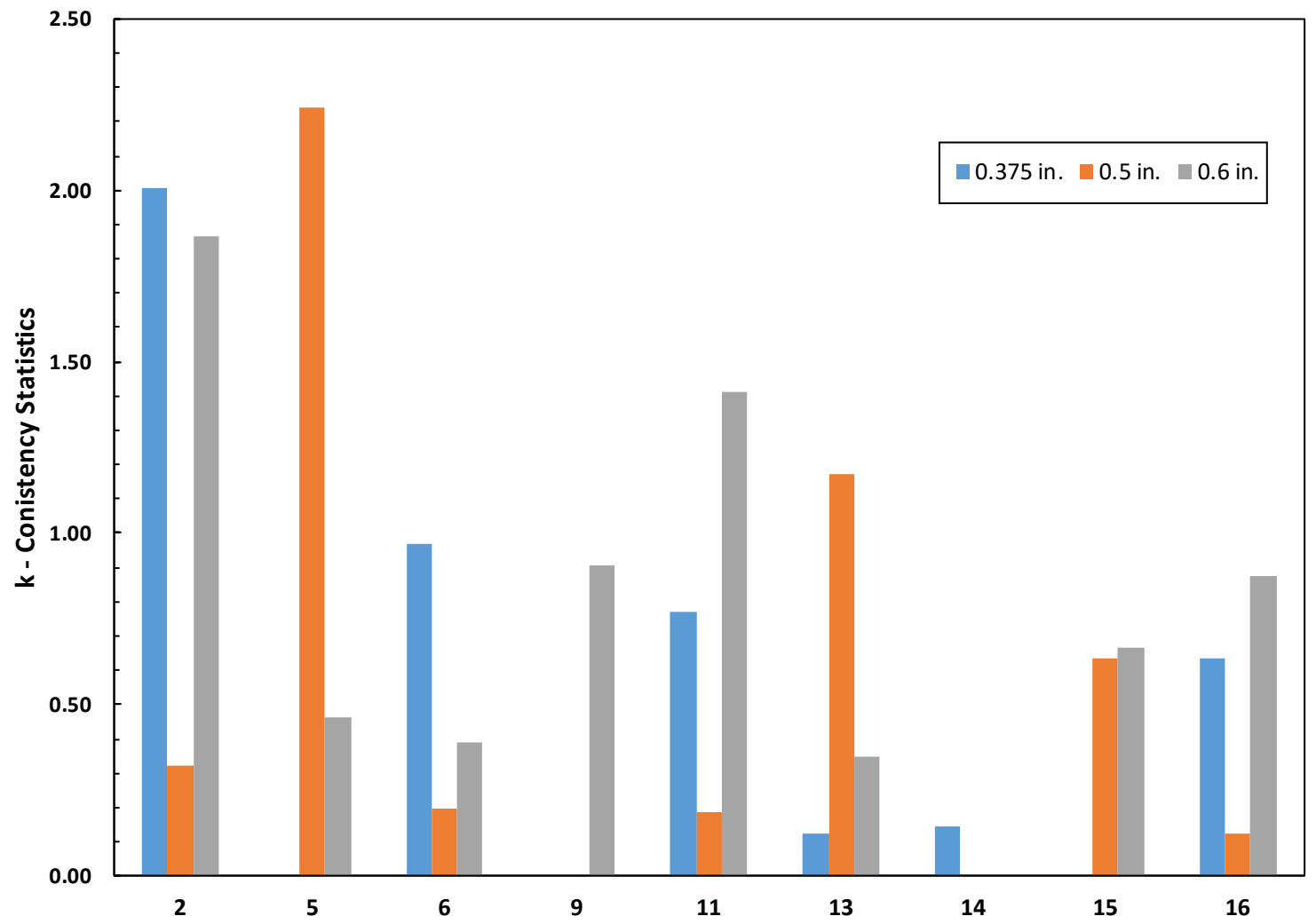

Figure 7 - Within-laboratory consistency (k) graph for elastic modulus. No lab exceeded the critical values. 


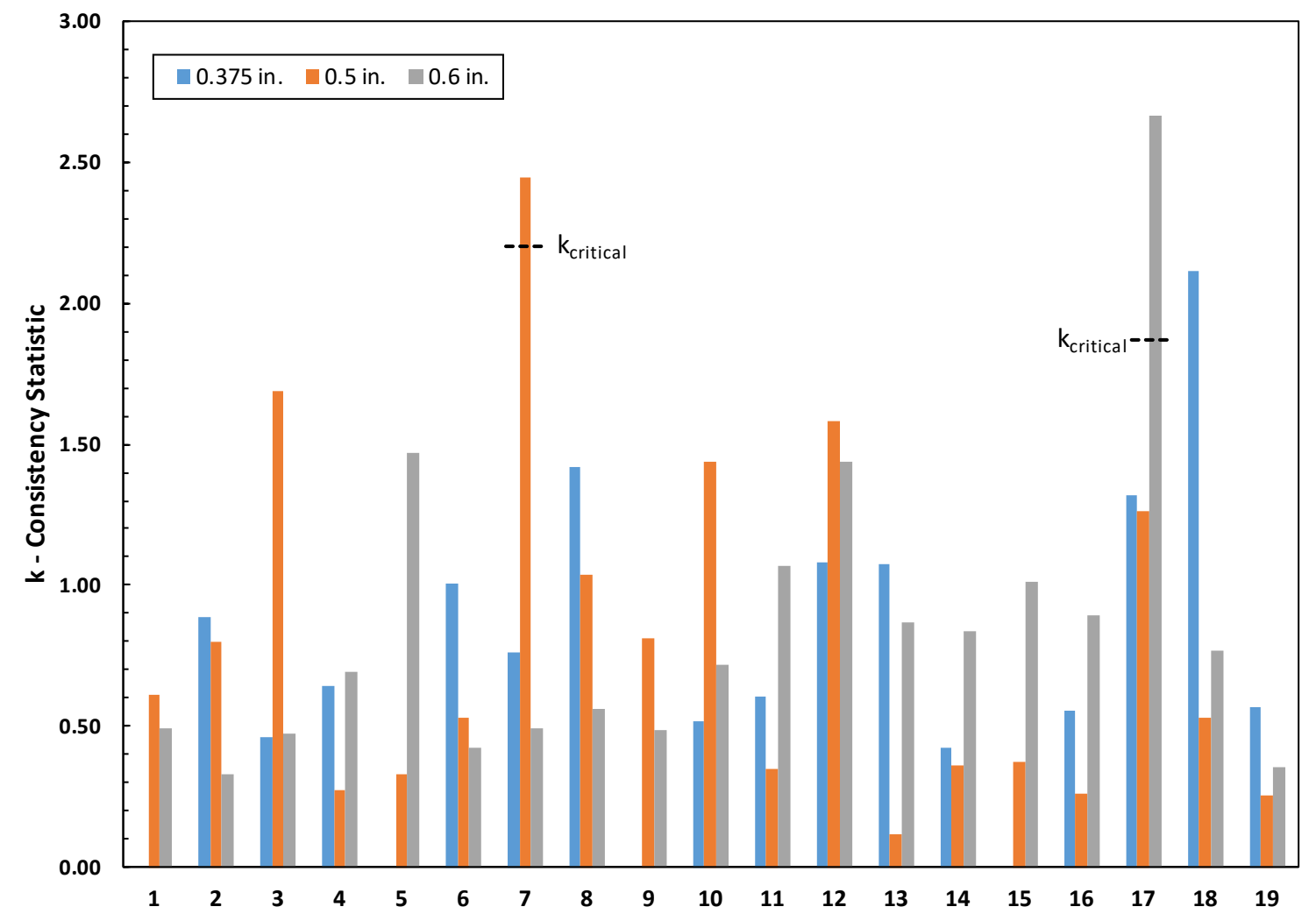

Figure 8 - Within-laboratory consistency (k) graph for breaking strength. Labs 2 (for 0.5 in. samples) and 7 (for 0.6 in. samples) exceeded the critical values.

\section{E2.3 Investigation of inconsistent ("flagged") results}

None of the patterns depicted in Figures 1 to 8 suggested that any of the participating labs should be removed from the analyses. According to ASTM E691-18, unusual or suspicious patterns include the following:

- One laboratory has all positive or all negative $h$ values, while the opposite is true for the remaining participants (Section 17.2.1).

- One laboratory has $h$ values of one sign for low property levels, and of the opposite sign for high property levels (Section 17.2.1.1).

- One laboratory has very large or very small $k$ values for all or most of the materials (Section 17.2.2).

Therefore, all test results reported in Annex C (and not highlighted with a pink background) were used for the establishment of the precision statement for ASTM Test Methods A1061/A1061M.

Hence, there was no need to recalculate the precision statistics listed in Section E.1.

The precision statistics calculated for each measured parameter and strand diameter have been summarized in Tables 1 to 4, including (ASTM E91-18, §21.1):

- the $95 \%$ repeatability limit, $r$, and

- $\quad$ the $95 \%$ reproducibility limit, $R$.

The precision statement for ASTM Test Methods A1061/A1061M was prepared in accordance with ASTM Practice E177-14, Use of the Terms Precision and Bias in ASTM Test Methods. 


\section{E3. Variation of Precision Statistics with Property Level}

Precision statistics, such as repeatability and reproducibility standard deviations and their respective limits $r$ and $R$, are often observed to vary with the values of the property level.

For this ILS, this can be observed in Figure 9 for yield strength and in Figure 10 for breaking strength. Conversely, no relationship between repeatability or reproducibility and property level was detected for elongation (Figure 11) and elastic modulus (Figure 12). This had to be expected, since yield and breaking strength are "absolute" values (which scale with strand diameter), while elongation and elastic modulus are "relative" or normalized values, and are therefore independent of the strand diameter.

If $r$ and $R$ are normalized by the average values, the situation is as depicted in Figure 13 (yield strength) and Figure 14 (breaking strength).

In all cases, reproducibility standard deviations and limits are larger than their repeatability counterparts.

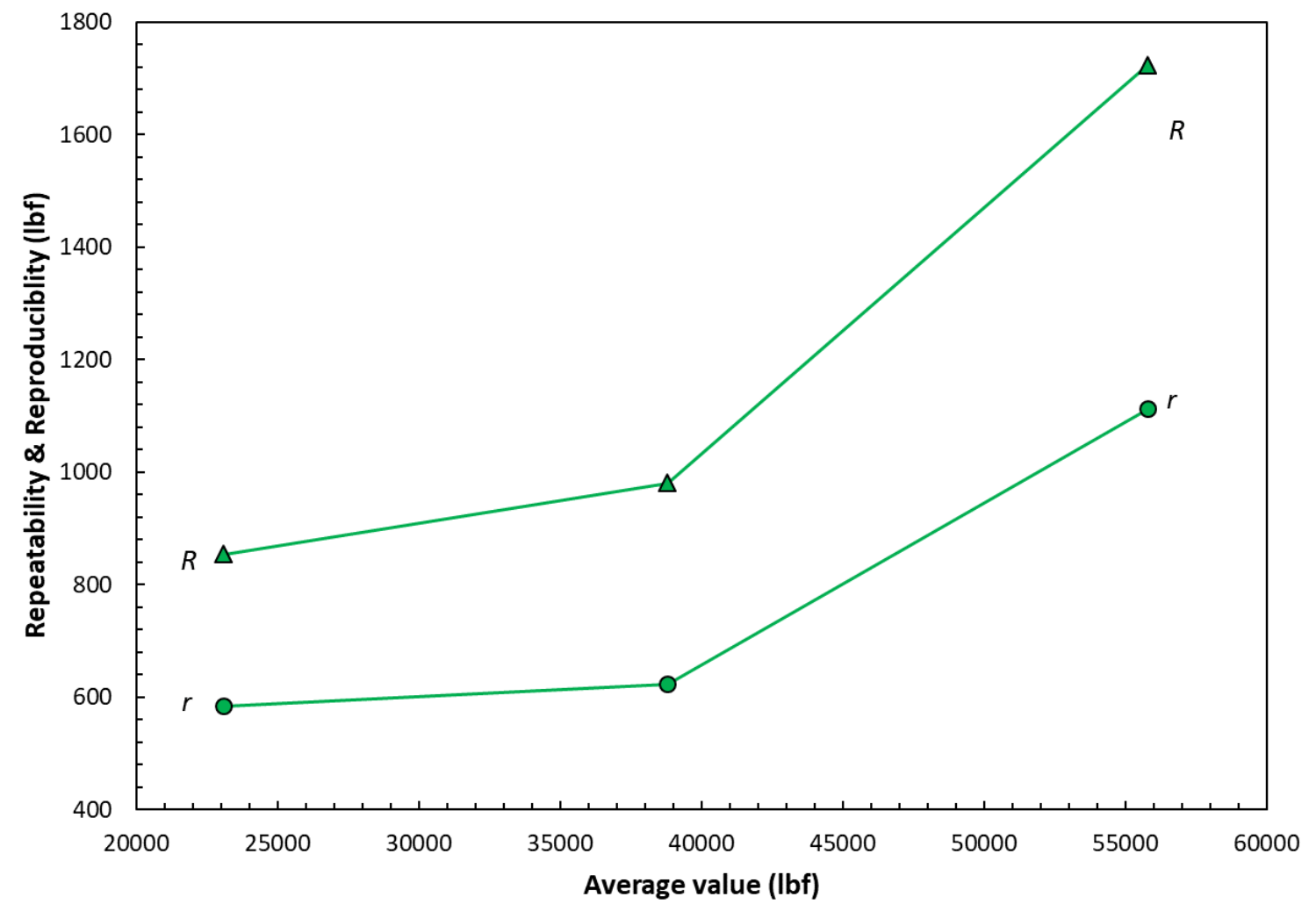

Figure 9 - Repeatability $(r)$ and reproducibility $(R)$ limits versus average values for yield strength. 


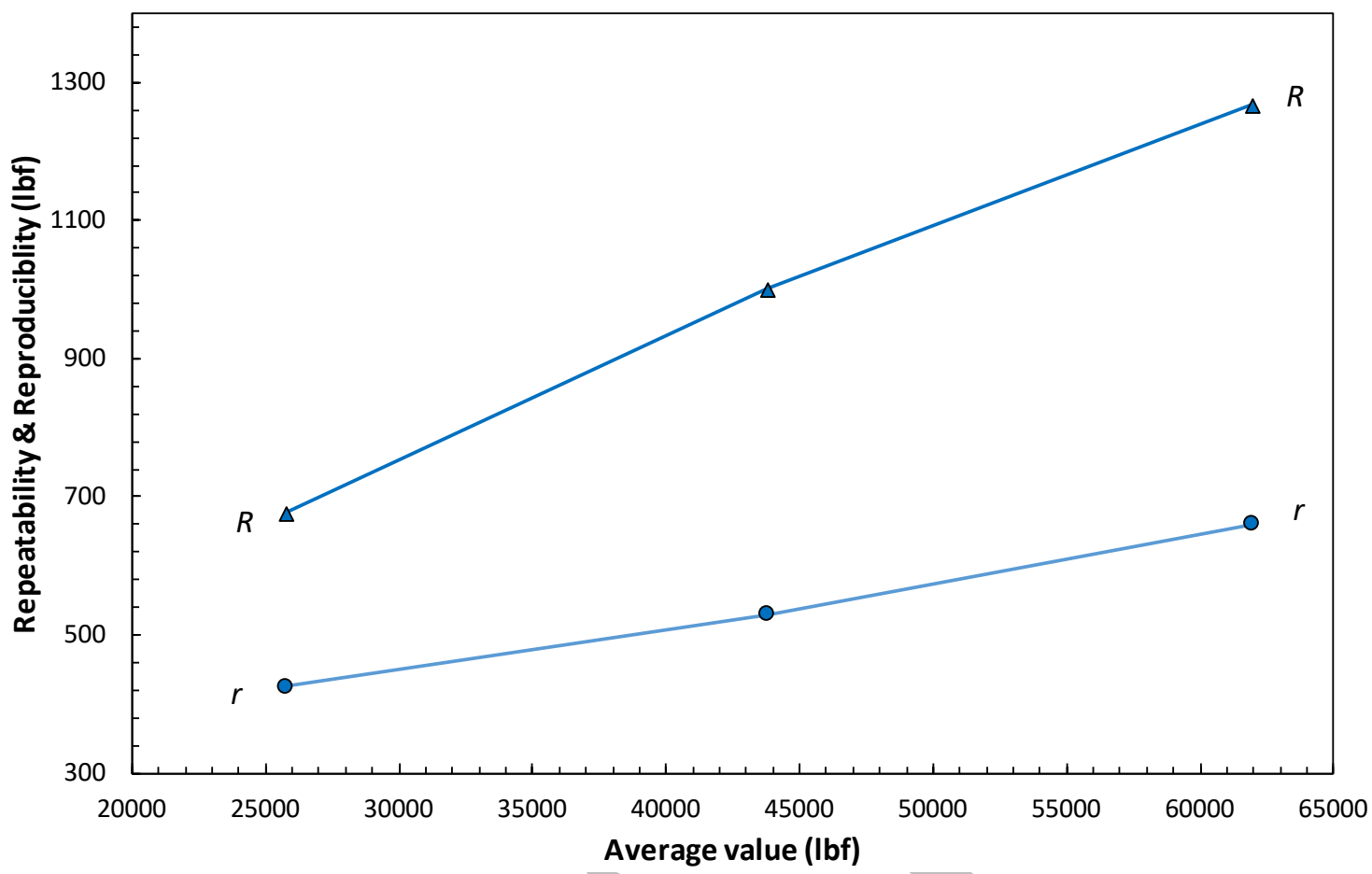

Figure 10 - Repeatability (r) and reproducibility (R) limits versus average values for breaking strength.

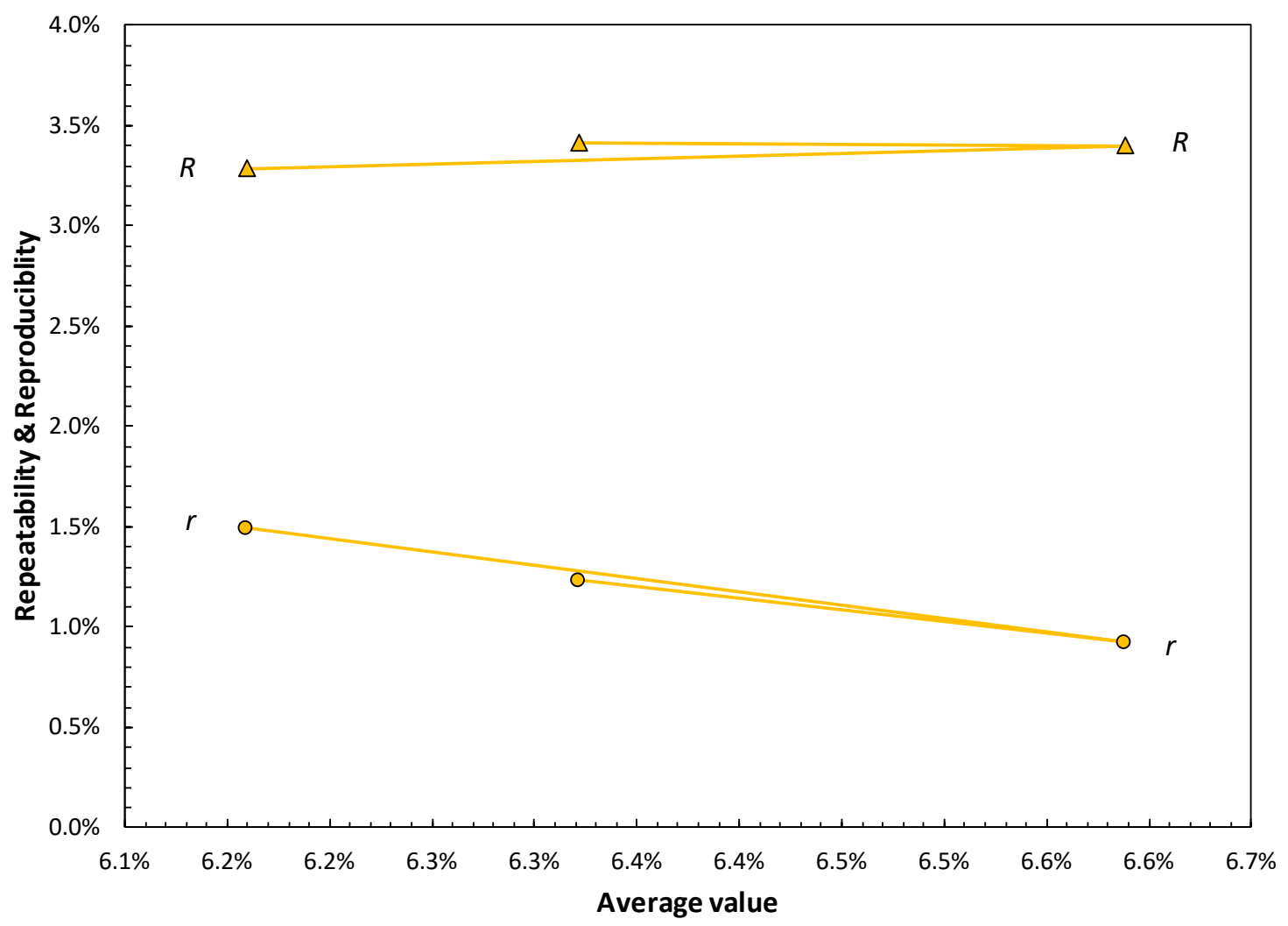

Figure 11 - Repeatability (r) and reproducibility (R) limits versus average values for elongation. 


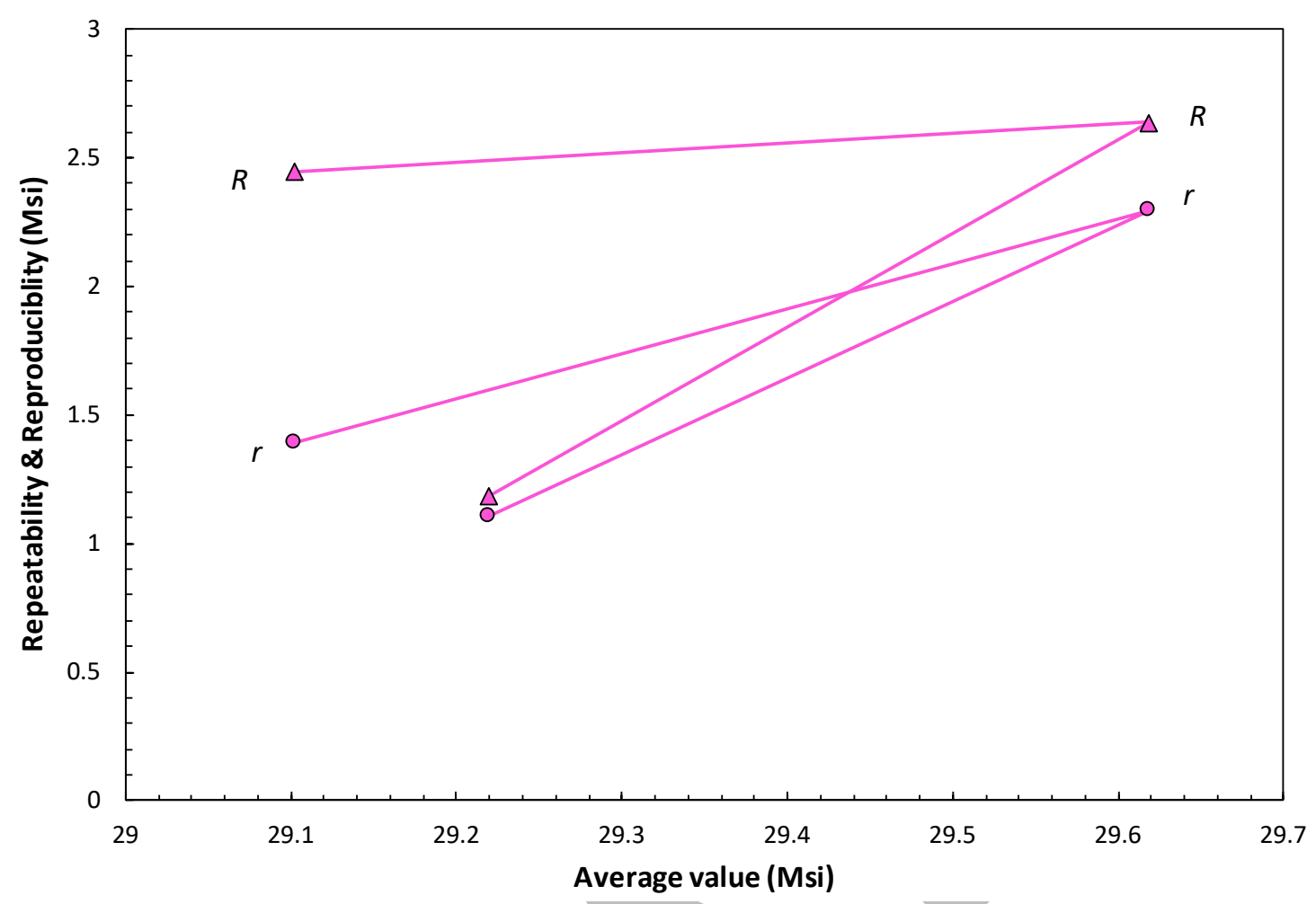

Figure 12 - Repeatability ( $r$ ) and reproducibility (R) limits versus average values for elastic modulus.

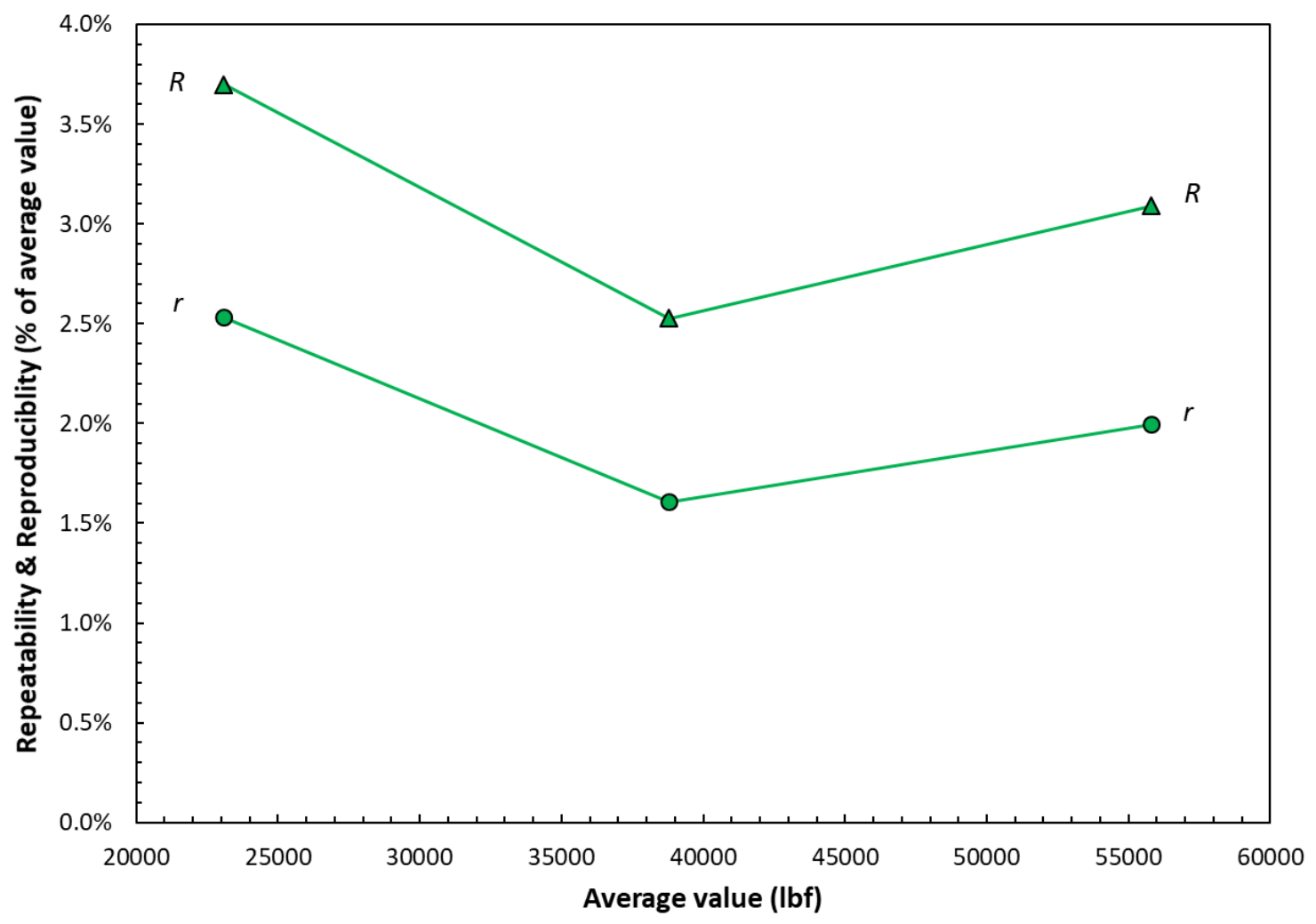

Figure 13 - Repeatability (r) and reproducibility (R) limits, normalized by average values, versus average values for yield strength. 


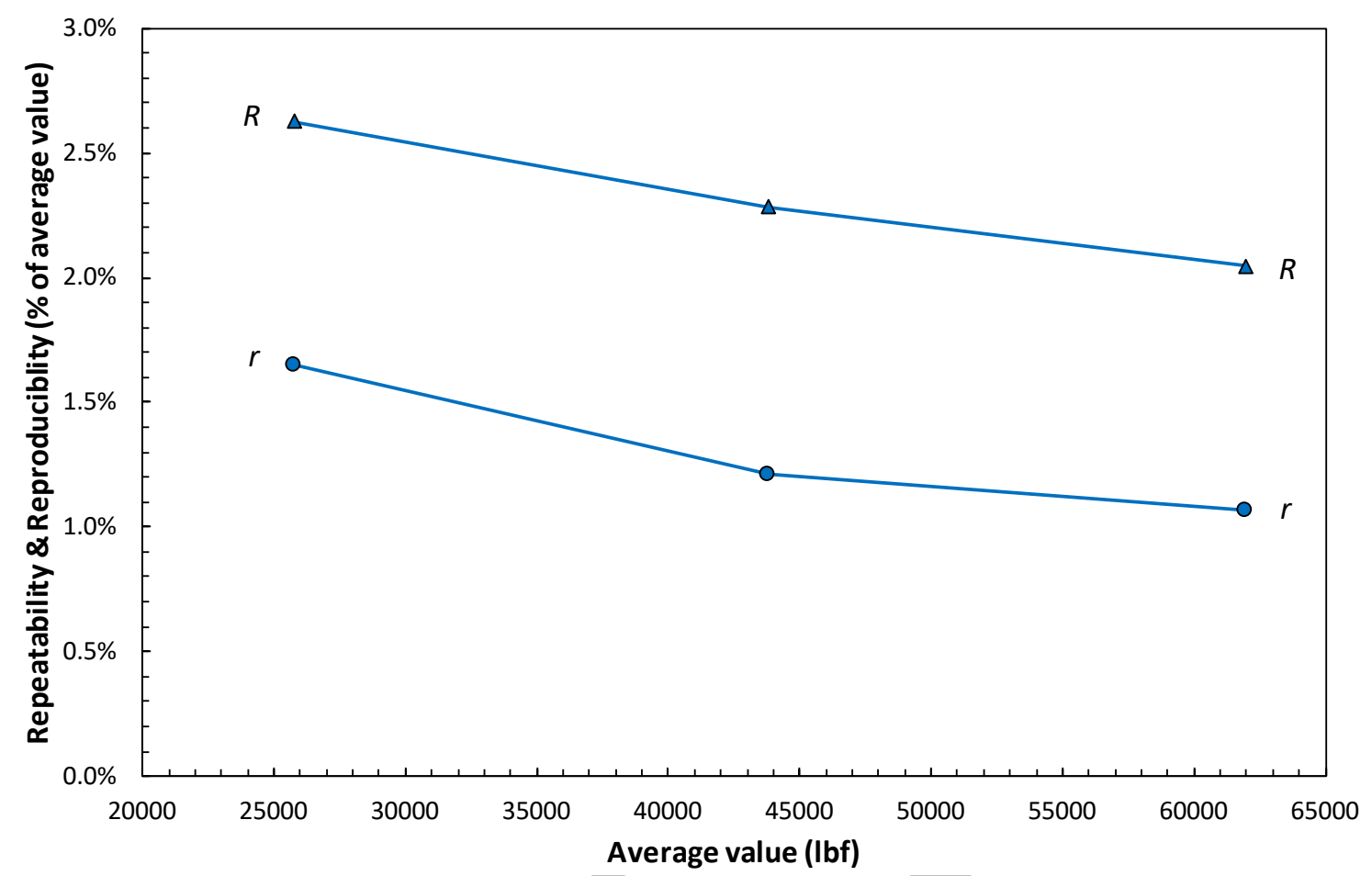

Figure 14 - Repeatability (r) and reproducibility (R) limits, normalized by average values, versus average values for breaking strength.

E - 31 


\section{APPENDIX F: PRECISION WITH RESULTS FROM WELDED STRAND EXCLUDED}

Table F.1 - Precision statistics for yield strength excluding results from strands with welded ends

\begin{tabular}{|c|c|c|c|c|c|}
\hline $\begin{array}{c}\text { Strand Size } \\
\text { in. }[\mathrm{mm}]\end{array}$ & $\begin{array}{c}\text { Mean of } \\
\text { Laboratory } \\
\text { Means, } \\
\overline{\overline{\boldsymbol{x}}} \\
\text { lbf [kN] }\end{array}$ & $\begin{array}{c}\text { Repeatability } \\
\text { Standard } \\
\text { Deviation, } \\
\boldsymbol{s}_{\boldsymbol{r}} \\
\text { lbf [kN] }\end{array}$ & $\begin{array}{c}\text { Reproducibility } \\
\text { Standard } \\
\text { Deviation, } \\
\boldsymbol{S}_{\boldsymbol{R}} \\
\text { Ibf [kN] }\end{array}$ & $\begin{array}{c}\text { Repeatability } \\
\text { Limit, } \\
r \\
\text { lbf }[\mathrm{kN}]\end{array}$ & $\begin{array}{c}\text { Reproducibility } \\
\text { Limit, } \\
R \\
\mathrm{lbf}[\mathrm{kN}]\end{array}$ \\
\hline $\begin{array}{c}0.375 \\
{[9.5]} \\
\end{array}$ & $\begin{array}{c}23103 \\
{[102.76]}\end{array}$ & $\begin{array}{c}188.88 \\
{[0.84014]}\end{array}$ & $\begin{array}{c}306.49 \\
{[1.3633]} \\
\end{array}$ & $\begin{array}{c}529 \\
{[2.35]}\end{array}$ & $\begin{array}{r}858 \\
{[3.82]} \\
\end{array}$ \\
\hline $\begin{array}{c}0.5 \\
{[12.7]}\end{array}$ & $\begin{array}{c}38785 \\
{[172.52]}\end{array}$ & $\begin{array}{c}226.21 \\
{[1.0062]}\end{array}$ & $\begin{array}{c}368.53 \\
{[1.6392]}\end{array}$ & $\begin{array}{c}633 \\
{[2.82]}\end{array}$ & $\begin{array}{c}1030 \\
{[4.59]}\end{array}$ \\
\hline $\begin{array}{c}0.6 \\
{[15.2]}\end{array}$ & $\begin{array}{c}55803 \\
{[248.21]}\end{array}$ & $\begin{array}{c}405.19 \\
{[1.8023]}\end{array}$ & $\begin{array}{c}637.45 \\
{[2.8354]}\end{array}$ & $\begin{array}{l}1130 \\
{[5.05]}\end{array}$ & $\begin{array}{c}1780 \\
{[7.94]}\end{array}$ \\
\hline
\end{tabular}

Table F.2 - Precision statistics for elastic modulus excluding results from strands with welded ends

\begin{tabular}{|c|c|c|c|c|c|}
\hline $\begin{array}{c}\text { Strand Size } \\
\text { in. }[\mathrm{mm}]\end{array}$ & $\begin{array}{c}\text { Mean of } \\
\text { Laboratory } \\
\text { Means, } \\
\overline{\overline{\boldsymbol{x}}} \\
10^{3} \mathrm{ksi}[\mathrm{GPa}] \\
\end{array}$ & $\begin{array}{c}\text { Repeatability } \\
\text { Standard } \\
\text { Deviation, } \\
\boldsymbol{s}_{\boldsymbol{r}} \\
10^{3} \mathrm{ksi}[\mathrm{GPa}]\end{array}$ & $\begin{array}{c}\text { Reproducibility } \\
\text { Standard } \\
\text { Deviation, } \\
\boldsymbol{S}_{\boldsymbol{R}} \\
10^{3} \mathrm{ksi}[\mathrm{GPa}]\end{array}$ & $\begin{array}{c}\text { Repeatability } \\
\text { Limit, } \\
r \\
10^{3} \mathrm{ksi}[\mathrm{GPa}]\end{array}$ & $\begin{array}{c}\text { Reproducibility } \\
\text { Limit, } \\
R \\
10^{3} \mathrm{ksi}[\mathrm{GPa}]\end{array}$ \\
\hline $\begin{array}{c}0.375 \\
{[9.5]}\end{array}$ & $\begin{array}{c}29.25 \\
{[201.7]}\end{array}$ & $\begin{array}{l}0.398 \\
{[2.74]}\end{array}$ & $\begin{array}{l}0.439 \\
{[3.03]}\end{array}$ & $\begin{array}{c}1.11 \\
{[7.65]}\end{array}$ & $\begin{array}{c}1.23 \\
{[8.48]}\end{array}$ \\
\hline $\begin{array}{c}0.5 \\
{[12.7]} \\
\end{array}$ & $\begin{array}{c}29.68 \\
{[204.6]}\end{array}$ & $\begin{array}{l}0.883 \\
{[6.09]} \\
\end{array}$ & $\begin{array}{c}1.01 \\
{[6.96]} \\
\end{array}$ & $\begin{array}{c}2.47 \\
{[17.0]} \\
\end{array}$ & $\begin{array}{c}2.83 \\
{[19.5]} \\
\end{array}$ \\
\hline $\begin{array}{c}0.6 \\
{[15.2]}\end{array}$ & $\begin{array}{c}29.16 \\
{[201.1]}\end{array}$ & $\begin{array}{l}0.527 \\
{[3.63]}\end{array}$ & $\begin{array}{l}0.922 \\
{[6.36]}\end{array}$ & $\begin{array}{c}1.48 \\
{[10.2]}\end{array}$ & $\begin{array}{c}2.58 \\
{[17.8]}\end{array}$ \\
\hline
\end{tabular}

Table F.3 - Precision statistics for elongation excluding results from strands with welded ends

\begin{tabular}{|c|c|c|c|c|c|}
\hline $\begin{array}{l}\text { Strand Size } \\
\text { in. }[\mathrm{mm}]\end{array}$ & $\begin{array}{c}\text { Mean of } \\
\text { Laboratory } \\
\text { Means }{ }^{a}, \\
\overline{\bar{x}} \\
\% \\
\end{array}$ & $\begin{array}{c}\text { Repeatability } \\
\text { Standard } \\
\text { Deviation }{ }^{\text {a }}, \\
\boldsymbol{s}_{\boldsymbol{r}} \\
\% \\
\end{array}$ & $\begin{array}{c}\text { Reproducibility } \\
\text { Standard } \\
\text { Deviation }^{\text {a }} \text {, } \\
\boldsymbol{S}_{\boldsymbol{R}} \\
\% \\
\end{array}$ & $\begin{array}{c}\text { Repeatability } \\
\text { Limit }^{\text {a }} \text {, } \\
r \\
\%\end{array}$ & $\begin{array}{c}\text { Reproducibility } \\
\text { Limit }^{\text {a }} \\
R \\
\%\end{array}$ \\
\hline $\begin{array}{c}0.375 \\
{[9.5]} \\
\end{array}$ & 6.37 & 0.48 & 1.35 & 1.4 & 3.8 \\
\hline $\begin{array}{c}0.5 \\
{[12.7]} \\
\end{array}$ & 6.52 & 0.35 & 1.34 & 1.0 & 3.8 \\
\hline $\begin{array}{c}0.6 \\
{[15.2]}\end{array}$ & 6.07 & 0.58 & 1.28 & 1.6 & 3.6 \\
\hline
\end{tabular}

a Because results from Laboratory 6 are excluded, these statistics are calculated from results collected from five laboratories, fewer than the minimum of six required by ASTM E691 
Table F.4 - Precision statistics for breaking strength excluding results from strands with welded ends

\begin{tabular}{|c|c|c|c|c|c|}
\hline $\begin{array}{l}\text { Strand Size } \\
\text { in. }[\mathrm{mm}]\end{array}$ & $\begin{array}{l}\text { Mean of } \\
\text { Laboratory } \\
\text { Means, } \\
\overline{\overline{\boldsymbol{x}}} \\
\text { lbf [kN] }\end{array}$ & $\begin{array}{c}\text { Repeatability } \\
\text { Standard } \\
\text { Deviation, } \\
\boldsymbol{s}_{\boldsymbol{r}} \\
\text { Ibf [kN] }\end{array}$ & $\begin{array}{c}\text { Reproducibility } \\
\text { Standard } \\
\text { Deviation, } \\
\boldsymbol{s}_{\boldsymbol{R}} \\
\text { Ibf }[\mathrm{kN}]\end{array}$ & $\begin{array}{c}\text { Repeatability } \\
\text { Limit, } \\
r \\
\mathrm{Ibf}[\mathrm{kN}]\end{array}$ & $\begin{array}{c}\text { Reproducibility } \\
\text { Limit, } \\
R \\
\text { lbf }[\mathrm{kN}]\end{array}$ \\
\hline $\begin{array}{l}0.375 \\
{[9.5]}\end{array}$ & $\begin{array}{c}25742 \\
{[114.50]}\end{array}$ & $\begin{array}{c}151.62 \\
{[0.67441]}\end{array}$ & $\begin{array}{c}225.09 \\
{[1.0012]}\end{array}$ & $\begin{array}{c}425 \\
{[1.89]}\end{array}$ & $\begin{array}{c}630 \\
{[2.80]}\end{array}$ \\
\hline $\begin{array}{c}0.5 \\
{[12.7]}\end{array}$ & $\begin{array}{c}43776 \\
{[194.72]}\end{array}$ & $\begin{array}{c}192.87 \\
{[0.85789]}\end{array}$ & $\begin{array}{c}311.25 \\
{[1.3844]}\end{array}$ & $\begin{array}{c}540 \\
{[2.40]}\end{array}$ & $\begin{array}{c}871 \\
{[3.88]}\end{array}$ \\
\hline $\begin{array}{c}0.6 \\
{[15.2]}\end{array}$ & $\begin{array}{c}61921 \\
{[275.43]}\end{array}$ & $\begin{array}{c}240.97 \\
{[1.0718]}\end{array}$ & $\begin{array}{c}416.30 \\
{[1.8517]}\end{array}$ & $\begin{array}{c}675 \\
{[3.00]}\end{array}$ & $\begin{array}{c}1170 \\
{[5.18]}\end{array}$ \\
\hline
\end{tabular}



